\title{
Effects of Chronic Electronic Vapor Exposure on Body Weight, Appetite, and Metabolism
}

\author{
Matthew J. Breit
}

Follow this and additional works at: https://researchrepository.wvu.edu/etd

\section{Recommended Citation}

Breit, Matthew J., "Effects of Chronic Electronic Vapor Exposure on Body Weight, Appetite, and Metabolism" (2017). Graduate Theses, Dissertations, and Problem Reports. 5257.

https://researchrepository.wvu.edu/etd/5257

This Thesis is protected by copyright and/or related rights. It has been brought to you by the The Research Repository @ WVU with permission from the rights-holder(s). You are free to use this Thesis in any way that is permitted by the copyright and related rights legislation that applies to your use. For other uses you must obtain permission from the rights-holder(s) directly, unless additional rights are indicated by a Creative Commons license in the record and/ or on the work itself. This Thesis has been accepted for inclusion in WVU Graduate Theses, Dissertations, and Problem Reports collection by an authorized administrator of The Research Repository @ WVU. For more information, please contact researchrepository@mail.wvu.edu. 


\title{
EFFECTS OF CHRONIC ELECTRONIC VAPOR EXPOSURE ON BODY WEIGHT, APPETITE, AND METABOLISM
}

\author{
Matthew J. Breit, B.S. \\ Thesis submitted to the School of Medicine, Division of Exercise Physiology at \\ West Virginia University in partial fulfillment of the requirements for the degree of \\ Master of Science in Exercise Physiology
}

I. Mark Olfert, Ph.D., Chair

Randall Bryner, Ed.D.

Stan Hileman, Ph.D.

Division of Exercise Physiology

Morgantown, West Virginia

2017

Keywords: e-cigarette, body weight, appetite regulation, metabolism

Copyright 2017 Matthew J. Breit 


\begin{abstract}
Effects of Chronic Electronic Vapor Exposure on Body Weight, Appetite, and Metabolism
\end{abstract}

\title{
Matthew J. Breit
}

Cigarette smokers weigh less than non-smokers and gain weight upon smoking cessation. Electronic cigarettes (E-cigs) have been used as a smoking cessation tool among many, however, their effects on metabolism, appetite, and energy balance are virtually unknown. This study compares the effects of chronic E-cig vapor exposure on body mass, food intake, metabolism, and body composition in mice. We hypothesized that E-cig exposure would elicit similar changes on body mass, body composition, food intake, and metabolic and appetite-regulating markers as conventional cigarettes (i.e. 3R4F reference cigarette). Female C57BL/6 mice were exposed to filtered room air $(\mathrm{n}=15)$, mainstream smoke from 3R4F reference cigarettes $(n=15)$, or E-cig vapor $(n=15)$ for a total of 8 -months $(4 \mathrm{~h} / \mathrm{d}, 5 \mathrm{~d} / \mathrm{wk})$. Body mass, food intake, metabolic and appetite-regulating markers, heat production, and body composition were measured. Weight gain, fat-free mass (FFM), and fat mass were significantly elevated in E-cig and control mice compared to 3R4F mice. Food consumption and heat production (kcal expended/hr) was significantly increased in E-cig mice compared to control and 3R4F mice. Appetiteregulating markers (NPY, POMC, leptin, and GLP-1) were similar between all groups. Mitochondrial uncouplers (UCP-1 and UCP-3) remained unchanged between E-cig and control groups, however, UCP1 was significantly elevated in E-cig mice compared to $3 \mathrm{R} 4 \mathrm{~F}$ mice and UCP-3 was significantly elevated in control vs. 3R4F mice. Oxygen consumption (VO2) and carbon dioxide production (VCO2) were also significantly elevated in E-cig and 3R4F mice compared to control mice, while respiratory exchange ratios (RER) were unchanged. Unlike conventional cigarettes, we found that E-cig exposure did not elicit reductions in total body or adipose mass. This suggests the effects of E-cig may not be the same as that occurring with traditional tobacco cigarettes, or that the exposure to nicotine and/or other chemicals in the E-cig liquid elicits a different response on appetite or feeding behavior. While E-cig mice increased food intake, their basal metabolism was also elevated, suggesting energy dissipation resulting in a similar net energy balance compared to control mice. Further studies are needed to evaluate the effect that flavorings and/or the compounds produced in E-cig vapor exert on metabolism, energy balance, and the neural regulation of appetite. 


\section{TABLE OF CONTENTS}

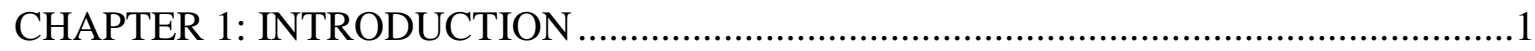

CHAPTER 2: BACKGROUND AND SIGNIFICANCE.............................................5

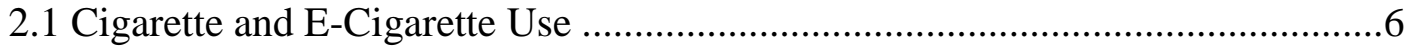

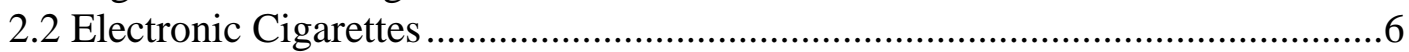

2.3 Nicotine Pharmacology ............................................................................ 9

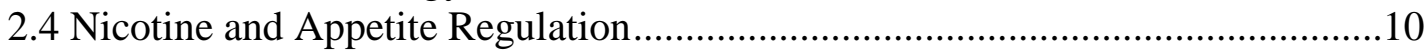

2.5 Nicotine and Obesity, Adiposity, and Body Composition.................................18

2.6 Nicotine and Energy Metabolism and Uncoupling Proteins .............................20

2.7 Summary of Background and Significance ................................................23

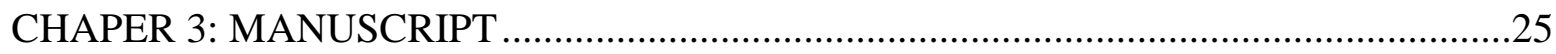

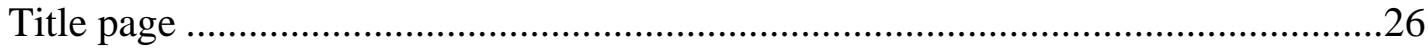

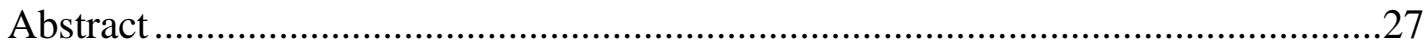

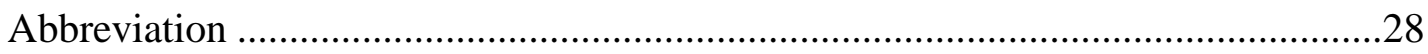

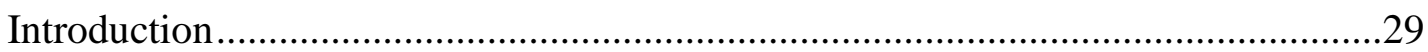

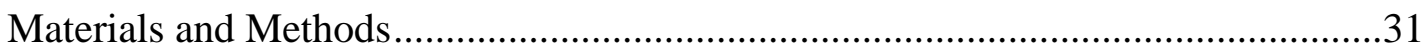

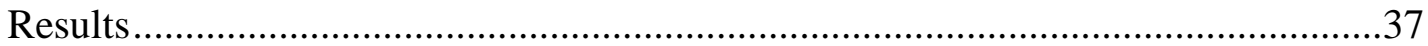

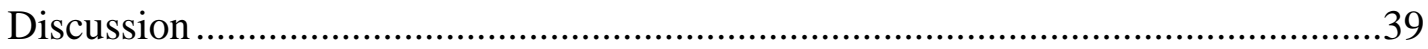

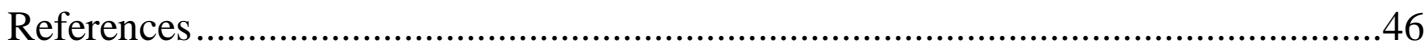

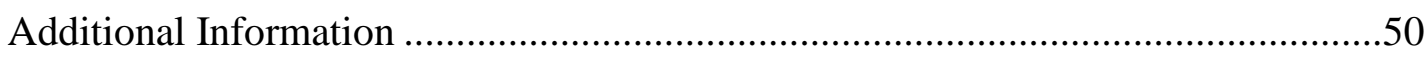

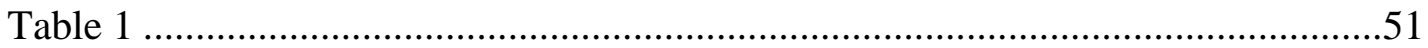

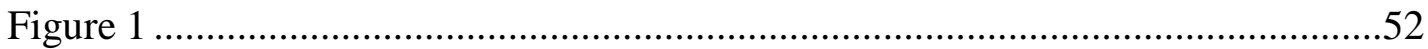

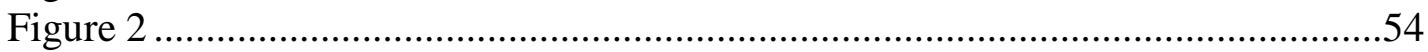

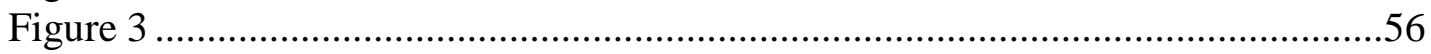

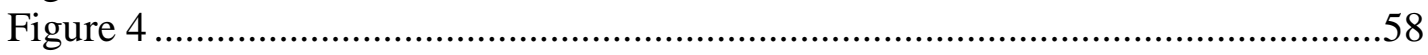

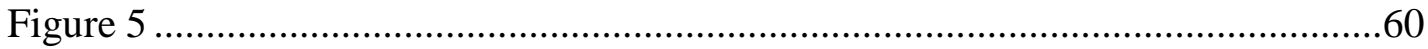

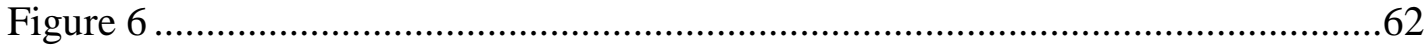

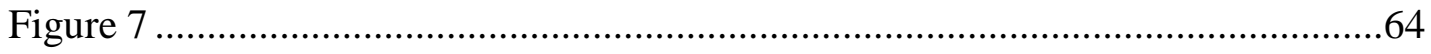

CHAPTER 4: SUMMARY AND DISCUSSION .....................................................66

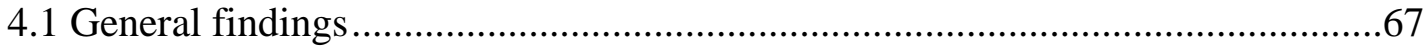

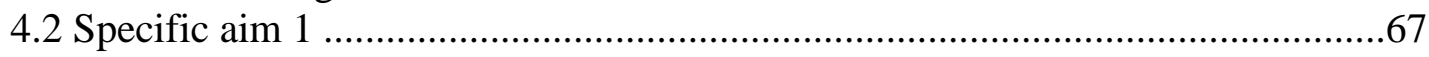

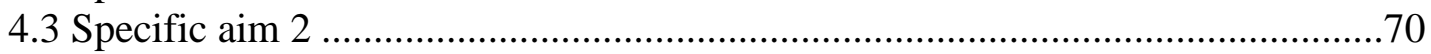

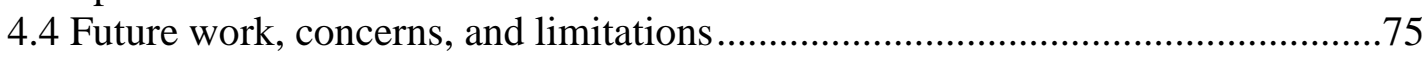

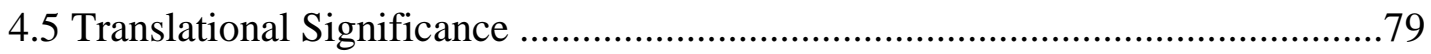

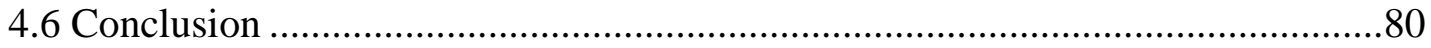

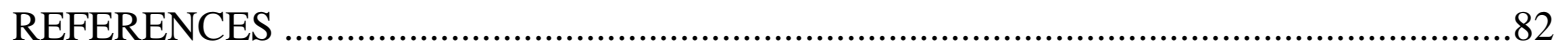


CHAPTER 1: INTRODUCTION 
Approximately 37 million U.S. residents smoke cigarettes (Jamal et al. 2016) and over 9 million U.S. residents have switched to electronic cigarettes (E-cigs) in hopes of cessation (Schoenborn and Gindi 2015). An overwhelming body of evidence across multiple species suggests cigarette smoking increases energy expenditure (Arai et al. 2001, Brees et al. 2008, Yoshida et al. 1999), decreases food intake (Tomoda et al. 2012, Chen et al. 2005, Chen et al. 2008), and promotes weight loss (Yoshida et al. 1999, Arai et al. 2001, Hodge et al. 1997), however, studies investigating these phenomena in regards to E-cig vapor are sparse and inconsistent.

Nicotine, the main addictive component in tobacco, causes the anorectic and thermogenic effect from smoking (Zoli and Picciotto 2012, Jo, Talmage and Role 2002, Tweed et al. 2012), however, the combination of sweet aromatics, taste, and flavor, in conjunction with nicotine and other chemicals present in E-cigs may influence appetite and body weight differently. Animal studies comparing effects of E-cig exposure on weight gain report conflicting results, as some studies resulted in increased body mass (Phillips et al. 2015, Russo et al. 2016), decreased body mass (El Golli et al. 2016, Golli et al. 2016, Sussan et al. 2015, McGrath-Morrow et al. 2015), or no effect on body mass (Ponzoni et al. 2015, Cravo et al. 2016, Phillips et al. 2016, Kogel et al. 2014, Caponnetto et al. 2013, Dawkins et al. 2012). Unlike traditional cigarettes, E-cigs appear to have varying physiological effects.

Nicotine acts on nicotinic cholinergic receptors both centrally and peripherally (McFadden, Cornier and Tregellas 2014) within the body, which interact with numerous physiological systems. Nicotine elicits an adrenergic catecholamine release from the adrenal medulla which act on brown adipose tissue (BAT) and white adipose tissue (WAT) to induce lipolysis and $\beta$-oxidation of free fatty acids (Brees et al. 2008). Nicotine binding sites have also been shown to be present in the arcuate nucleus (ARC), an important appetite-regulating region of the hypothalamus (Pelleymounter 1997). This suggests a direct effect of nicotine on appetite regulation via neuropeptide-Y (NPY) and pro- 
opiomelanocortin (POMC) cell populations (Huang, Xu and van den Pol 2011), thereby producing an anorectic effect by inhibiting NPY and stimulating POMC neurons.

Propylene glycol and glycerol, the main constituents of E-cig e-liquid, are mildly sweet (Miao et al. 2016) and may enhance the sweetening effects of ethyl maltol (Moskowitz et al. 1974, Farsalinos et al. 2015), a sweet taste potentiator which was found in $75 \%$ of e-liquid samples tested (Miao et al. 2016). Moreover, a comprehensive random-sample market analysis of 159 e-liquids reported over $73 \%$ of products contained diacetyl (Farsalinos et al. 2015), which has been shown to decrease glucagon-like peptide-1 (GLP-1) production, a potent appetite suppressant, in enteroendocrine cells (McCarthy et al. 2017). E-cig use has also been shown to significantly increase appetite ratings, or perceived hunger, in humans (Cravo et al. 2016). Finally, e-liquid can contain artificial intense sweeteners, such as sucralose (Williams 2016) and stevia (Landau 2015), which have been shown to promote food intake through a NPY-dependent mechanism, disrupt sleeping patterns, and increase activity patterns (Wang et al. 2016). Together, these offer potential mechanisms for a hyperphagic response from E-cig use.

The anorectic effects of nicotine may be altered by flavoring aromatic pathways and homeostatic, hedonic (pleasure), and motivation and reward-system regulation. The combination of added flavorings and nicotine and their effects on food intake and body mass have not been studied exclusively. Therefore, studies aimed at understanding the metabolic and behavioral side effects of E-cig use are warranted. The aim of this study is to determine the metabolic and physiological effects of E-cig vapor exposure compared to similar total time exposure to traditional cigarettes and filtered air. We herein examine multiple appetite regulatory factors and energy metabolism markers in female C57BL/6 mice including leptin, GLP-1, POMC, NPY, uncoupling protein-1 (UCP-1), UCP-3, VO2, VCO2, and RER. The rationale for this study was supported by matching for exposure length (4hr/day/8months) and mass of particulate matter (PM) collected after each hour of exposure as seen in previous literature (Ansari et al. 2016). This matching renders similar PM exposure paradigms. Using this model, we 
expect to gain insight into the metabolic effects and appetite regulatory changes in response to E-cigs. While the E-cig industry is over a decade old, there has been extremely limited data evaluating their safety and efficacy. High doses of some flavor chemicals may be safe when ingested, but can be dangerous when inhaled (Allen et al. 2016). This study evaluates the effect of long-term E-cig vapor exposure in a mouse model to determine what, if any, effects occur on appetite regulation and obesity in response to cappuccino flavored E-cig vapor.

\section{Specific Aim 1: Determine the effects of long-term E-cig exposure on body mass, feed}

behavior, and body composition. Our hypothesis is that E-cig vapor will decrease bodyweight, food intake, white adipose tissue (WAT), brown adipose tissue (BAT), and FFM, in-line with 3R4F exposure. Nicotine has been shown to decrease bodyweight, food intake, adipose tissue mass and FFM, while increasing metabolic activity, therefore, we assume the nicotine content in E-cig and 3R4F exposures will elicit similar physiological response.

\section{Specific Aim 2: Determine the metabolic and molecular consequences on appetite} regulation pathways with long-term exposure to E-cig vapor. Our working hypothesis is that E-cigs will decrease plasma leptin and glucagon-like peptide-1 (GLP-1), and hypothalamic neuropeptide-Y (NPY) mRNA expression, while increasing, hypothalamic pro-opiomelanocortin (POMC) mRNA expression, UCP-1 in BAT and UCP-3 in muscle. Nicotine has been show to increase POMC mRNA expression and decrease NPY mRNA expression. Nicotine has also been shown to decrease leptin and increase uncoupling proteins UCP-1 and UCP-3. 
CHAPTER 2: BACKGROUND AND SIGNIFICANCE 


\subsection{Cigarette and E-Cigarette Usage}

Worldwide, cigarette smoking and tobacco usage cause over 6 million deaths per year and is expected to reach 8 million by 2030 (WHO 2011). Cigarette smoking in the U.S. by adults (18 and older) has decreased from 42 million in 2013 (Jamal et al. 2014), to approximately 37 million currently (Jamal et al. 2016). Concurrent with the decline in cigarette smoking, an alarming increase in electronic cigarette (E-cig) use has been reported, as 9 million people currently use these products (Schoenborn and Gindi 2015). In a meta-analysis of 28 published E-cig studies evaluating awareness, current use, and perceived risk of E-cigs, it was found that current cigarette smokers were more likely to use E-cigs (27.2\%) than former cigarette smokers (15.7\%) and non-smokers (2.5\%), respectively (Xu et al. 2016). This indicates that current cigarette smokers are more willing to find alternatives, such as E-cigs, to aid in smoking cessation.

Tobacco use and cigarette smoking are the two leading causes of preventable death in the United States, together causing over 480,000 deaths per year, or 1,300 deaths per day (USDHHS 2014). Moreover, cigarette smoking costs the U.S. over $\$ 300$ billion each year in lost productivity and direct medical costs (USDHHS 2014, Xu et al. 2015). Together, with the advent of E-cig production in 2004 and increased public knowledge of the detrimental health effects of smoking tobacco products, individuals have been switching to E-cigs in hopes of lessening their health risks from tobacco exposure. Therefore, an in-depth understanding of their physiological effects is necessary.

\subsection{Electronic Cigarettes}

The American Lung Association (ALA) defines E-cigs, a popular new smoking product, as an electronic nicotine delivery system (ENDS). E-cigs, the most common ENDS prototype, are devices that vaporize a liquid (e-liquid) which is inhaled by the consumer, instead of using tobacco leaves used in regular cigarettes. Since the inception of E-cigs to the global market in 2004, they have been heavily marketed as a "safe" alternative to cigarette smoking. With over 500 brands and 8,000 flavors of e-liquid 
on the market, the Food and Drug Administration (FDA) has only recently developed regulations for these products following an announcement in 2016. This FDA oversight will require E-cig manufactures to register with the FDA and submit their full ingredient lists and proprietary blends, which will be implemented effective August 8, 2018 (ALA 2017).

E-cigs are lithium battery-powered devices that produce an aerosol through a resistive heating coil when activated. The solution, or e-liquid, is packaged in disposable cartridges and contains propylene glycol, glycerol, nicotine $(0 \mathrm{mg} / \mathrm{ml}-50 \mathrm{mg} / \mathrm{ml})$, various flavors, and other chemicals when vaporized (Lam and West 2015). All E-cigs contain a battery, a body/cartridge, and an atomizer with a heating coil. First-generation E-cig models resemble traditional cigarettes and contain low-power batteries, while new-generation E-cigs (tank versions) contain a larger body and are capable of higher wattage output through electronic circuits providing the ability to set the power delivery. Activation of a first-generation E-cig, or inhalation, triggers a sensor that activates the heating element to vaporize the e-liquid and produces an aerosol, unlike the new-generation E-cig designs which contain a manually activated switch that activates the heating coil. New-generation devices are much more popular among E-cig users and produce higher energy to the atomizer (Farsalinos et al. 2014a), resulting in significantly elevated nicotine absorption, indicating that the nicotine delivery capability is correlated to the wattage of the E-cig. Unlike first-generation E-cigs, new-generation E-cig power output is "tunable," enabling the user to adjust the voltage of the device, which can alter the nicotine delivery.

Multiple studies have examined the chemical composition of E-cigs (Allen et al. 2016, Farsalinos et al. 2014a, Tierney et al. 2016, Jensen et al. 2015), effects of E-cig exposure to laboratory animals (Ponzoni et al. 2015, El Golli et al. 2016, Golli et al. 2016, Sussan et al. 2015, Hwang et al. 2016, Ansari et al. 2016, Lo Sasso et al. 2016, Phillips et al. 2015, Phillips et al. 2016, Kogel et al. 2014, McGrath-Morrow et al. 2015, Farsalinos et al. 2014b), and human clinical studies (Cravo et al. 2016, Caponnetto et al. 2013, Dawkins et al. 2012, Russo et al. 2016), however, the metabolic risks attributed 
to E-cigs are still widely unknown and require elucidation. The varying methodological protocols (tobacco cessation, liquid injection, varying nicotine content and exposure time) makes it difficult to cross-compare any tobacco related study involving cigarettes or E-cigs.

More than 8,000 e-liquid flavors are available on the market (Allen et al. 2016) and most are categorized in five groups: tobacco flavored (cigarette), fruit flavors (blueberry), menthol flavors, sweet flavors (bubble gum), and other flavors (coffee). While the majority of cigarette ads are targeted towards adults, who are legally allowed to smoke over the age of 18 , provocative industry tactics and marketing schemes with cartoon characters and candy flavors (fruit loops and bubble gum) are clear indicators of marketing E-cigs to youth (Farsalinos et al. 2015). In 2014, 9.2\% of high school students and $2.5 \%$ of middle school students were using cigarettes (Arrazola et al. 2015), however, marketing of E-cigs to the younger population has proven successful, as a 900\% increase in E-cig usage among high school students was reported between 2011 and 2015, per the U.S. Surgeon General report (USDHHS 2016).

An analysis of 30 representative e-liquids available on the U.S. market revealed that almost half of the products $(13 / 30)$ contained more than $1 \%$ by weight $(10 \mathrm{mg} / \mathrm{ml})$ of added chemical flavorants, with a select few flavorants being more popular in e-liquids: vanillin, ethyl vanillin, maltol, ethyl maltol, benzaldehyde, benzyl alcohol, ethyl butyrate, and ethyl acetate (Tierney et al. 2016). In a study of 51 eliquids, 76\% (39/51) contained diacetyl (239ug/E-cig), and 23/46 of products contained 2,3pentanedione and acetoin (Allen et al. 2016). In a study of 159 e-liquids products, diacetyl and acetyl propionyl were present in $73 \%$ of the samples, with more flavor samples containing diacetyl alone (Farsalinos et al. 2015). Diacetyl has been shown to decrease glucagon-like peptide-1 (GLP-1) in enteroendocrine cells (McCarthy et al. 2017), a potent appetite suppressant, which offers a potential mechanism for hyperphagia in E-cig use. 


\subsection{Nicotine Pharmacology}

Nicotine, a chemical compound found in tobacco, is one of the most commonly used psychostimulant drugs used worldwide, analogous to caffeine. Nicotine acts on nicotinic cholinergic receptors both centrally and peripherally (McFadden et al. 2014) within the body. Acetylcholine activates neuronal nicotinic acetylcholine receptors (nAChR), which consist of ligand-gated ion channels and are located ubiquitously on neuronal and non-neuronal tissue and organs that regulate energy homeostasis and regulate bodyweight (Zoli and Picciotto 2012). These receptors also respond to nicotine, as nicotine acts on both central and peripheral nicotinic cholinergic receptors, such as high affinity $\alpha 4-\beta 2$ receptors and low-affinity $\alpha 7$ receptors (McFadden et al. 2014).

Nicotine binding sites have been shown to be present in the arcuate nucleus (ARC), an important appetite-regulating region of the hypothalamus (Pelleymounter 1997), suggesting a direct effect of nicotine on appetite regulation. A specific subunit, $\alpha 7 \mathrm{nAChR}$, is densely expressed in the hypothalamus and when activated, modulates appetite-related circuits (NPY/AgRP, POMC/CART neurons) within the hypothalamus (McFadden et al. 2014, Sargent 1993) and inhibits feeding behavior. Food intake and eating behaviors are affected by binding of nicotine to these alpha- 7 nicotinic acetylcholine receptors and may elicit the anorexigenic effects seen from smoking (McFadden et al. 2014).

Nicotine also acts peripherally on presynaptic nAChRs located on the adrenal medulla of the kidney. Activation of these nAChRs triggers the release of both epinephrine and norepinephrine in response to an acute smoke exposure (Sala, Nistri and Criado 2008, Zhao, Chen and Sharp 2007, Westfall and Watts 1964), thereby increasing activity of the sympathetic nervous system. Moreover, nicotine enhances norepinephrine turnover (Yoshida et al. 1999, Brees et al. 2008, Lupien and Bray 1988) and elevates neuronal catecholamine release from varying nicotine doses (Arqueros, Naquira and Zunino 1978). Nicotine also has a direct effect on adipocytes by increasing lipolysis and fatty acid breakdown, which express high-affinity nicotinic binding sites (Liu, Mizuta and Matsukura 2004). 
Together, these data support the notion that nicotine directly effects the central nervous system (CNS) and the activity of multiple organs involved in energy homeostasis.

Multiple studies have reported significantly reduced nicotine absorption from E-cig exposure compared to traditional cigarette smoking (Russo et al. 2016, Allen et al. 2016, Farsalinos et al. 2014a, Farsalinos et al. 2014b), which may cause limited weight loss and anorectic appetite effects as nicotine is the main driver of these processes. However, the various flavors and other chemicals in the e-liquid remain untested in relation to their impact on bodyweight and appetite. Farsalinos et. al. (2014a) reported that serum nicotine levels were significantly less after 5, 20, 35, 50, and 65 minutes following use of first-generation E-cigs compared to new-generation E-cigs. Moreover, after smoking a traditional cigarette for 5 minutes (18.8 ng nicotine/ml), nicotine levels were $185 \%$ and $286 \%$ higher compared to the new-generation and first-generation E-cigs, respectfully (Farsalinos et al. 2014a). This indicates that nicotine delivery and absorption is significantly lower compared to traditional cigarettes.

Cigarette smoking and nicotine injections may elicit different physiological effects. Thousands of chemicals in cigarettes may play a role in the anorectic effect of cigarettes on energy metabolism (acetone, arsenic, carbon monoxide), however, nicotine has the most overarching and documented effects on body weight and appetite suppression (Jo et al. 2002, Tweed et al. 2012). The interactions at play between various artificial flavors and flavoring aromatics, in conjunction with nicotine and harmful chemicals, such as acetone and formaldehyde, have been unidentified. It is extremely difficult to compare cigarette smoke studies with nicotine injection data, and even more challenging to add another variable, such as E-cig flavorings. This study will lay the rudimentary framework for future studies to evaluate the effects of flavorings in combination with nicotine in E-cigs.

\subsection{Nicotine and Appetite Regulation}

An overwhelming number of studies indicate that nicotine (both I.P. injections and smoke exposure) reduces appetite (Mangubat et al. 2012, Yoshida et al. 1999, Arai et al. 2001) and alters 
feeding patterns (Jo et al. 2002, Zoli and Picciotto 2012). The anorectic effect of nicotine involves multiple complex neurochemical pathways that regulate satiety and feeding patterns. As nicotine has a high affinity for nAChRs on multiple tissues, specifically ones that regulate energy metabolism, the physiological responses to nicotine are vast.

Appetite is regulated through multiple physiological and psychological forces, from the distention of the stomach signaling satiety, to hormones that communicate with the brain, such as insulin, leptin, and ghrelin. Moreover, environmental, emotional, cultural, pharmacological, and psychological factors play major roles in influencing appetite and feeding behaviors. In addition, numerous homeostatic circuits underlie food intake (Morton, Meek and Schwartz 2014) and feeding is regulated by pleasant aromas (hedonic) or reward-based sensations, which override homeostatic controls when consuming energy dense foods, increasing desire to consume palatable foods (Lutter and Nestler 2009). Sight and smell of palatable food increases dopamine release from the ventral tegmental area (VTA), which contributes to the reward value of food (Morin et al. 2017). Activation of this pathway results in loss of control over intake of food (Stoeckel et al. 2008). While the physiological regulation of appetite is a major player in the regulation of appetite, and therefore, bodyweight, it is just one factor influencing appetite, among many mentioned above. This study will examine the physiological role of appetite regulation at the level of the hypothalamus and peripheral tissue.

The hypothalamus, a region of the forebrain, plays a key role in regulation of energy balance. The arcuate nucleus (ARC), a specific region within the hypothalamus, is known as the main nucleus in regards to receiving and relaying nutrient-related sensory information from the peripheral circulation (Blouet and Schwartz 2010). Two primary "first-order" neurons within the ARC include cells expressing the orexigenic neuropeptides neuropeptide-Y (NPY) and agouti-related peptide (AgRP), and those expressing the anorexigenic neuropeptides pro-opiomelanocortin (POMC) and cocaine-and amphetamine-related transcript (CART). Peripheral signals, such as leptin and ghrelin, act directly on 
the ARC to influence the release of these four neuropeptides, which ultimately influence appetite (Park and Ahima 2015). Raised levels of ghrelin, suggesting a starvation state and inadequate energy stores, act to stimulate NPY/AgRP expression to increase hunger and initiate feeding, while inhibiting POMC/CART expression. Conversely, elevated levels of leptin or insulin, such as after a meal and indicating a fed state, act to increase expression of POMC/CART to terminate feeding, while decreasing expression of NPY/AgRP. Nicotine binding sites have been shown to be present in the ARC (Pelleymounter 1997), and $\alpha 7 \mathrm{nAChRs}$ on NPY and POMC neurons are stimulated by nicotine (McFadden et al. 2014) suggesting a direct effect of nicotine on appetite regulation.

As previously mentioned, POMC, an anorexigenic peptide, has an inhibitory effect on appetite, while NPY, an orexigenic peptide, stimulates appetite and promotes obesity (Jo et al. 2002). POMC exerts its appetite regulatory effects by being cleaved into multiple peptides including $\alpha$-MSH, which acts to suppress appetite. Nicotine has been shown to excite hypothalamic $\alpha 7 \mathrm{nAChRs}$ on NPY and POMC neurons (Huang et al. 2011), with a greater depolarization and spike frequency response from POMC neurons, eliciting a potential mechanism through which POMC may suppress appetite (Huang et al. 2011). Discovered in 2011, activation of POMC neurons and subsequent melanocortin-4 receptor (MC4R) activation have been deemed the "smoking gun" in nicotine's anorectic phenomenon, as nicotine was shown to activate the melanocortin-4 receptors (MC4R) within the hypothalamus that ultimately signal satiety (Mineur et al. 2011, Huang et al. 2011). However, considering these facts, the central and peripheral underlying mechanisms attributed to the effects of nicotine's effect on appetite regulation remain unclear.

NPY, an orexigenic peptide, has a stimulatory effect on appetite and promotes obesity. While the majority of cigarette smoking and nicotine injection studies on rodents report a downregulated NPY mRNA expression within the hypothalamus (Pelleymounter et al. 1995, Jang et al. 2003, Hur et al. 2010, Martinez de Morentin et al. 2012, Frankish et al. 1995, Li and Kane 2003) with an expected concurrent 
reduction in food intake, data regarding the effects of smoke/nicotine exposure on NPY expression are controversial. NPY mRNA has also been reported to increase from smoke/nicotine exposure (Mineur et al. 2011, Fornari et al. 2007, Chen et al. 2007, Li et al. 2000) or not change significantly (Chen et al. 2005), however, nicotine dosages and smoke exposure study designs may play a major role in these discrepancies. As POMC mRNA expression and spike frequency are significantly elevated with nicotine administration (Mineur et al. 2011, Huang et al. 2011), nicotine's anorectic effects may be predominately driven through this pathway instead of NPY-expressing neurons. This study will be the first of its kind to examine the effects of E-cig exposure on POMC and NPY mRNA expression within the hypothalamus.

Leptin, the main satiety hormone, is a 167-amino acid peptide and is synthesized and released from white adipose tissue, while circulating leptin is directly proportional to body fat stores and reflects the amount of long-term energy storage (Park and Ahima 2015). Leptin exerts its effects on the central nervous system (CNS) by attaching to its receptor (OB-R) and interacts with a multifaceted neural network to regulate food intake, and specifically, the arcuate nucleus (ARC) of the hypothalamus, which is highly express OB-R. The ARC, containing NPY and POMC, both of which express high levels of a7nAChRs (Erickson, Clegg and Palmiter 1996, McFadden et al. 2014), are the main sites for leptin binding. Leptin is released from white adipose tissue in response to a meal and inhibits orexigenic neurons that synthesize NPY, while stimulating anorexigenic neurons that synthesize POMC, resulting in anorexigenic effects and decreased food intake (Erickson et al. 1996). OB-R distribution overlaps that of nicotinic receptors in the hypothalamus (Jo et al. 2002), indicating a possible link between smoking and leptin sensitivity. While some studies indicate altered leptin levels from smoking and in vivo nicotine treatments, these effects may be secondary effects to food intake, fat lipolysis, and metabolism (Zoli and Picciotto 2012). 
Peripheral signals, such as leptin and ghrelin, act directly on the ARC to influence the release of NPY and POMC, which ultimately influence appetite (Park and Ahima 2015). Multiple studies have reported cigarette smoke and nicotine injections reducing serum leptin levels (Chen et al. 2005, Chen et al. 2008, Tomoda et al. 2012, Li and Kane 2003), with serum leptin reductions correlating in response to nicotine dosages and WAT weight. Controversy surrounds the effect of nicotine on serum leptin levels, as it was found that nicotine exposure did not significantly alter leptin mRNA in cultured adipocytes, or the leptin release from adipocytes (Reseland et al. 2005), suggesting that nicotine does not directly affect leptin release. However, in a study with 2,092 current cigarette smokers, individuals had significantly decreased leptin compared to non-smokers, independent of BMI (Hodge et al. 1997). This may indicate that cigarette smoking independently reduces serum leptin levels.

Glucagon-like peptide-1 (GLP-1), a 37 amino acid proglucagon-derived peptide in a family that includes glucagon and GLP-2, is synthesized in the enteroendocrine intestinal epithelial L-cells in the intestinal mucosal, where it responds to neuroendocrine impulses and ingested nutrients (Brubaker and Anini 2003). GLP-1 is a known potent appetite suppressant and is secreted in response to nutrient intake (Brubaker and Anini 2003) and acts on the GLP-1 receptors highly expressed in the hypothalamus (McMahon and Wellman 1998) and nucleus of the solitary tract (NTS) (Hayes, Bradley and Grill 2009). Through these actions, GLP-1 regulates body weight and food intake (Phillips et al. 2016, Turton et al. 1996). In a study of 159 e-liquids products, diacetyl and acetyl propionyl were present in $73 \%$ of the samples, with more flavors containing only diacetyl (Farsalinos et al. 2015). Diacetyl has been shown to decrease GLP-1 production in enteroendocrine cells (McCarthy et al. 2017), eliminating its potent appetite suppressant effects, and which may offer a potential mechanism for increased appetite and food intake with E-cig use.

GLP-1 receptors have also been identified on reward centers in the brain (mesolimbic reward system, ventral tegmental area, and nucleus accumbens). Activation of GLP-1 receptors on these centers 
reduces intake of highly-palatable foods (Alhadeff, Rupprecht and Hayes 2012). Just as palatable food stimulates dopamine transmission in the nucleus accumbens (Norgren, Hajnal and Mungarndee 2006), nicotine also significantly increases dopamine release (Egecioglu, Engel and Jerlhag 2013, Jo et al. 2002). Dopamine stimulates meal initiation and is associated with number of meals and meal duration (Meguid et al. 2000). Clearly, multiple appetite regulating factors from nicotine exposure have both appetite suppressing and stimulating effects.

Odors play a fundamental role in perception of flavor and drive for food consumption. Exposure to various food and non-food odors increases appetite scores in humans both acutely (5 minutes) and chronically (60 minutes). Moreover, sweet odors (chocolate) and savory odors (meat) increased appetite to a greater extent than other aromas (Ramaekers et al. 2014). Food cues, such as the smell, taste, or sight of appetizing food, enhances appetite and salivation in individuals (Fedoroff, Polivy and Herman 2003), while odor alone has the ability to significantly increase appetite (Yeomans 2006). This "appetizer effect" is a form of classical conditioning and results from anticipation of a meal to optimize digestion and absorption of soon-to-be-ingested nutrients; this is called the cephalic phase (Nederkoorn, Smulders and Jansen 2000).

E-cigs utilize a liquid-based ingredient mixture as a nicotine delivery vehicle, called e-liquid. Eliquid contains propylene glycol, glycerol, water, and nicotine, which can be combined with various flavors. Without FDA regulations in effect until 2018, e-liquid may contain numerous unknown and unlabeled ingredients. As millions of individuals are switching from cigarettes to E-cigs in hope of cessation, the post-cessation weight gain may be augmented due to the flavoring profiles in e-liquid (Caponnetto et al. 2013, Russo et al. 2016, Cravo et al. 2016).

The AHA defines low-calorie sweeteners, artificial sweeteners, and non-caloric sweeteners as non-nutritive sweeteners (NNSs), since they offer no nutritional benefits and offer low or zero calories (AHA 2014). NNSs are derived from plants, herbs, or sugar, and have a greater intensity of sweetness 
compared to sugar, therefore, low concentrations can be used to sweeten foods and beverages (Clinic 2013). The FDA has approved the label of "Generally Recognized as Safe" to five NNSs (aspartame, acesulfame-K, neotame, saccharin, and sucralose), which are hundreds of times sweeter than sucrose and are used in several products worldwide (AHA 2014). While these products are approved by the FDA, an ongoing debate persists over their effect on body weight, appetite regulation, and energy metabolism. Interestingly, NNS consumption compared to sucrose, glucose, or control groups, has been shown to scientifically increase body weight without increasing caloric intake (Swithers and Davidson 2008, Feijo et al. 2013, Foletto et al. 2016), suggesting an altered metabolism.

E-cigs often contain numerous ingredients that improve taste and stability, such as sweeteners, flavorants, colorants, dextrins, starches, cellulose, carbohydrates, and polyols. Interestingly, artificial sweeteners, such as sucralose (Williams 2016) and stevia (Landau 2015) are often used in e-liquid to provide sweet flavors. Sucralose consumption increases dopamine release at similar levels compared to sucrose consumption (de Araujo et al. 2008), and indicates reinforcement factors for sweetness exist from sweet flavor alone. It was discovered that nicotine enhances the response for caloric sugar intake reward, primarily driven by sweetness, rather than caloric content of the food (Rupprecht et al. 2016). Nicotine has been shown to increase the response for a saccharin and sucrose fluid reward, however, not for enhancement for chow food reward sweetened with sucrose or saccharin. A wide array of multisensory reward systems are at play, such as taste perception and post-prandial awards, and moreover, visual and olfactory anticipatory cues play a major role in the full effect of an "adequate meal" (de Araujo et al. 2008). Artificial sweeteners also activate different taste pathways in the brain from sucrose, and the brain distinguishes sucrose (calorie-dense) from intense sweeteners (non-caloric) when the conscious mind does not (Frank et al. 2008). This may have major implications as NNSs are used for sugar substitution, and it may subconsciously increase added sugar intake. If E-cigs employ the use of NNSs to sweeten their e-liquid to improve the palatability, taste, and mouthfeel of vaping, the 
possible ingestion of the e-liquid may influence appetite in a completely different way compared to inhalation.

Multiple studies have examined the effects of E-cig exposure on anthropometric measures (Ponzoni et al. 2015, El Golli et al. 2016, Sussan et al. 2015, Cravo et al. 2016, Russo et al. 2016, Caponnetto et al. 2013, Kogel et al. 2014, Phillips et al. 2016, Phillips et al. 2015, McGrath-Morrow et al. 2015). However, there is controversy between the relationship, as one chronic, 7-month exposure of E-cig vapor increased bodyweight over control animals (Phillips et al. 2015), some E-cig studies saw a decrease in body weight (Sussan et al. 2015, El Golli et al. 2016, McGrath-Morrow et al. 2015), and others saw no effect (Ponzoni et al. 2015, Cravo et al. 2016, Russo et al. 2016, Caponnetto et al. 2013, Phillips et al. 2016, Kogel et al. 2014). Two studies using similar nicotine content as our study exposed mice to E-cigs and traditional cigarettes, (Kogel et al. 2014, Phillips et al. 2016), however, only one study resulted in weight loss. Interestingly, a third study displayed the opposite effect, reporting an increase in weight from E-cig exposure (Phillips et al. 2015). The added flavorings in the E-cig may overpower nicotine's lipolytic and anorexigenic effects.

McGrath-Morrow et al. (2015) exposed neonatal mice to E-cig vapor containing 0\% nicotine or $1.8 \%$ nicotine and both groups experienced weight loss. This suggests either nicotine is not the sole source of weight loss in E-cig vapor, or a prepubertal stunted growth effect occurred with exposure to Ecig vapor. The same controversy surrounds E-cig use and food intake, as one study reported decreased food intake (El Golli et al. 2016), four reported no change (Ponzoni et al. 2015, El Golli et al. 2016, Kogel et al. 2014, Phillips et al. 2016), and one reported increased appetite in humans (Cravo et al. 2016). The combination of nicotine and various other chemicals in the E-cig liquid may elicit a differing response than cigarette or nicotine injection alone.

While there is clear evidence that cigarette smoking suppresses appetite through the actions of nicotine-mediated pathways, it is unclear in regards to E-cig vapor and inhalation of nicotine and other 
aromatics. This new product which provides added flavors and aromatics to nicotine delivery has the potential to interfere with appetite regulating pathways. E-cigs introduce novel complications to the regulation of appetite, as the effects of added flavors and nicotine have not been studied in such a context. A variety of conscious and subconscious factors play into appetite and therefore, body weight effects, such as altered feeding patterns, addiction, taste profile, microflora, sleep patterns, stress, anxiety, mouthfeel, flavor, smell, sight, and hormonal responses within the body. Therefore, a thorough investigation into the effects of added flavors and nicotine must be conducted.

\subsection{Nicotine and Obesity, Adiposity, and Body Composition}

In humans, obesity is thought of as an energy imbalance between consumption of calories and calories expended. However, the etiology of obesity contains multiple factors and cannot be explained solely by the hypothesis of calories-in verses calories-out. For example, obesity has been attributed to viral infections (Dhurandhar et al. 2002) and bacterial infections (Turnbaugh et al. 2008), termed infectobesity, rather than an imbalance between caloric intake and energy expenditure. The AD-36 adenovirus has been reported to increase body fat in monkeys (Dhurandhar et al. 2002) and lean, germfree mice given a microbiota transplantation from mice with diet-induced obesity (DIO) gained significantly more adipose tissue than transplants from lean donors (Turnbaugh et al. 2008). Obesity has also been attributed to an altered energy metabolism (Breslow et al. 1999), as ob/ob mice (leptin deficient) gain significantly more weight due to decreased energy metabolism and lack of satiation. Together, these data provide insight to the complexities of obesity and the various factors that contribute to it.

Cigarette smoking is the leading preventable cause of death in the U.S. (USDHHS 2014), followed closely by obesity-related chronic diseases. The obesity rate for U.S. adults is now over $37 \%$ (CDC 2016) which contributes to heart disease, stroke, and type II diabetes. To compound these diseases, an obese smoker has a lifespan 13 years less than that of a normal weight nonsmoker (Chiolero 
et al. 2008). Moreover, cigarette cessation has been attributed to a $14 \%$ rise in US obesity rates

(Courtemanche, Tchernis and Ukert 2016) and alternative nicotine therapies, such as E-cigs are currently being used to help mitigate these effects. Clearly, smoking cessation and weight management are two primary ways to assist in disease prevention and healthy aging.

An overwhelming body of scientific evidence and longitudinal studies suggest that cigarette smokers weigh less than non-smokers (Audrain-McGovern and Benowitz 2011, Albanes et al. 1987) and gain significantly more weight upon cessation (Mozaffarian et al. 2011), which makes people reluctant to quit (Chiolero et al. 2008) and intentionally use cigarette smoking as an effective weight loss tool (Potter et al. 2004). The Second National Health and Nutrition Examination Survey (NHANES II) examined the relationship between tobacco use and bodyweight of 12,103 individuals (Albanes et al. 1987) and found a direct correlation between cigarette smoking and a lower bodyweight. Moreover, a 10-year study examining the body mass index (BMI) and mortality of over 9,000 cigarette smokers resulted in smokers exhibiting a significantly reduced BMI compared to nonsmokers, and gained weight exceeding that of non-smoker baseline levels (Audrain-McGovern and Benowitz 2011) upon smoking cessation. Experimentally, both acute (Sanigorski et al. 2002, Frankish et al. 1995) and chronic (Sztalryd et al. 1996, Mangubat et al. 2012, Yoshida et al. 1999, Arai et al. 2001, Rasmussen 1998) moderate nicotine dose injections $(>1.0 \mathrm{mg} / \mathrm{kg})$ also elicit this anorectic bodyweight response, apart from effects of cigarette smoke. However, acute, low dose nicotine injections ( $<1.0 \mathrm{mg} /$ day) have no effect on body weight (Lupien and Bray 1988, Brees et al. 2008). This provides compelling evidence that nicotine in moderate to high doses has a potent anorectic effect and reduces bodyweight, unlike low doses.

Catecholamines released in response to nicotine binding to the adrenal medulla act on $\beta 3$ adrenergic receptors on brown adipose tissue (BAT) and white adipose tissue (WAT) to induce lipolysis and $\beta$-oxidation of free fatty acids (Brees et al. 2008). In cultured adipocytes, nicotine increases lipolysis (An et al. 2007), while inhibiting lipoprotein lipase (LPL) activity (Chajekshaul et al. 1994) and fatty 
acid synthesis (An et al. 2007). Nicotine decreases LPL by 30\% and it's suggested that nicotine diverts fat storage from the adipose tissue to be utilized by the muscle as free fatty acids (FFA) (Sztalryd et al. 1996). In a study evaluating the effect of nicotine on body composition in mice, it was found that 42 days of nicotine injections $(1.5 \mathrm{mg} / \mathrm{kg} /$ day) significantly decreased lean mass while fed a high-fat diet, however, no effect was seen in mice fed standard chow (Mangubat et al. 2012). This may be due to increased fat deposition in the muscle of mice fed a high-fat diet.

While it has been extensively proven that nicotine's effect on nicotine-mediated pathways is the main driver of the anorectic response seen from cigarette smoking, it is unclear what effects nicotine will elicit when combined with various flavors and aromatics in the e-liquid, rather than the thousands of other chemicals in traditional cigarettes. While this study cannot extrapolate which added flavors or aromatic interactions are causing a weight/appetite response, it will be able to answer what physiological repercussions occur from inhalation of nicotine and added flavors, combined, from E-cig exposure.

\subsection{Nicotine and Energy Metabolism and Uncoupling Proteins}

Oxidative phosphorylation, the synthesis of mitochondrial adenosine triphosphate (ATP) from adenosine diphosphate (ADP) substrate, is driven by the flow of electrons from NADH to oxygen. In 1961, Peter Mitchell demonstrated that oxidation is coupled to the electron transport chain by proton pumping across the mitochondrial membrane, which creates a proton motive force for protons across the mitochondrial inner membrane (Mitchell 1961). This proton motive force pushes protons through ATP synthase and couples proton transport to phosphorylation of ADP (Nicholls and Rial 1984). However, when ADP phosphorylation is inhibited, mitochondria still consume some oxygen, which means coupling of respiration to ATP synthesis is defective. Inner mitochondrial membrane leaks may impair coupling of oxidative phosphorylation, therefore, an uncoupling mechanism has been proposed.

Uncoupling protein (UCP) homologues are evolutionarily related mitochondrial transporters (Ricquier and Bouillaud 2000). Uncoupling proteins activate substrate oxidation and dissipate energy as 
heat instead of storing it as ATP. These are immensely important for energy balance, weight maintenance, and energy metabolism. UCP1 is exclusively found in brown adipose tissue (BAT) and is involved in cold-induced thermogenesis, causes proton leakage, and decreases mitochondrial electron chain efficiency, leading to heat production (Azzu and Brand 2010). UCP1 is a mitochondrial proton carrier and shifts the energy metabolism from producing ATP to releasing heat, which contributes to increased energy expenditure in smokers (Chen et al. 2007, Klesges et al. 1989).

Uncoupling protein-3 (UCP3) is primarily found in skeletal muscle. UCP3 is involved in mitochondrial fatty acid oxidation and the prevention of reactive oxygen species (ROS)-induced oxidative damage and lipid hyperoxide $(\mathrm{LOOH})$ oxidative stress within the mitochondria (Cioffi et al. 2009). Unlike UCP1, UCP3 is a mild-uncoupler and is involved in energy metabolism through mitochondrial fatty acid oxidation and mitochondrial uncoupling at the level of the muscle. Through mild uncoupling and protection from ROS/LOOH-induced oxidative damage, UCP3 offers protection against obesity and type 2 diabetes mellitus (T2DM).

Nicotine acts peripherally on WAT and BAT (Yoshida et al. 1999, Klesges et al. 1989) and decreases the mass of each tissue (Chen et al. 2005, Chen et al. 2007, Yoshida et al. 1999). BAT is the principal mediator of adaptive thermogenesis in rodents and is activated through $\beta 3$-adrenergic receptors. Nicotine and cigarette smoking stimulates release of catecholamines (NE, EPI) from the adrenal medulla (Sala et al. 2008), which act on $\beta 3$-adrenergic receptors on BAT and WAT to induce lipolysis and $\beta$-oxidation of free fatty acids (Brees et al. 2008). Studies show nicotine increases UCP1 mRNA and protein expression in BAT and WAT (Arai et al. 2001, Yoshida et al. 1999), while others show a decrease in BAT UCP1 expression, but increased UCP3 expression (Chen et al. 2005, Chen et al. 2008).

Oxygen consumption (VO2) is defined as the amount of $\mathrm{O} 2$ consumed and used by the body through the process of aerobic metabolism. As lungs take up $\mathrm{O} 2$, the $\mathrm{O} 2$ is used to produce ATP in the 
mitochondria of cells. Therefore, measuring VO2 is a well-documented marker to calculate the total energy expenditure of a subject. Similarly, carbon dioxide production (VCO2) is defined as the amount of carbon dioxide that an individual exhales after transport through the body, making it an excellent marker for cellular metabolic processes (Marvyn et al. 2015). As CO2 is a by-product of cellular respiration, measuring VCO2 is a reliable marker for metabolism. These two values are useful for measuring the respiratory exchange ratio (RER), which is the ratio of VCO2/VO2. RER estimates the source of fuel substrates being used to produce ATP by cells at basal and low-intensity exercise periods (Marvyn et al. 2015). An RER = 1.0 suggest the carbohydrates $(\mathrm{CHO})$ are the primary source of energy, while $\mathrm{RER}=0.7$ suggests fats are being used for energy production.

$$
\begin{aligned}
& \mathrm{VO} 2(\mathrm{ml} / \mathrm{min})=\mathrm{HR} \times \mathrm{SV} \times \mathrm{A}-\mathrm{vO} 2 \text { difference } \\
& \mathrm{VCO} 2(\mathrm{ml} / \mathrm{min})=\mathrm{VE} \times(\mathrm{FeCO} 2-\mathrm{FiCO} 2) \\
& \mathrm{RER}=\mathrm{VCO} 2 / \mathrm{VO} 2
\end{aligned}
$$

Cigarette smoking and I.P. nicotine administration have been reported to elevate total body oxygen consumption, or VO2, by 6\% and 9\% in canines, respectively (Ilebekk, Miller and Mjos 1975). However, when $\beta$-pyridylcarbinol was administered to inhibit lipolysis, total body oxygen consumption was unaltered between groups. This suggests that an increased mobilization and consumption of freefatty acids (FFAs) was the likely mediator of the rise in total body oxygen consumption. As nicotine has been reported to increase lipolysis and fatty acid breakdown (Liu et al. 2004), an increased FFA consumption due to nicotine exposure is likely. RER values in habitual smokers (varying from light to heavy smokers) have been reported to be similar to non-smokers during a maximal treadmill cardiovascular test (Bruce treadmill protocol) and range between 1.0-1.2 (Suminski et al. 2009), however, smokers at rest may have a significantly lower RER, suggesting increased FFA metabolism. This will be the first study to examine the effects of E-cig exposure on VCO2, VO2, and RER. 
Total daily expenditure is calculated as the sum of resting metabolic rate, thermic effect of food, and physical activity, while resting metabolic rate (RMR) accounts for nearly $70 \%$ of total energy expenditure in humans. A small change in RMR could drastically alter energy balance and weight status. Heavy smoking increased 24-hr energy expenditure by $10 \%$ in humans (Hofstetter et al. 1986), resulting in $200 \mathrm{kcals} / 24 \mathrm{hrs}$, which, without a change in food intake, would result in a $10 \mathrm{~kg}$ weight loss in one year. Nicotine increases thermogenesis by increasing lipolysis in adipose tissue via inhibition of lipoprotein lipase (LPL) activity and decrease of triglyceride (TG) storage, which in turn reduces overall net adipose storage (Jo et al. 2002). Moreover, nicotinic receptor activation by nicotine increases UCP1 expression in both WAT and BAT (Arai et al. 2001). Taken together, this data indicates nicotine has a direct lipolytic effect on adipose tissue and while increasing metabolism, results in weight loss.

While there is clear evidence that cigarette smoking has some effect on energy metabolism and increases thermogenesis through the actions of nicotine-mediated pathways, it is unclear in regards to Ecig vapor and inhalation of nicotine and other aromatics. To our knowledge, no other study has examined the effects of chronic E-cig exposure on uncoupling proteins and resting metabolic rate.

\subsection{Summary of Background and Significance}

This research is important for three main reasons. First, while there has been substantial research on nicotine or added flavors on appetite regulation and body weight, the combinative effects of added flavors and nicotine in E-cig vapor on appetite, body composition, and metabolism are virtually unknown. This study is the first of its kind to evaluate the effects of E-cigs on energy metabolism and neuroendocrine peptides. While E-cigs are marketed as a safe alternative to cigarette smoking, they still produce formaldehyde, a known carcinogen. While nicotine has been proven to induce weight loss, the added chemicals and ingredients in E-cigs, such as the various flavors, have unknown effects on our physiology and appetite in combination with nicotine. Second, a review of the literature involving nicotine and metabolism demonstrated multiple inconsistencies regarding the appetite-regulatory factors 
at play with nicotine administration, specifically, leptin, ghrelin, NPY, and POMC (Jang et al. 2003, Frankish et al. 1995).The majority of studies examining the metabolic effects of cigarette smoke and nicotine injections are acute. With this chronic, 8-month study, we will shed light on long-term effects of these potentially harmful consumer products. Third, one of the most serious public health issues is obesity and its relation to chronic diseases. We have chosen to study the effects of nicotine on weight loss because understanding the etiology of obesity, weight loss, and subsequent weight gain with nicotine cessation, will increase our understanding of this health epidemic and may help ameliorate such a response.

E-cigs are being marketed as a tobacco cessation tool, and while traditional cigarette smoking induces weight loss by inhibiting hunger and increasing thermogenesis, it remains unclear if the same holds true for E-cigs. Nicotine alters NPY and POMC mRNA expression which results in hypophagia, however nothing is known about the effects from E-cig exposure. Nicotine also increases thermogenesis and lipolysis by acting on nAChRs within the CNS, however, no research has been done on E-cigs. Ecigs contain both nicotine and added flavors, which may have a dissimilar physiological effect of traditional cigarettes. As weight gain is seen in individuals who quit tobacco cigarettes, if they transition to E-cigs, the weight gain may be more pronounced due to added flavorings altering appetite and subsequent caloric intake. Consequently, there is a need to investigate the role of E-cigs in the role of energy metabolism and appetite regulation. 
CHAPTER 3: MANUSCRIPT 
EFFECTS OF ELECTRONIC CIGARETTE VAPOR ON BODY WEIGHT, FOOD INTAKE, BODY COMPOSITION, \& METABOLISM

Matthew J. Breit ${ }^{1}$, Hannah N. Hoskinson ${ }^{1}$, Chris P. Pitzer ${ }^{1}$, Stan Hileman², Zhongxin $\mathrm{Wu}^{3}$, Randall Bryner $^{1}$, I.M. Olfert ${ }^{14}$

West Virginia University School of Medicine, One Medical Center Dr. Morgantown, WV 26505

(1) Division of Exercise Physiology

(2) Department of Physiology and Pharmacology

(3) Division of Anatomy Neurobiology

(4) West Virginia Clinical and Translational Sciences Institute (WVCTSI)

Short Title: E-cigarettes and body composition

Total Words: 5143

Corresponding Author:

Mark Olfert, Ph.D.

West Virginia University School of Medicine

Division of Exercise Physiology

One Medical Center Dr.

Morgantown, WV 26506-9105

Tel 304-293-7597

Fax 304-293-5513

molfert@hsc.wvu.edu 


\section{ABSTRACT}

Nicotine and cigarette smoking promotes weight loss and suppresses appetite. Since 2007, the use of electronic cigarettes (E-cig) has increased dramatically in the US, however only a few studies have examined the long-term consequences of e-vapor, particularly in the context of appetite regulation/weight management. This study compares the effects of chronic E-cig vapor exposure on food intake, body weight, and body composition in mice. We hypothesized that E-cigs would elicit similar changes on body mass, adiposity, and food intake as conventional cigarettes (i.e. 3R4F reference cigarette). Female C57BL/6 mice were exposed to filtered room air ( $\mathrm{n}=15)$, mainstream smoke from 3R4F reference cigarette $(n=15)$, or E-cig vapor $(n=15)$ for a total of 8 months. Assessments of body mass, food intake, body composition, metabolism, and appetite-regulating peptides following daily exposure (4 h/d, 5d/wk, 8/mo) are shown. Food and water were administered ad libitum. E-cig, control, and 3R4F mice increased body mass by 52\%, 47\%, and 38\%, respectively, over 8 months. E-cig mice had $14 \%$ higher body mass compared to $3 \mathrm{R} 4 \mathrm{~F}$ mice $(\mathrm{p}<0.01)$. E-cig mice had significantly elevated mean fat-free mass (FFM, 18.2 $\pm 0.2 \mathrm{~g})$ and mean fat mass $(3.8 \pm 0.3 \mathrm{~g})$ compared to $3 \mathrm{R} 4 \mathrm{~F}(17.0 \pm 0.2 \mathrm{~g}$ and $2.99 \pm 0.2 \mathrm{~g})$ mice $(\mathrm{p}<0.01)$. Body mass, FFM, and fat mass were similar between E-cig and control mice. Food consumption was significantly increased in E-cig mice $(50.7 \pm 2.3 \mathrm{~g})$ compared to $3 \mathrm{R} 4 \mathrm{~F}(42.8 \pm 0.8 \mathrm{~g})$ and control mice $(45.2 \pm 1.0 \mathrm{~g}, \mathrm{p}<0.05)$ respectively, over a 15-day food trial, however, NPY, POMC, leptin, and GLP-1 were similar between all groups. Heat production (kcal/hr) during light-phase was significantly greater in E-cig mice by $15 \%$ and $16 \%$ compared to $3 \mathrm{R} 4 \mathrm{~F}$ and control groups, respectively ( $\mathrm{p}<0.01)$. Heat during dark-phase also tended to be greater in E-cig mice by $7 \%$ and $8 \%$ compared to 3R4F and control, respectively, but did not reach significance $(\mathrm{p}=0.18)$. Light-phase oxygen consumption (VO2) was also significantly increased in E-cig (16\%) and 3R4F (12\%) mice compared to control mice $(\mathrm{p}<0.05)$, however, it was unchanged during dark-phase. Light-phase carbon dioxide production $(\mathrm{VCO} 2)$ was significantly higher in E-cig mice $(17 \%, \mathrm{p}<0.05)$ and trended towards 
significance in $3 \mathrm{R} 4 \mathrm{~F}$ exposed mice $(\mathrm{p}=0.06)$ compared to control mice. Dark-phase VCO2 was not different among groups ( $\mathrm{p}>0.05)$. Respiratory exchange ratio (RER) was not different among groups during either the light- or dark-phase. E-cig BAT UCP-1 expression was significantly increased compared to 3R4F mice ( $\mathrm{p}<0.05)$ and muscle UCP-3 was significantly increased in control mice compared to 3R4F mice $(\mathrm{p}<0.05)$. Unlike conventional cigarettes, we found that E-cig exposure did not elicit reductions in total body or fat mass. This suggests the effects of E-cig may not be the same as that occurring with traditional tobacco cigarettes, or that the exposure to nicotine and/or other chemicals in the E-cig liquid elicits a different response on appetite or feeding behavior. While E-cig mice increased food intake, their heat production was also elevated, suggesting energy dissipation and increased metabolism resulting in a similar net energy balance compared to control mice. Further studies are needed to evaluate the effect that flavorings and/or the compounds produced in E-cig vapor exert on metabolism, energy balance, and the neural regulation of appetite.

\author{
Abbreviations \\ E-cig - electronic Cigarette \\ ARC- arcuate nucleus \\ NPY - neuropeptide-y \\ POMC - pro-opiomelanocortin \\ CART - cocaine and amphetamine-related transcript \\ AgRP - agouti-related peptide \\ OB-R - leptin receptor \\ GnWAT - gonadal white adipose tissue \\ RpWAT - retroperitoneal white adipose tissue \\ BAT - brown adipose tissue \\ WAT - white adipose tissue \\ UCP - uncoupling protein \\ 3R4F - cigarette \\ CLAMS - comprehensive lab animal monitoring system \\ GA - gastrocnemius \\ FFM - fat-free mass \\ RER - respiratory exchange ratio \\ TBST - tris-buffered saline with Tween 20 \\ GLP-1 - glucagon-like peptide-1
}




\section{INTRODUCTION}

Approximately $37 \%$ of the U.S. population is obese (CDC 2016) and cigarette cessation has been attributed to a $14 \%$ rise in these rates (Courtemanche et al. 2016). Electronic cigarettes (E-cigs) are nicotine delivery devices, currently used by more than over 9 million U.S. residents in hopes of smoking cessation (Schoenborn and Gindi 2015). An overwhelming body of evidence across multiple species suggests cigarette smoking increases energy expenditure (Arai et al. 2001, Brees et al. 2008, Yoshida et al. 1999), decreases food intake (Tomoda et al. 2012, Chen et al. 2005, Chen et al. 2008), and promotes weight loss (Yoshida et al. 1999, Arai et al. 2001, Hodge et al. 1997), however, studies investigating these phenomena in regards to E-cig vapor are sparse and inconsistent.

E-cigs utilize a liquid-based ingredient mixture as a nicotine delivery vehicle, called e-liquid. Eliquid contains propylene glycol, glycerol, water, and nicotine, which can be combined with various flavors. Nicotine acts on nicotinic cholinergic receptors both centrally and peripherally (McFadden et al. 2014) within the body. Nicotine binding sites have been shown to be present in the arcuate nucleus (ARC), an important appetite-regulating region of the hypothalamus (Pelleymounter 1997), suggesting a direct effect of nicotine on appetite regulation via neuropeptide-Y (NPY) and pro-opiomelanocortin (POMC) neurons (Huang et al. 2011). Moreover, nicotine elicits catecholamine release from the adrenal medulla which act on brown adipose tissue (BAT) and white adipose tissue (WAT) to induce lipolysis and $\beta$-oxidation of free fatty acids (Brees et al. 2008).

Propylene glycol and glycerol, the main constituents of E-cig e-liquid, are mildly sweet (Miao et al. 2016) and may enhance the sweetening effects of ethyl maltol (Farsalinos et al. 2015, Moskowitz et al. 1974), a sweet taste potentiator which was found in $75 \%$ of e-liquid tested (Miao et al. 2016). Moreover, a comprehensive random-sample market analysis of 159 e-liquids found over $73 \%$ of products contained diacetyl (Farsalinos et al. 2015), which has been shown to decrease glucagon-like peptide-1 (GLP-1) in enteroendocrine cells (McCarthy et al. 2017), a potent appetite suppressant. 
Together, these offer a potential mechanism for hyperphagia with E-cig use. E-cig use has also been shown to significantly increase appetite ratings, or perceived hunger, in humans (Cravo et al. 2016). Finally, e-liquid can contain artificial intense sweeteners, such as sucralose (Williams 2016) and stevia (Landau 2015), which have been shown to promote food intake through a NPY-dependent mechanism, disrupt sleeping patterns, and increase activity patterns (Wang et al. 2016). Together, these offer a potential mechanism for diet-induced obesity through an increased hyperphagic response following chronic E-cig use.

Food cues, such as the smell, taste, or sight of food enhances appetite and salivation in individuals (Fedoroff et al. 2003), while sweet odor has a potent appetite stimulating effect (Yeomans 2006). A form of classical conditioning, this "appetizer effect" results from anticipation of a meal to optimize digestion and absorption of soon-to-be-ingested nutrients, also known as the cephalic phase (Nederkoorn et al. 2000). While the effects of nicotine on appetite and bodyweight are robust, the combination of the inhalation of nicotine and sweet aromatics (e-liquid) is largely unknown. As millions of individuals are switching from cigarettes to E-cigs in hope of cessation, the post-cessation weight gain may be augmented due to the flavoring profiles in e-liquid (Caponnetto et al. 2013, Russo et al. 2016, Cravo et al. 2016).

Literature surrounding E-cig use on body weight and food intake are controversial, as some studies report increased weight gain (Phillips et al. 2015, Russo et al. 2016), decreased weight gain (El Golli et al. 2016, Golli et al. 2016, Sussan et al. 2015, McGrath-Morrow et al. 2015), or no weight gain (Ponzoni et al. 2015, Cravo et al. 2016, Phillips et al. 2016, Kogel et al. 2014, Caponnetto et al. 2013, Dawkins et al. 2012), without investigating the mechanistic cause. The anorectic effects of nicotine may be altered by flavoring aromatic pathways and homeostatic, hedonic, and reward-system regulation. Therefore, studies aimed at understanding the metabolic and behavioral side effects of E-cig use are warranted. 
The purpose of this study was to determine the metabolic and physiological effects of chronic Ecig vapor exposure. We hypothesize that E-cig exposed mice will exhibit decreased food intake, increased lipolysis, and increased cage activity, resulting in a decreased body mass compared to litter mate controls.

\section{MATERIALS AND METHODS}

All experiments were approved by and conducted in accordance with the guidelines of the West Virginia University Institutional Animal Care and Use Committee.

Animals

Forty-five C57BL/6 female mice bred in pathogen-free environments were obtained from Jackson Laboratory, Bar Harbor, Maine, USA (Stock \#000664, respectively) and were 10 weeks old upon arrival (Table 1). Mice were allowed a one week acclimatization period and randomly divided into three treatment groups ( $\mathrm{n}=15 /$ group) consisting of a conventional reference cigarette (3R $4 \mathrm{~F}$, exposed to mainstream smoke), E-cig (exposed to mainstream vapor), or control (exposed to filtered air). Mice were 13-14 weeks old at exposure initiation, followed by 8 months of exposure (ending at $\sim 12$ months of age). Mice were group housed by treatment (4-5 mice/cage), kept on a 12-h light/dark cycle, $22 \pm 4{ }^{\circ} \mathrm{C}$ temperature, $39 \pm 6 \%$ relative humidity, and provided an ad libitum tap water and standard chow diet (18\% fat, 24\% protein, 58\% CHO; Teklad Diet, Madison, WI), unless otherwise noted. Cob bedding was changed on a bi-weekly basis. Mice were monitored daily for health, mortality, and morbidity. 3R4F Reference Cigarette, E-Cigarette, Smoke/Vapor Generation, and Exposure

Mice were exposed as single respective treatment groups (i.e. E-cig, 3R4F cigarette, or filtered air) at the same time ( $\mathrm{n}=15 /$ group) using identical $15.1 \mathrm{~L}$ whole body exposure chambers. E-cig vapor and tobacco smoke was gradually introduced during the first 8 weeks, after which point the mice were consistently exposed to four 1-hour exposure blocks, with each exposure separated by 30 minute intervals of fresh air breaks, resulting in an intermittent exposure pattern for a total exposure time of 4 
hours each day (occurring over 6-hour window of time each day). This daily regime was applied 5 days/week for a total of 8 months.

The $3^{\text {rd }}$ generation, tank-style, E-cig device was purchased online (eGrip ${ }^{\mathrm{TM} O L E D}$, Joyetch, ShenZhen, China, www.joyetch.com). The E-cig device was activated by a custom-made electronically controlled cradle (courtesy of Dr. Powsiri Klinkhachorn, Dept. of Electrical Engineering, West Virginia University, Morgantown, WV, USA) that allowed precise and reliable control of the frequency and duration of E-cig activation. The E-cig was activated every 99 seconds for a 5-second duration (3839/puffs/hour), with voltage set at $4.8 \mathrm{~V}$. E-liquid was purchased from Joyetech and a local vendor (VaporHut, Morgantown, West Virginia, USA), containing 50\% vegetable glycerin, 50\% propylene glycol, cappuccino flavoring extract, and $18 \mathrm{mg} / \mathrm{ml}$ nicotine. Estimated nicotine concentrations of E-cig exposure was $27 \mathrm{mg}$ nicotine/day (1.5 $\mathrm{ml}$ e-liquid x $18 \mathrm{mg}$ nicotine/ml).

3R4F standard reference cigarettes ( $9.5 \mathrm{mg}$ tar, $0.73 \mathrm{mg}$ nicotine) were purchased from the University of Kentucky, Center for Tobacco Reference Products (http://www.ca.eky.edu/refcig), were stored in $4^{\circ} \mathrm{C}$ for the duration of the study and set in room air one week prior to use. One cigarette was loaded and lit on the ventilator inlet every 10 minutes, resulting in 6 cigarettes/hr (24 cigarettes/day of the 4-hr exposure paradigm).

Vapor, smoke, and air were generated and delivered independently, but identically, to each respective group polypropylene exposure chamber. Rodent ventilators (Harvard Apparatus Dual Phase Control Respirator, Model 55-0715, South Natick, Massachusetts, USA), with 55ml tidal puff volume were used. Control mice received filtered air (Whatman, GE Healthcare Life Sciences, Carbon Cap 150) from a central compressed air line. Each chamber had a bias flow of $\sim 31 / \mathrm{min}$ and all exposures occur simultaneously each day. 


\section{Measurements}

Prior to smoke/vapor exposure initiation, a series of non-invasive, ex and in-vivo measurements were conducted. These included: EchoMRI body composition analysis and metabolic assessment using a comprehensive lab animal monitoring system (CLAMS) as later described. Midpoint measurements for non-invasive assessments were conducted at months 2 and 5 of treatment.

\section{Body Weight and Food Intake}

Animal body mass was measured twice each week between 0700 and 0800 to monitor growth and general health. Individual food intake was measured at week 3, 7, 19, 23, and 29 over a three-day span (Friday-Monday, during periods of no exposures) in mice individually caged. Total caloric intake

(energy density) was calculated as grams of chow eaten x 3.1 (as chow was $3.1 \mathrm{kcal} / \mathrm{g}$ ). The 15 -day food intake was calculated by the summation of total calories consumed during food measurement trials at weeks 3, 7, 19, 23, and 29. Weekly, group food intake was also measured during the last month of exposure and reported as g/week.

Body Composition, Adipose, and Muscle Tissue

Body fat, fat free mass (FFM), free water (FW), and total body water (TBW) were measured with an EchoMRI small animal body composition analyzer (Model 100H; Houston, TX, www.echomri.com) at month 0,2, 5 and 8. On a separate day from the laboratory pre-testing, but prior to the first exposure, animals entered the body composition analyzer for determination of body fat, FFM, FW, and TBW. This procedure was non-invasive, does not require anesthesia, and correlates strongly with DEXA measurements (Galgani, Smith and Ravussin 2011). Three measurements were conducted on each animal. Measurements were conducted between 0600 and 1000 in a basal state, at least 24 hours post last exposure. 


\section{Tissue Collection and Processing}

Upon completion of the 8-month exposures, animals were sacrificed after an 8-hour caloric fast and 24-hours post final any exposure. Animals were anesthetized (ketamine/xylazine intraparietal (IP) dose) and administered a paralytic agent (IP, pancuronium bromide, $0.8 \mathrm{mg} / \mathrm{kg}$ ). Major organs were carefully dissected, weighed, flash frozen, and stored at $-80^{\circ} \mathrm{C}$ for later analysis. Blood was collected from a heart puncture and allowed to clot at room temperature for 30 minutes, followed by centrifugation (2000g for 10 minutes at $4^{\circ} \mathrm{C}$ ). Serum was collected and flash frozen in liquid nitrogen, and stored at $-80^{\circ} \mathrm{C}$ for subsequent determination of serum leptin (\#90030, Crystal Chem Inc. Downers Grove, IL, USA) and GLP-1 (\#EZGLP1T-36K, Millipore, St. Charles, MO, USA) by ELISA assay. Urine was collected at month 5 immediately after exposure (hour 1, 2, and 3 post exposure) for determination of urinary cotinine (CALBIOTECH, El Cajon, California, USA) by ELISA assay. No sample dilutions were necessary. All three ELISA kits was used per the manufacturer's instructions. Leptin, GLP-1, and cotinine were measured on one assay kit. Immediately following blood collection, animals were decapitated, the brain was removed on ice, and the hypothalamus was excised, flash frozen, and stored at $-80^{\circ} \mathrm{C}$ for determination of total mRNA concentrations of neuropeptide-y (NPY) and pro-opiomelanocortin (POMC) using reverse transcription polymerase chain reaction (rt-PCR). White adipose tissue (retroperitoneal (RpWAT) and gonadal (GnWAT), interscapular brown adipose tissue (BAT) and gastrocnemius (GA) muscle were dissected, weighed, snap frozen, and stored at $-80^{\circ} \mathrm{C}$ for later determination of total protein expression of UCP-1 and UCP-3 using western blotting technique.

Western blot analysis

Basal protein expression of BAT UCP-1 and GA UCP-3 were analyzed using western blot. BAT samples were homogenized in Lysis Buffer (5.96 g HEPES (50 mM), $4.38 \mathrm{~g} \mathrm{NaCl}(150 \mathrm{mM}), 50 \mathrm{~mL}$ glycerol (10\%), $5 \mathrm{~mL}$ Triton X-100 (1\%)), pH of 7.5 with an EDTA-free protease inhibitor tablet 
(cOmplete Mini, $1 \mathrm{tab} / 10 \mathrm{ml})$. Muscle GA samples were homogenized in Tris-buffered saline (50mM tris/ $\mathrm{HCl}, 150 \mathrm{mM} \mathrm{NaCl}, 0.5 \%$ Triton X-100), a protease inhibitor tablet, and $\mathrm{H} 2 \mathrm{O}$. After homogenization, BAT and GA samples were incubated by gentle rotation for 40 minutes at $4^{\circ} \mathrm{C}$, followed by centrifugation $\left(16,100 \mathrm{~g}, 20 \mathrm{~min}\right.$, at $\left.4^{\circ} \mathrm{C}\right)$. The supernatants were collected and stored at $-80{ }^{\circ} \mathrm{C}$ for later determination of UCP-1 and UCP-3 protein content by western blot. Total protein was measured by Bradford assay (\#23236 Pierce Coomassie Plus Protein Assay Kit, Thermo Scientific, Rockford, IL).

Total protein for UCP-1 $(60 \mu \mathrm{g})$ and UCP-3 $(60 \mu \mathrm{g})$ were reduced, denatured, electrophoresed with a 4-12\% SDS-PAGE (NuPAGE Novex 4-12\% Tris-Acetate Midi Gel, Invitrogen, Burlington, ON, Canada), transferred onto a $0.45 \mathrm{um}$ nitrocellulose membrane (Pierce nitrocellulose membrane, Thermo Scientific, Rockford, IL), stained with Ponceau S (Boston BioProducts, Ashland, MA), and imaged. After a 5-minute incubation period, the Ponceau $\mathrm{S}$ was rinsed in deionized water, followed by trisbuffered saline with $0.05 \%$ Tween-20 (TBST) before blocking with 5\% non-fat dry milk (NFDM) in 50ml TBST for one hour at room temperature. After blocking, the BAT membrane was probed with a primary (1:500, rabbit anti-mouse IgG Abcam, Cambridge, MA, USA) antibody diluted in 5\% NFDM in TBST at $4^{\circ} \mathrm{C}$ for 24 hours by gentle rocking and a secondary $(1: 1000$, goat anti-rabbit IgG HRPconjugated, \#p0217, Dako) antibody for 1 hour at room temperature diluted in TBST. Muscle GA membrane was probed with a primary (1:500, rabbit anti-mouse IgG, ThermoFisher Scientific Rockford, IL, USA) antibody diluted in 5\% NFDM in TBST at $4^{\circ} \mathrm{C}$ for 24 hours by gentle rocking and a secondary (1:5000, goat anti-rabbit IgG HRP-conjugated, \#32460, ThermoFisher Scientific, Rockford, IL) antibody for 1 hour at room temperature diluted in TBST. Chemiluminescent detection (Pierce ECL, Thermo Scientific, Rockford, IL) was carried out and digitally imaged (G:BOX Gel imager, Syngene, Cambridge, UK) using Genesnap software (Ver. 7.01, Syngene, Cambridge, UK). Protein expression 
levels were quantified using NIH ImageJ Software (v1.62) and represented as optical density in arbitrary units (AU). Protein of interest area was normalized to total protein obtained from Ponceau S staining.

\section{Polymerase Chain Reaction (PCR)}

Hypothalamus samples were homogenized (Bead Mill 4, \#15-340-164, Thermo Scientific, Waltham, MA, USA) using QIAzol Lysis Reagent (QIAGEN). Briefly, RNA was extracted from hypothalamus tissues using QIAzol Lysis Reagent (QIAGEN) and cDNA was generated using identical amounts of RNA (25ul) from each hypothalamus sample (44ng/ul) in a QuantiTect Reverse Transcription Kit (QIAGEN). Real-time PCR measurement of individual cDNA (44ng) were made using RT² SYBR Green Mastermix (QIAGEN), RNase-free water, RT² qPCR Primer Assay (1uL), and cDNA synthesis reaction (1uL) per sample were combined. Samples $(25 \mathrm{uL})$ were then placed in the Rotor-Gene Q real-time cycler (QIAGEN). Cycling conditions for the Rotor-Gene consisted of activating HotStart DNA Taq Polymerase $\left(1 \mathrm{cycle}, 10 \mathrm{~min}, 95^{\circ} \mathrm{C}\right)$ and performing florescence data collection $\left(40\right.$ cycles, $15 \mathrm{~s}$ at $95^{\circ} \mathrm{C}, 30 \mathrm{~s}$ at $\left.60^{\circ} \mathrm{C}\right)$. The threshold cycle $(\mathrm{Ct})$ was calculated for each well and fold change relative to $\beta$-actin was reported. POMC (QIAGEN, RefSeq no. NM_008895.4), NPY (QIAGEN, RefSeq no. NM_023456.2), and $\beta$-Actin (Cell Signaling Technology, 1:2000, \#3700) RT² qPCR primers were used.

\section{Metabolic Monitoring}

Animals were monitored for three days (singly housed) prior to the exposures and during the last month of exposure (48 hours post last exposure) in a Comprehensive Lab Animal Monitoring System (Oxymax CLAMS, Columbus Instruments). This non-invasive procedure measured basal metabolism, cage movement, sleep patterns, and food monitoring, more specifically, measuring maximal oxygen consumption (VO2), carbon dioxide production (VCO2), respiratory exchange ratio (RER), heat, sleep $\%$, and activity. Metabolic heat was calculated as: Heat $=(3.815+1.232 * \mathrm{RER}) * \mathrm{VO} 2$. Animals were 
individually housed for 3 days, receiving no exposure for the duration of the experiment and provided food and water ad libitum.

Statistical Analysis

All data are presented as \pm SEM. Statistical analyses were performed using Statview Statistical Software package (version 5.0.01; SAS Institute, Inc., Cary, NC). For examining body mass, food intake, body fat, and free fat mass, a repeated measures ANOVA (rANOVA) was used. An ANOVA was used when comparing treatment groups for leptin, GLP-1, UCP-1, UCP-3, NPY, POMC, and overall food intake. Where a main effect was observed, post hoc testing was performed using student's $t$ tests.

\section{$\underline{\text { RESULTS }}$}

\section{Body Mass, Weight Gain, and Body Composition}

All groups had similar body masses during the first month, however, E-cig and control mice had a significantly higher body mass between months 2-7 compared to 3R4F mice ( $<<0.05$, Figure $1 A$ ). At

month 8 , E-cig mice had a significantly higher body mass than $3 \mathrm{R} 4 \mathrm{~F}$ mice $(+10 \%$; $\mathrm{p}<0.05$, respectively, Figure 1A), but not compared to control mice. At month 8, E-cig mice had gained significantly more weight than $3 \mathrm{R} 4 \mathrm{~F}$ mice $(+32 \%$; $\mathrm{p}<0.01$, respectively, Figure $1 \mathrm{~B})$, while control mice tended to gain more weight than $3 \mathrm{R} 4 \mathrm{~F}$ mice $(+23 \%)$, although this difference did not reach statistical significance $(\mathrm{p}=0.056)$. No statistical significance was found between E-cig and control body mass or weight gain.

All groups mice had similar FFM and fat mass at prior to exposure. Mean FFM was significantly reduced in $3 \mathrm{R} 4 \mathrm{~F}$ mice compared to E-cig and control mice $(-6 \%$ and $-5 \% ; \mathrm{p}<0.01$, respectively, Table 1$)$ throughout the study. Similarly, mean EchoMRI fat mass was significantly reduced in 3R4F mice compared to E-cig and control mice $(-26 \%$ and $-24 \% ; \mathrm{p}<0.05$, respectively, Table 1$)$ throughout the study. E-cig and control mice had an elevated FFM at month 2 compared to 3R4F mice, and E-cig mice had an elevated FFM at months 5 and 8 ( $\mathrm{p}<0.05$, Figure 1C) compared to 3R4F mice. E-cig and control 
mice had elevated fat mass at months 2 and 5 compared to 3R4F mice, but no difference at month 8 (Figure 1D). No statistical significance was found between E-cig and control FFM or fat mass.

3R4F mice experienced a significant reduction in BAT mass compared to control mice (-22\%; respectively, $\mathrm{p}<0.05$, Figure $2 \mathrm{~A})$, but not compared to E-cig mice (-13\%). There were no differences in RpWAT or GnWAT weights between groups.

\section{Food Intake and Appetite Regulating Hormones}

E-cig mice consumed significantly more kcals during the total 15-day food intake measurement trials ( 3 day averages) compared to $3 \mathrm{R} 4 \mathrm{~F}$ and control (50.7 \pm 2.3 vs. $42.8 \pm 0.8$ and $45.2 \pm 1.0 \mathrm{~g}, \mathrm{p}<0.01$, respectively, Figure 3A). 3R4F mice consumed significantly less kcals than E-cig and control mice at week 3, however, there were no significant differences between E-cig, 3R4F, and control kcal consumption during the individual 3-day feeding trials at weeks 7, 19, 23, and 29 (Figure 3B). Group food intake (Figure 3C) during the final month of exposures tended to be higher in E-cig compared to 3R4F mice, but did not reach statistical significance $(\mathrm{p}=0.13)$. Hypothalamic NPY and POMC mRNA expression was unaltered between groups (Figure 4A\&B). Serum leptin and total GLP-1 concentrations were not different between groups (Figure 4C\&D).

\section{$\underline{\text { Basal Metabolism and Uncoupling Proteins }}$}

E-cig mice did not show significant differences in UCP-3 expression compared to either control or 3R4F mice, however, control mice had elevated UCP-3 muscle expression $(\mathrm{p}<0.05)$ compared to 3R4F mice by western blot analysis (Figure 5A\&B). E-cig mice had significantly higher UCP-1 expression in BAT compared to 3R4F mice $(\mathrm{p}<0.05)$, however, remained unchanged compared to control mice (Figure 5C\&D).

Heat production $(\mathrm{kcal} / \mathrm{hr})$ was significantly higher in E-cig mice by $15 \%$ and $16 \%$ during the light-phase compared to 3R4F and control groups, respectively ( $\mathrm{p}<0.01$, Figure 6A). Dark-phase heat production was not significant between groups (Figure 6B). Cage activity and movement was not 
different between groups during the day or night (Figure 6D,E,F). Total sleep was not significantly difference between groups (Figure 6G,H,I).

Light-phase oxygen consumption ( $\left.\mathrm{VO}_{2}\right)$ was significantly higher in E-cig (16\%) and 3R4F (12\%) exposed mice compared to control ( $\mathrm{p}<0.05$, Figure 7A). Dark-phase VO2 consumption was not different among groups ( $\mathrm{p}>0.05$, Figure 7B). Light-phase carbon dioxide production (VCO2) was significantly higher in E-cig mice (17\%, $<<0.05$, Figure $7 \mathrm{D})$, and trended towards significance in $3 \mathrm{R} 4 \mathrm{~F}$ exposed mice $(\mathrm{p}=0.06)$ compared to control mice. Dark-phase VCO2 was not different among groups ( $>0.05$, Figure 7E). Respiratory exchange ratio (RER) was not different among groups during either the light- or dark-phase (Figure 7G,H).

\section{Nicotine Absorption}

Urine cotinine values were not significantly different between 3R4F and E-cig mice, however, 3R4F cotinine levels were trending towards significance ( $\mathrm{p}=0.070$, Table 1$)$ compared to E-cigs. Cotinine levels in control mice were undetectable.

\section{DISCUSSION}

The main findings of this study were that E-cig vapor exposure induced hyperphagia and increased heat expenditure without inducing weight gain in this rodent model. These data suggest that, like traditional cigarettes, basal metabolism is increased, however, E-cig exposure increases food intake instead of producing an expected anorectic effect.

\section{Effect of E-Cig Vapor on Body Mass and Body Composition}

E-cig exposed mice did not differ in body weight after the 8-month exposure compared to control mice, likewise, body fat and FFM were also unchanged (Table 1). At the time of sacrifice, GnWAT, RpWAT, and BAT masses were similar between the two groups (Table 1). Moreover, body fat and FFM EchoMRI measurements indicated similar fat and lean tissue growth in each group (Figure 1C\&D). Traditional smoke exposure is known to increase lipolysis and decrease body weight (Tweed et 
al. 2012), however, through this study, we have discovered that chronic E-cig vapor exposure does not have similar anorectic effects as traditional cigarettes. In a similar E-cig exposure study, rats injected I.P. with e-liquid containing nicotine significantly decreased body mass, while e-liquid ( $0 \%$ nicotine) did not alter body mass (El Golli et al. 2016). This finding demonstrates that nicotine is the major component for weight loss in an E-cig model. The discrepancy for lack of weight loss in our E-cig mice could be due to inadequate nicotine absorption delivered from E-cig vapor compared to I.P. injections, exhibited by a trend for less urine cotinine levels compared to 3R4F mice (Table 1). Indeed, Farsalinos et al. (2014) determined plasma nicotine levels are 185\% higher from smoking one traditional cigarette compared to E-cig vapor. Regardless, these data agree with Ponzoni et al. (2015) and Phillips et al. (2015), that E-cig vapor (containing nicotine) does not alter body mass in mice following 2-months and 8-months of exposure, respectively. Collectively, these data suggest chronic exposure to E-cig vapor, unlike traditional cigarettes, do not elicit weight loss, lipolysis, or muscular atrophy.

\section{Effect of E-Cig Vapor on Food Intake and Energy Metabolism}

E-cig exposed mice displayed increased heat production (Figure 6A), without a concurrent decrease in body mass (Figure 1A) compared to control mice. However, E-cig exposed mice also consumed significantly more kcals than control mice (Figure 3A). Together, these data suggest an alteration in basal metabolism and appetite regulation in E-cig mice. To test this, we measured UCP-1, UCP-3, NPY, POMC, leptin, and total GLP-1 under basal, fasted conditions after the 8-month exposure, and $\mathrm{VO} 2, \mathrm{VCO} 2$, and RER during month 0 and 7. Within the brain, leptin acts on OB-R-expressing neurons and interacts with a multifaceted neural network to regulate long-tern energy balance. Leptin, released from white adipose tissue in response to a meal, inhibits orexigenic neurons that synthesize NPY, while stimulating anorexigenic neurons that synthesize POMC, resulting in anorexigenic effects and decreased food intake (Erickson et al. 1996). Circulating serum leptin levels are directly correlated to white adipose mass, thereby reflecting long term energy storage (Park and Ahima 2015). Similarly, 
GLP-1 is a known potent appetite suppressant and is secreted in response to nutrient intake (Brubaker and Anini 2003). Both serum leptin and GLP-1 concentrations were similar in E-cig exposed mice compared to controls and 3R4F mice (Figure 4C\&D). As WAT weights were similar and all mice underwent an 8-hour fast prior to euthanasia, these results were not surprising. It was found that nicotine administration reduces food intake and body mass through a leptin-independent pathway (Sanigorski et al. 2002), as both lean and obese animals experienced significant weight reductions, while plasma leptin levels dropped in the lean animals only.

As E-cig exposed mice displayed hyperphagia over the 8-month exposure, we measured NPY and POMC mRNA expression, two key appetite-regulating cell populations within the arcuate nucleus (ARC) of the hypothalamus. Both NPY and POMC mRNA expression were unaltered in E-cig and 3R4F mice compared to control mice (Figure 4A\&B). Leptin binding to OB-R-expressing neurons within the hypothalamus initiates the cascade of synthesizing POMC while inhibiting NPY, so without elevated serum leptin levels, a null effect on POMC and NPY mRNA was expected. Future studies should measure activation of neurons in response to E-cig exposure. While we did not see any significant differences, nicotine has been shown to excite both hypothalamic NPY and POMC neurons through binding to $\alpha 7 \mathrm{nAChRs}$ on the neurons (Huang et al. 2011), with a greater depolarization and spike frequency response from POMC neurons, eliciting a potential mechanism through which nicotine may suppress appetite (Huang et al. 2011). Future studies should evaluate the spike frequencies and depolarization values between NPY and POMC following E-cig exposure. Moreover, future studies should examine the effects of E-cig vapor on POMC neurons and the melanocortin system, specifically, $\alpha-\mathrm{MSH}, \mathrm{AgRP}$, and MC4R expression. Moreover, the co-expressed NPY/AgRP and POMC/CART cell populations, as well as reward centers of the brain should be examined to extrapolate any motivational reward of E-cig use. As NPY expression is significantly increased from a high-fat chow diet, studying a smoke cessation model and switching to E-cig use would be extremely beneficial to parse out the 
appetite regulatory mechanisms involved in E-cig use. Other possible neural circuits (reward-based mechanisms) and satiety factors (CCK, PYY, insulin, and gut distention) may also be a factor in E-cig exposure and should be examined in future studies.

This is the first study to report hyperphagia in response to chronic E-cig vapor exposure. E-cig exposure has been reported to significantly increase appetite rating scores by $14 \%$ in humans (Cravo et al. 2016) and decrease food intake in mice (El Golli et al. 2016) injected with e-liquid. Interestingly, mice injected with e-liquid alone ( $0 \%$ nicotine) consumed the same amount of kcals as controls, however, mice injected with e-liquid $(0.5 \mathrm{mg}$ nicotine $/ \mathrm{kg} / \mathrm{day})$ consumed significantly less food than control animals (El Golli et al. 2016). That study, unlike ours, administered e-liquid intraperitoneally instead of vaporizing the e-liquid. Nicotine pharmacokinetics could be significantly different between I.P. injections and vapor exposure models. Previous studies reporting reduced nicotine absorption from E-cig (Farsalinos et al. 2014a, Allen et al. 2016) compared to cigarette smoke may result in a limited lipolytic and adrenergic effect elicited by E-cig use. One explanation for the limited anorectic results from E-cig exposure are due to urine cotinine levels. Urine cotinine values tended to be higher in $3 \mathrm{R} 4 \mathrm{~F}$ mice compared to E-cig ( $\mathrm{p}=0.070$, Table 1). E-liquid nicotine content was externally verified (University of Virginia) and contained the listed amount of nicotine $(18 \mathrm{mg} / \mathrm{ml})$.

\section{Effect of E-Cig Vapor on Energy Expenditure}

A novel finding of this study was that E-cig exposure increased heat production $(\mathrm{kcal} / \mathrm{h}), \mathrm{VO}$, and VCO2, resulting in higher basal metabolism during the day (period of least activity in normal mice), but not at night (period of greatest cage activity, Figure 6B). This suggests chronic E-cig use increases basal metabolic activity without altering cage activity or metabolism when mice are most active. An increased basal metabolism explains the lack of weight gain in the E-cig mice in the face of an increased caloric intake. 
To measure basal metabolism and a possible mechanism for heat production, white adipose UCP-1 and gastrocnemius muscle UCP-3 were examined. UCP-1 causes leakage of protons and a decreased efficiency of the mitochondrial electron transport chain (respiratory chain), resulting in heat production (Zoli and Picciotto 2012). Nicotine, like caffeine, is a stimulant and acts to suppress appetite, induce thermogenesis, and reduce weight. Cigarette smoking and nicotine have been shown to increase basal metabolic rate (BMR) by releasing catecholamines, epinephrine and norepinephrine, which increase thermogenesis (Tweed et al. 2012). Light-phase VO2 was significantly higher in E-cig and 3R4F mice compared to controls (Figure 7A) but not during dark-phase, suggesting an increased basal metabolic rate and greater energy expenditure during the period of a rodent's dormant period. Similarly, light-phase VCO2 was significantly higher in E-cig mice (Figure 7D), and trended towards significance in 3R4F exposed mice compared to controls. As $\mathrm{CO} 2$ is a marker for cellular metabolism, an elevated level suggests an increased metabolism in the E-cig mice.

In contrast to previous studies (Chen et al. 2008, Sanigorski et al. 2002), 3R4F mice did not significantly reduce their food intake, even while decreasing their body mass and in the face of reduced UCP-1 and UCP-3 expression, suggesting a mechanism of energy preservation and decreased thermogenesis. Our testing of food intake (15 days out of 240 days) provided only a snapshot of total caloric intake, thus 3R4F mice may have consumed significantly fewer calories, resulting in decreased UCP-1 and UCP-3 expression, as fasting and chronic food deprivation has been reported to significantly decrease BAT UCP-1 expression to preserve energy and decrease thermogenesis (Champigny and Ricquier 1990).

To date, this is the first study to measure uncoupling proteins and basal metabolism in an E-cig model. Interestingly, Phillips et al (2015) reported significantly higher body masses in a similar E-cig exposure paradigm model following 8-months of exposure, without a change in food intake. Without examining energy metabolism in these mice, it can be extrapolated that those mice had a significantly 
reduced basal metabolism, which resulted in a higher body mass. Contrary to our study, we report increased heat expenditure which may influence basal metabolism. Future studies examining the causal mechanism between metabolism, food intake, and body mass are needed to parse out these differences.

\section{Interpretation and significance}

Cigarette smoking has been shown to increase thermogenesis and decrease energy intake and body mass, while smoking cessation has been shown to significantly increase weight gain. Studies have investigated the use of E-cigs as a smoking cessation tool (Cravo et al. 2016, Caponnetto et al. 2013, Dawkins et al. 2012, Russo et al. 2016) and have reported an elevated body mass at 12 and 24 weeks after smoking cessation and while using E-cigs. Our study evaluated various metabolic factors in response to chronic E-cig vapor exposure, and while we did not see significant results for body mass, we report an increased food intake which may contribute to weight gain following smoke cessation.

Our data support the notion that E-cigs do not alter weight status, however this remains untested as a smoking cessation model and in a human population. The physiological responses to smoking cessation (weight gain and increased appetite) may be exacerbated by switching to an alternative nicotine delivery device, such as an E-cig. The mechanism underlying hyperphagia remains unknown, as none of our appetite-regulating hormones and peptides showed any difference, nevertheless we have observed that E-cig mice increase food intake due to chronic exposure.

It is well accepted that smoking and nicotine cause an anorectic effect, reducing body mass and food intake, while increasing thermogenesis and lipolysis. Added flavors have been shown to induce appetite, but the combination of these two inputs are unknown. This study shows that long-term exposure to a sweetened flavor (cappuccino) and nicotine prevents the anorectic effects that smoking and nicotine alone induce. Similar weight gain indicates that, unlike traditional cigarettes, E-cig vapor does not induce an anorectic state and a negative energy balance which would lead to reduced weight, rather, E-cig mice exhibited a hyperphagic response by consuming significantly more kcals than control 
mice. Increased food intake without increased body mass is very illogical. With an increased food intake, an increased BMR provides a solid mechanism for heat dissipation that would result in an equal energy balance and no weight gain/loss. Thus, propose that this similar weight gain pattern in the face of hyperphagia is due to an increased basal metabolism. These data could also suggest a novel mechanism for hyperphagia and BMR from chronic E-cig use with a sweet-flavored e-liquid. As this rodent model produced promising preliminary results, future studies should examine the effects of E-cig vapor on body mass and appetite regulation in humans. 


\section{REFERENCES}

1. Allen, J. G., S. S. Flanigan, M. LeBlanc, J. Vallarino, P. MacNaughton, J. H. Stewart \& D. C. Christiani (2016) Flavoring Chemicals in E-Cigarettes: Diacetyl, 2,3-Pentanedione, and Acetoin in a Sample of 51 Products, Including Fruit-, Candy-, and Cocktail-Flavored ECigarettes. Environmental Health Perspectives, 124, 733-739.

2. Arai, K., K. Kim, K. Kaneko, M. Iketani, A. Otagiri, N. Yamauchi \& T. Shibasaki (2001) Nicotine infusion alters leptin and uncoupling protein $1 \mathrm{mRNA}$ expression in adipose tissues of rats. American Journal of Physiology-Endocrinology and Metabolism, 280, E867-E876.

3. Brees, D. J., M. R. Elwell, F. D. Tingley, S. B. Sands, A. B. Jakowski, A. C. Shen, J. H. Cai \& M. B. Finkelstein (2008) Pharmacological Effects of Nicotine on Norepinephrine Metabolism in Rat Brown Adipose Tissue: Relevance to Nicotinic Therapies for Smoking Cessation. Toxicologic Pathology, 36, 568-575.

4. Brubaker, P. L. \& Y. Anini (2003) Direct and indirect mechanisms regulating secretion of glucagon-like peptide-1 and glucagon-like peptide-2. Canadian Journal of Physiology and Pharmacology, 81, 1005-1012.

5. Caponnetto, P., D. Campagna, F. Cibella, J. B. Morjaria, M. Caruso, C. Russo \& R. Polosa (2013) EffiCiency and Safety of an eLectronic cigAreTte (ECLAT) as Tobacco Cigarettes Substitute: A Prospective 12-Month Randomized Control Design Study. Plos One, 8.

6. CDC. 2016. Adult Obesity Facts. Atlanta, GA: Centers for Disease Control and Prevention.

7. Champigny, O. \& D. Ricquier (1990) Effects of fasting and refeeding on the level of uncoupling protein messenger-rna in rat brown adipose-tissue - evidence for diet-induced and cold-induced responses. Journal of Nutrition, 120, 1730-1736.

8. Chen, H., M. J. Hansen, J. E. Jones, R. Vlahos, G. P. Anderson \& M. J. Morris (2008) Longterm cigarette smoke exposure increases uncoupling protein expression but reduces energy intake. Brain Research, 1228, 81-88.

9. Courtemanche, C., R. Tchernis \& B. Ukert. 2016. The Effect of Smoking on Obesity: Evidence from a Randomized Trial. National Bureau of Economic Research.

10. Cravo, A. S., J. Bush, G. Sharma, R. Savioz, C. Martin, S. Craige \& T. Walele (2016) A randomised, parallel group study to evaluate the safety profile of an electronic vapour product over 12 weeks. Regulatory Toxicology and Pharmacology, 81, S1-S14.

11. Dawkins, L., J. Turner, S. Hasna \& K. Soar (2012) The electronic-cigarette: Effects on desire to smoke, withdrawal symptoms and cognition. Addictive Behaviors, 37, 970-973.

12. El Golli, N., H. Dkhili, Y. Dallagi, D. Rahali, M. Lasram, I. Bini-Dhouib, M. Lebret, J.-P. Rosa, S. El Fazaa \& M. Allal-El Asmi (2016) Comparison between electronic cigarette refill liquid and nicotine on metabolic parameters in rats. Life Sciences, 146, 131-138.

13. Erickson, J. C., K. E. Clegg \& R. D. Palmiter (1996) Sensitivity to leptin and susceptibility to seizures of mice lacking neuropeptide Y. Nature, 381, 415-418. 
14. Farsalinos, K. E., K. A. Kistler, G. Gillman \& V. Voudris (2015) Evaluation of Electronic Cigarette Liquids and Aerosol for the Presence of Selected Inhalation Toxins. Nicotine \& Tobacco Research, 17, 168-174.

15. Farsalinos, K. E., A. Spyrou, K. Tsimopoulou, C. Stefopoulos, G. Romagna \& V. Voudris (2014) Nicotine absorption from electronic cigarette use: comparison between first and newgeneration devices. Scientific Reports, 4.

16. Fedoroff, I., J. Polivy \& C. P. Herman (2003) The specificity of restrained versus unrestrained eaters' responses to food cues: general desire to eat, or craving for the cued food? Appetite, 41, 7-13.

17. Golli, N. E., A. Jrad-Lamine, H. Neffati, H. Dkhili, D. Rahali, Y. Dallagi, M. V. El May \& S. El Fazaa (2016) Impact of e-cigarette refill liquid exposure on rat kidney. Regulatory Toxicology and Pharmacology, 77, 109-116.

18. Hodge, A. M., R. A. Westerman, M. P. deCourten, G. R. Collier, P. Z. Zimmet \& K. Alberti (1997) Is leptin sensitivity the link between smoking cessation and weight gain? International Journal of Obesity, 21, 50-53.

19. Huang, H., Y. Xu \& A. N. van den Pol (2011) Nicotine excites hypothalamic arcuate anorexigenic proopiomelanocortin neurons and orexigenic neuropeptide Y neurons: similarities and differences. Journal of Neurophysiology, 106, 1191-1202.

20. Kogel, U., W. K. Schlage, F. Martin, Y. Xiang, S. Ansari, P. Leroy, P. Vanscheeuwijck, S. Gebel, A. Buettner, C. Wyss, M. Esposito, J. Hoeng \& M. C. Peitsch (2014) A 28-day rat inhalation study with an integrated molecular toxicology endpoint demonstrates reduced exposure effects for a prototypic modified risk tobacco product compared with conventional cigarettes. Food and Chemical Toxicology, 68, 204-217.

21. Landau, S. M. 2015. System and Method for Altering the Perceived Flavor of a Liquid or Vapor Passing into the Mouth. Google Patents.

22. McCarthy, T., C. Bruen, F. O'Halloran, H. Schellekens, K. Kilcawley, J. F. Cryan \& L. Giblin (2017) Aroma compound diacetyl suppresses glucagon-like peptide-1 production and secretion in STC-1 cells. Food Chemistry, 228, 35-42.

23. McFadden, K. L., M.-A. Cornier \& J. R. Tregellas (2014) The role of alpha-7 nicotinic receptors in food intake behaviors. Frontiers in Psychology, 5.

24. McGrath-Morrow, S. A., M. Hayashi, A. Aherrera, A. Lopez, A. Malinina, J. M. Collaco, E. Neptune, J. D. Klein, J. P. Winickoff, P. Breysse, P. Lazarus \& G. Chen (2015) The Effects of Electronic Cigarette Emissions on Systemic Cotinine Levels, Weight and Postnatal Lung Growth in Neonatal Mice. Plos One, 10.

25. Miao, S., E. S. Beach, T. J. Sommer, J. B. Zimmerman \& S. E. Jordt (2016) High-Intensity Sweeteners in Alternative Tobacco Products. Nicotine \& Tobacco Research, 18, 2169-2173.

26. Moskowitz, H. R., R. A. Kluter, J. Westerling \& H. L. Jacobs (1974) Sugar sweetness and pleasantness - evidence for different psychological laws. Science, 184, 583-585. 
27. Nederkoorn, C., F. T. Y. Smulders \& A. Jansen (2000) Cephalic phase responses, craving and food intake in normal subjects. Appetite, 35, 45-55.

28. Park, H. K. \& R. S. Ahima (2015) Physiology of leptin: energy homeostasis, neuroendocrine function and metabolism. Metabolism-Clinical and Experimental, 64, 24-34.

29. Pelleymounter, M. A. (1997) Leptin and the physiology of obesity. Current Pharmaceutical Design, 3, 85-97.

30. Phillips, B., E. Veljkovic, S. Boue, W. K. Schlage, G. Vuillaume, F. Martin, B. Titz, P. Leroy, A. Buettner, A. Elamin, A. Oviedo, M. Cabanski, H. De Leon, E. Guedj, T. Schneider, M. Talikka, N. V. Ivanov, P. Vanscheeuwijck, M. C. Peitsch \& J. Hoeng (2016) An 8-Month Systems Toxicology Inhalation/Cessation Study in Apoe(-/-) Mice to Investigate Cardiovascular and Respiratory Exposure Effects of a Candidate Modified Risk Tobacco Product, THS 2.2, Compared With Conventional Cigarettes (vol 149, pg 411, 2016).

Toxicological Sciences, 151, 462-464.

31. Phillips, B., E. Veljkovic, M. J. Peck, A. Buettner, A. Elamin, E. Guedj, G. Vuillaume, N. V. Ivanov, F. Martin, S. Boue, W. K. Schlage, T. Schneider, B. Titz, M. Talikka, P. Vanscheeuwijck, J. Hoeng \& M. C. Peitsch (2015) A 7-month cigarette smoke inhalation study in C57BL/6 mice demonstrates reduced lung inflammation and emphysema following smoking cessation or aerosol exposure from a prototypic modified risk tobacco product. Food and Chemical Toxicology, 80, 328-345.

32. Ponzoni, L., M. Moretti, M. Sala, F. Fasoli, V. Mucchietto, V. Lucini, G. Cannazza, G. Gallesi, C. N. Castellana, F. Clementi, M. Zoli, C. Gotti \& D. Braida (2015) Different physiological and behavioural effects of e-cigarette vapour and cigarette smoke in mice. European Neuropsychopharmacology, 25, 1775-1786.

33. Russo, C., F. Cibella, P. Caponnetto, D. Campagna, M. Maglia, E. Frazzetto, E. Mondati, M. Caruso \& R. Polosa (2016) Evaluation of Post Cessation Weight Gain in a 1-Year Randomized Smoking Cessation Trial of Electronic Cigarettes. Scientific Reports, 6.

34. Sanigorski, A., R. Fahey, D. Cameron-Smith \& G. R. Collier (2002) Nicotine treatment decreases food intake and body weight viaa leptin-independent pathway in Psammomys obesus. Diabetes Obesity \& Metabolism, 4, 346-350.

35. Sussan, T. E., S. Gajghate, R. K. Thimmulappa, J. F. Ma, J. H. Kim, K. Sudini, N. Consolini, S. A. Cormier, S. Lomnicki, F. Hasan, A. Pekosz \& S. Biswal (2015) Exposure to Electronic Cigarettes Impairs Pulmonary Anti-Bacterial and Anti-Viral Defenses in a Mouse Model. Plos One, 10.

36. Tweed, J. O., S. H. Hsia, K. Lutfy \& T. C. Friedman (2012) The endocrine effects of nicotine and cigarette smoke. Trends in Endocrinology and Metabolism, 23, 334-342.

37. Wang, Q. P., Y. Q. Lin, L. Zhang, Y. A. Wilson, L. J. Oyston, J. Cotterell, Y. Qi, T. M. Khuong, N. Bakhshi, Y. Planchenault, D. T. Browman, M. T. Lau, T. A. Cole, A. C. N. Wong, S. J. Simpson, A. R. Cole, J. M. Penninger, H. Herzog \& G. G. Neely (2016) Sucralose Promotes Food Intake through NPY and a Neuronal Fasting Response. Cell Metabolism, 24, 75-90. 
38. Williams, J. R. 2016. Alkaloid Composition for E-Cigarette. Google Patents.

39. Yeomans, M. R. (2006) Olfactory influences on appetite and satiety in humans. Physiology \& Behavior, 87, 800-804.

40. Yoshida, T., N. Sakane, T. Umekawa, A. Kogure, M. Kondo, K. Kumamoto, T. Kawada, I. Nagase \& M. Saito (1999) Nicotine induces uncoupling protein 1 in white adipose tissue of obese mice. International Journal of Obesity, 23, 570-575.

41. Zoli, M. \& M. R. Picciotto (2012) Nicotinic Regulation of Energy Homeostasis. Nicotine \& Tobacco Research, 14, 1270-1290. 


\section{ADDITIONAL INFORMATION}

\section{$\underline{\text { Competing Interests }}$}

None declared.

\section{$\underline{\text { Author Contributions }}$}

I.M.O., Z.W., and B. E. conceived the project and M.J.B and H.N.H helped to design the study. M.B., H.H., and C.P. exposed animals, conducted the experiments, and collected data. M.B. and I.M.O. participated in writing the manuscript, and all authors contributed in editing and approving the manuscript.

$\underline{\text { Funding }}$

This project was supported by funding from the National Institutes of Health Grant - P20GM103434 (West Virginia IDeA Network for Biomedical Research Excellence, I.M.O.) and the Marshall-West Virginia University Health Initiative Award (I.M.O. and Dr. Piyali Dasgupta)

\section{$\underline{\text { Acknowledgements }}$}

The authors would like to thank William Mandler, Kayla Branyan, Evan DeVallance, Eiman Aboaziza, Richard Nolan, Morgan Pelley, Mireia Fabrega, Gregory Ede, Sam Salmassi for their assistance in exposures, laboratory experiments, and overall assistance. 
Table 1

\begin{tabular}{|c|c|c|c|c|}
\hline & Control & E-cig & $3 \mathrm{R} 4 \mathrm{~F}$ & p-value \\
\hline & $\mathrm{n}=13$ & $\mathrm{n}=11$ & $\mathrm{n}=13$ & \\
\hline \multicolumn{5}{|l|}{ Body Mass (g) } \\
\hline Initial & $19.7 \pm 0.3$ & $19.6 \pm 0.2$ & $19.8 \pm 0.3$ & n.s. \\
\hline Final & $28.9 \pm 0.7$ & $29.8 \pm 1.0 \#$ & $27.1 \pm 0.7$ & $p<0.05$ \\
\hline Weight Gain (g) & $9.3 \pm 0.5$ & $10.2 \pm 0.9 \#$ & $7.4 \pm 0.6$ & $\mathrm{p}<0.05$ \\
\hline \multicolumn{5}{|l|}{ FFM $(g)$} \\
\hline Initial & $15.8 \pm 0.2$ & $15.5 \pm 0.4$ & $15.1 \pm 0.3$ & n.s. \\
\hline Final & $19.5 \pm 0.3$ & $19.9 \pm 0.2 \#$ & $18.7 \pm 0.2$ & $\mathrm{p}<0.05$ \\
\hline Mean & $18.0 \pm 0.2$ & $18.2 \pm 0.2 \#$ & $17.0 \pm 0.2 *$ & $\mathrm{p}<0.01$ \\
\hline \multicolumn{5}{|l|}{ Body Fat Mass (g) } \\
\hline Initial & $1.7 \pm 0.1$ & $1.9 \pm 0.3$ & $1.6 \pm 0.1$ & n.s. \\
\hline Final & $5.9 \pm 0.6$ & $5.9 \pm 0.7$ & $4.7 \pm 0.5$ & n.s. \\
\hline Mean & $3.8 \pm 0.3$ & $3.9 \pm 0.3 \#$ & $3.0 \pm 0.2 *$ & $\mathrm{p}<0.05$ \\
\hline RpWAT (mg) & $170 \pm 15$ & $187 \pm 15$ & $170 \pm 24$ & n.s. \\
\hline GnWAT (mg) & $976 \pm 99$ & $975 \pm 131$ & $811 \pm 94$ & n.s. \\
\hline BAT (mg) & $100 \pm 8$ & $91 \pm 7$ & $80 \pm 5^{*}$ & $\mathrm{p}<0.05$ \\
\hline $\begin{array}{l}\text { Urine Cotinine } \\
\qquad(\mathrm{ng} / \mathrm{ml})\end{array}$ & $0.0 \pm 0$ & $24.3 \pm 0.6$ & $47.4 \pm 9.4$ & $\mathrm{p}=0.070$ \\
\hline
\end{tabular}

$* \mathrm{p}<0.05$ compared to control group, \#p<0.05 compared to 3R4F group. 
A
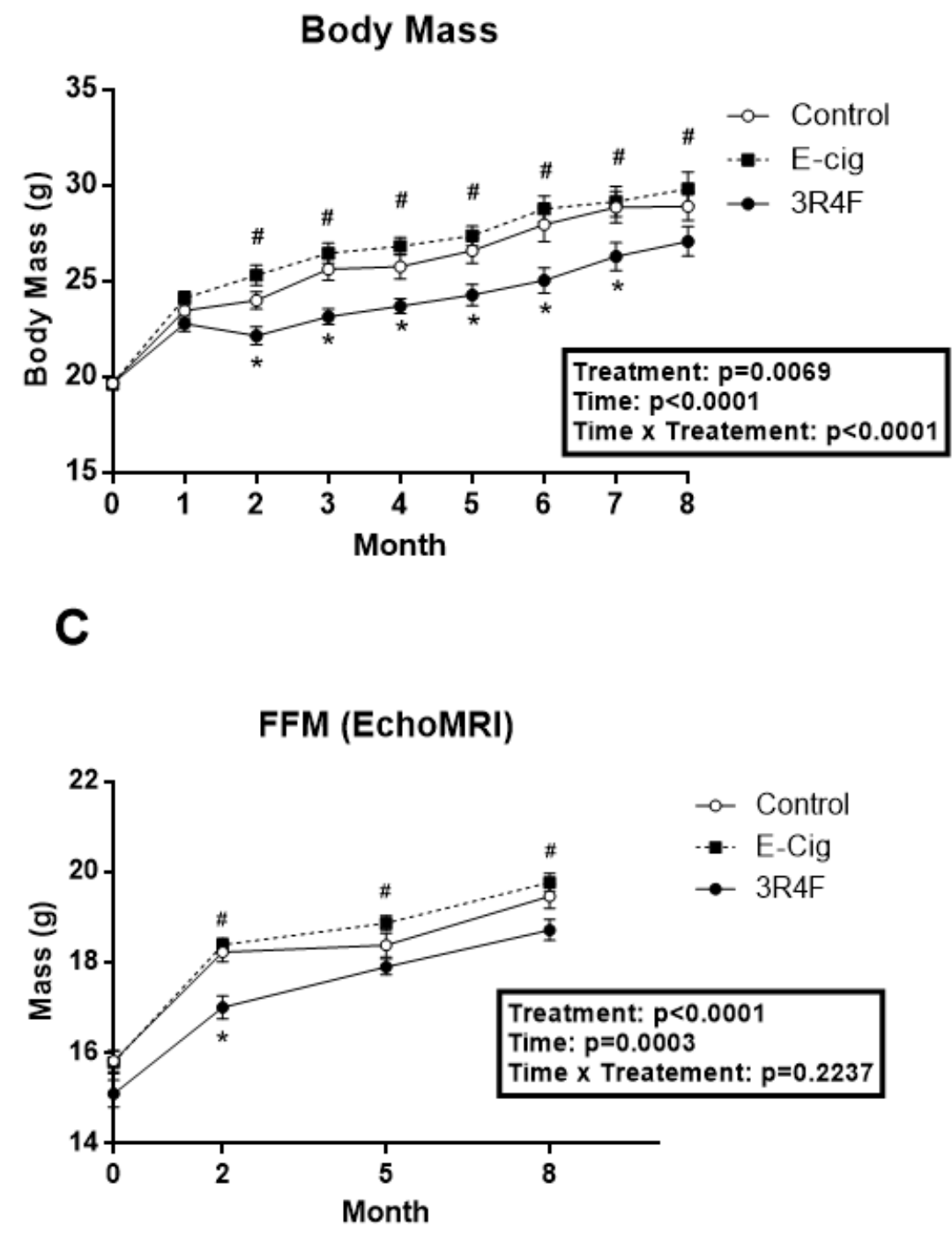

B

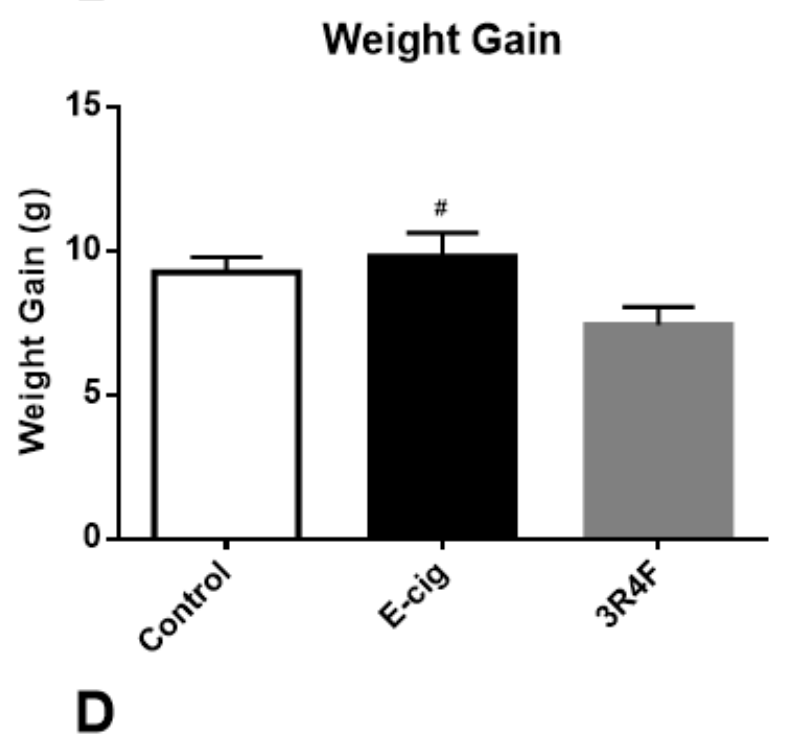

Fat Mass (EchoMRI)

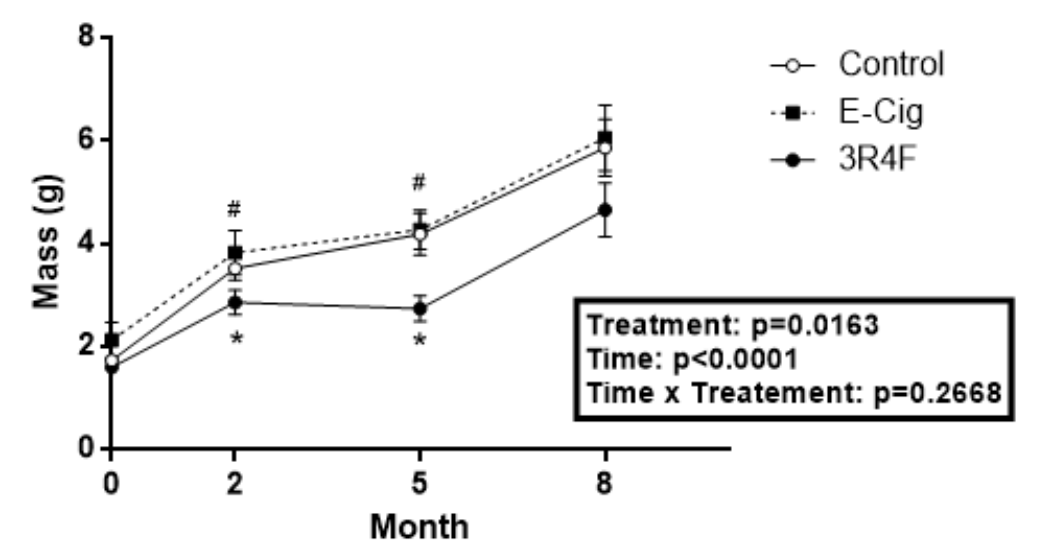

Figure 1 
Figure 1. Body mass, weight gain, FFM, and Fat Mass of control, E-cig, and 3R4F mice. Body mass (A) was measured 2 times a week $(n=133 R 4 F, n=13$ control, and $n=11$ E-cig). Weight gain (B) of animals were calculated as body mass at time of euthanasia minus initial body mass before exposure initiation. Fat Mass (C) and FFM (D) analyzed via EchoMRI Body Composition Analyzer measuring live body composition at month $0,2,5$, and 8 . Data presented as mean \pm SEM. Repeated measures ANOVA was used for body mass, FFM, and fat mass, while weight gain was analyzed by ANOVA and Fisher's Partial Least-Squares Difference (PLSD). Values are expressed as mean \pm SEM. * p $<0.05$ different from control, \# $\mathrm{p}<0.05$ different from 3R4F. Chronic E-cig exposure had no effect on body mass, total gain, FFM, or fat mass compared to controls, while 3R4F exposed mice experienced significant body mass loss, and reduced weight gain, FFM and fat mass. 

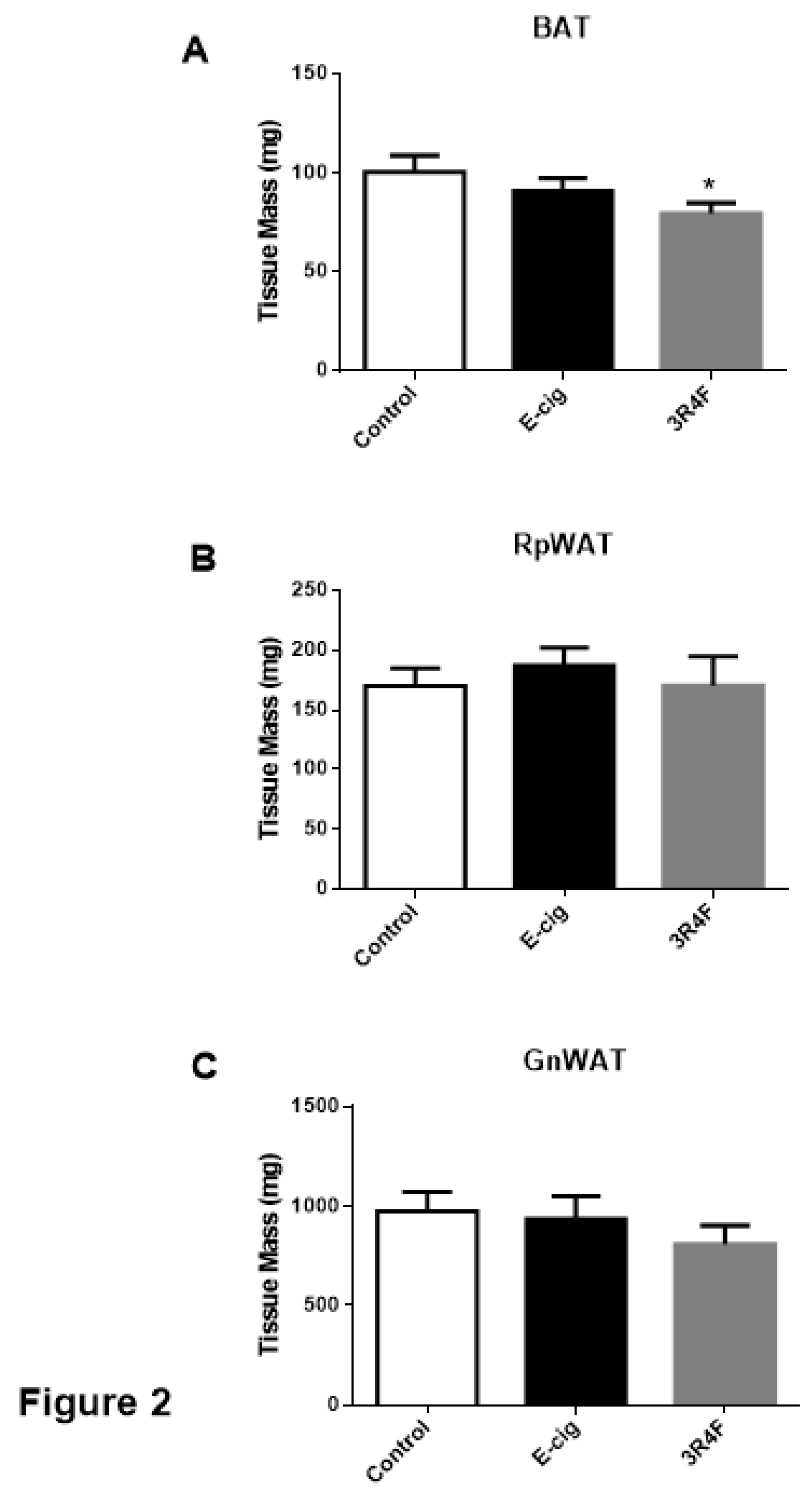
Figure 2. Brown adipose tissue (BAT) weight, retroperitoneal white adipose tissue (RpWAT), and gonadal white adipose tissue (GnWAT) weight in control, E-cig, and 3R4F mice. Tissue mass of brown adipose tissue (BAT, A), retroperitoneal white adipose tissue (RpWAT, B), and gonadal white adipose tissue (GnWAT, C) were measured at time of euthanasia after the 8-month exposure. $\mathrm{N}=13$ Control, $\mathrm{n}=12$ 3R4F, $\mathrm{n}=11$ E-cig for all figures. Values are expressed as mean \pm SEM and after an 8-hr caloric fast. * $\mathrm{p}<0.05$ different from control, \# $\mathrm{p}<0.05$ different from 3R4F. Chronic E-cig exposure had no effect on BAT, RpWAT, and GnWAT, while 3R4F exposed mice displayed significantly less BAT than control mice. 
A

15-Day Food Intake

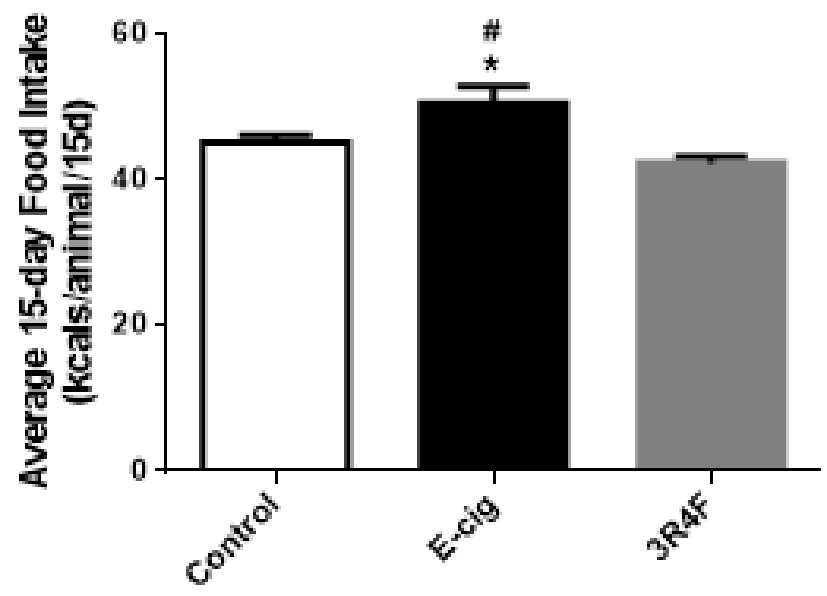

B

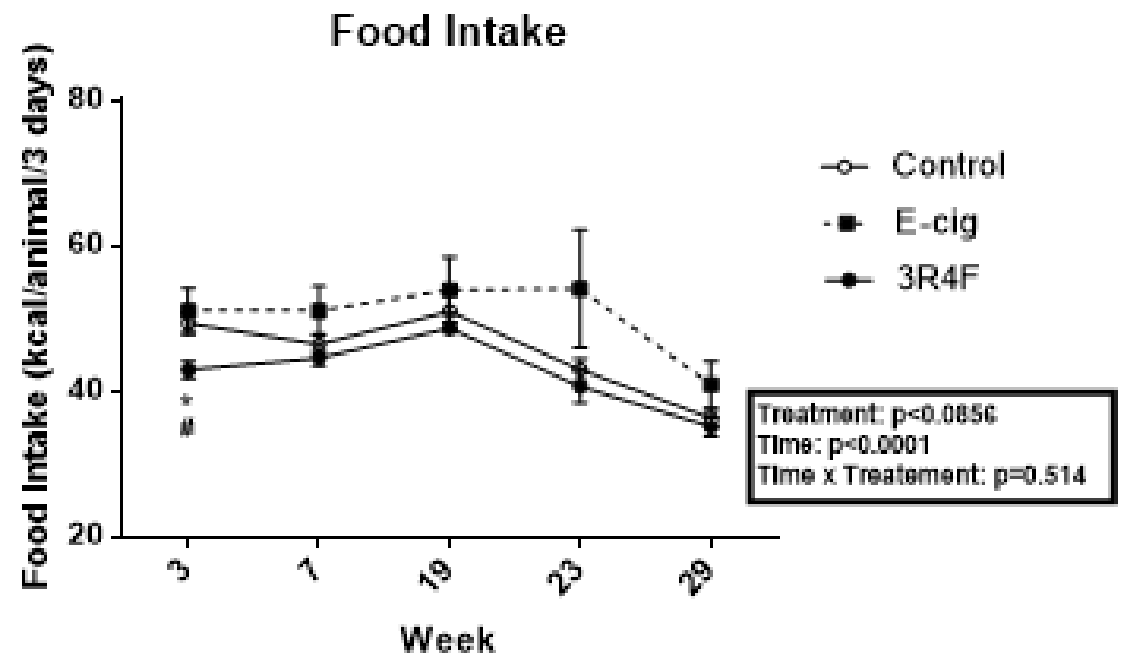

Figure 3

C

1 Month Group Feed

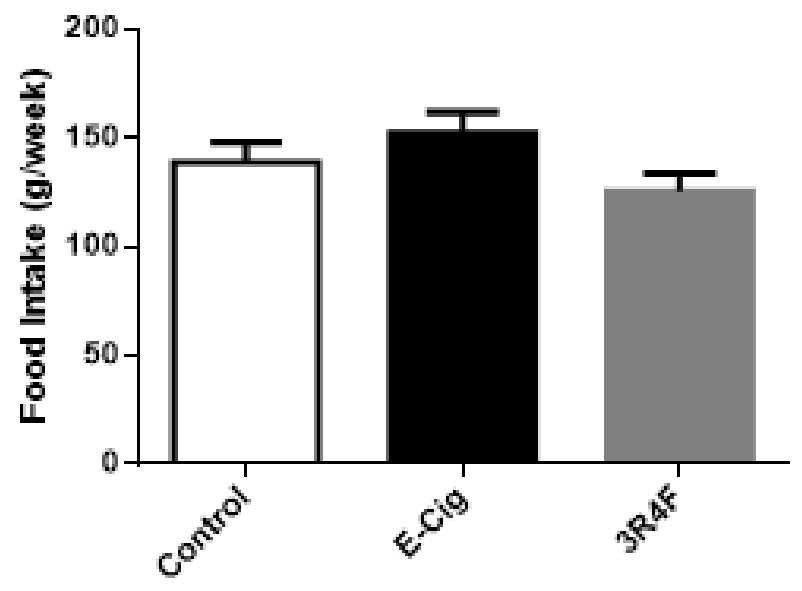


Figure 3. Combined (15-day) food intake, food intake, and group food intake of control, E-cig, and

3R4F mice. Total food intake over 15 days (A) was calculated as total kcals consumed per treatment group over the course of the 5 feeding experimental weekends. Average food intake (B, 3-day) was measured at weeks 3, 7, 19, 23, and 29 from Friday-Monday during no exposures in individual housing $(\mathrm{n}=13$ 3R4F, $\mathrm{n}=13$ control, $\mathrm{n}=12$ E-cig). Kilocalories (kcals) were calculated as grams eaten $\mathrm{x} 3.1$. Values are expressed as mean \pm SEM. Repeated measures ANOVA was used for food intake (B). Weekly, group food intake (C) was measured during the last month of exposure and reported as g/week. $* \mathrm{p}<0.05$ different from control, \# $\mathrm{p}<0.05$ different from 3R4F. Chronic E-cig exposure significantly increase total caloric intake over 15 days compared to control and 3R4F exposed mice. 3R4F mice consumed significantly fewer kcals compared to E-cig and control mice at w3, but not during the remaining weeks. 

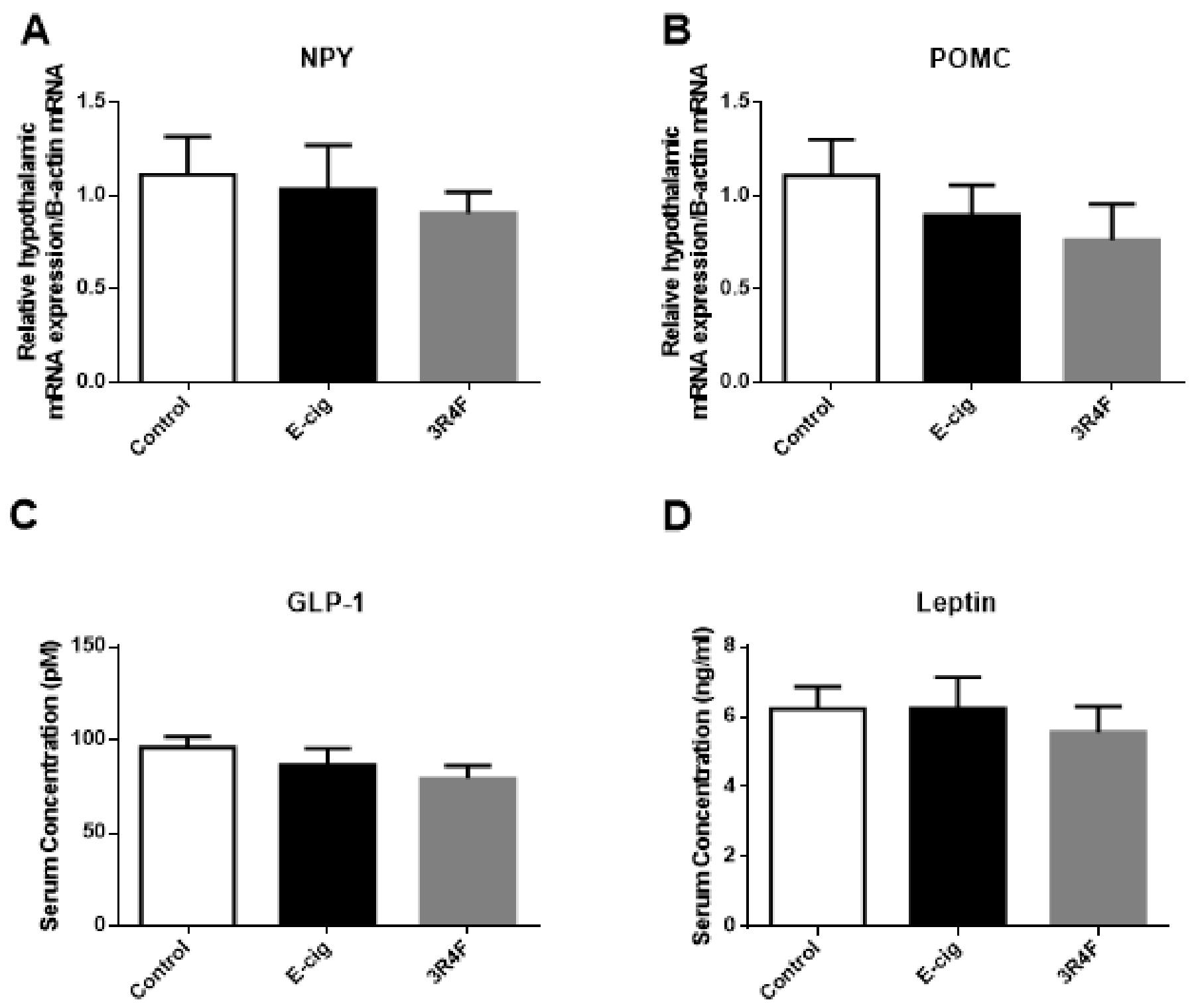

Figure 4 
Figure 4. RT-PCR analysis of hypothalamic neuropeptide-Y (NPY) and pro-opiomelanocortin (POMC), and serum concentration of glucagon-like peptide-1 (GLP-1) Total and leptin.

Neuropeptide-Y (NPY, A) and pro-opiomelanocortin (POMC, B) mRNA expression are relative to $\beta$ actin mRNA $(n=8)$. Gene expression values are expressed as fold change relative to control mean values (B-actin). Mean circulating serum GLP-1 Total $(\mathrm{C}, \mathrm{n}=12,12,11)$ and leptin $(\mathrm{D}, \mathrm{n}=12,11,13)$ values as analyzed by ELISA kit. Leptin concentrations are expressed as ng/ml and GLP-1 Total are expressed as picomolar $(\mathrm{pM})$ on a standard log. Values are expressed as mean \pm SEM and after an 8 -hr caloric fast. * $\mathrm{p}<0.05$ different from control, \# $\mathrm{p}<0.05$ different from 3R4F. Chronic E-cig exposure had no effect on POMC or NPY mRNA gene expression. Similarly, leptin and GLP-1 Total concentrations were unchanged in E-cig mice compared to control animals. 
Figure 5

A

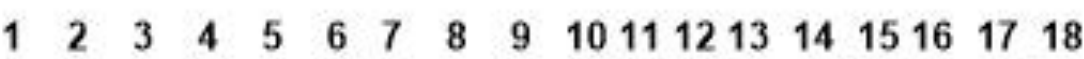

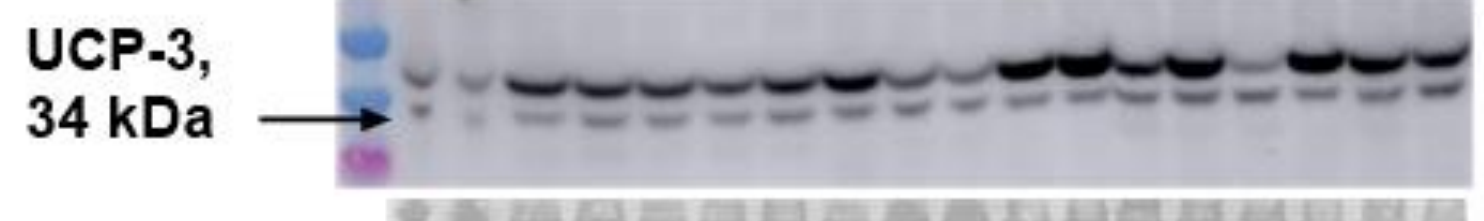

Ponceau S

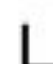

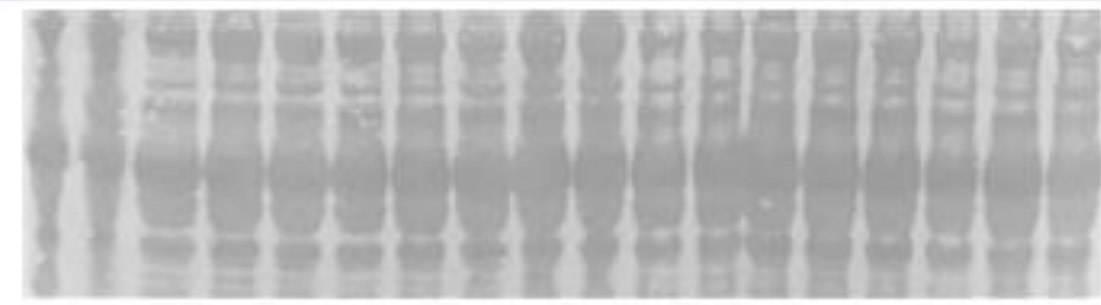

L

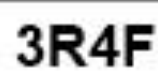

C

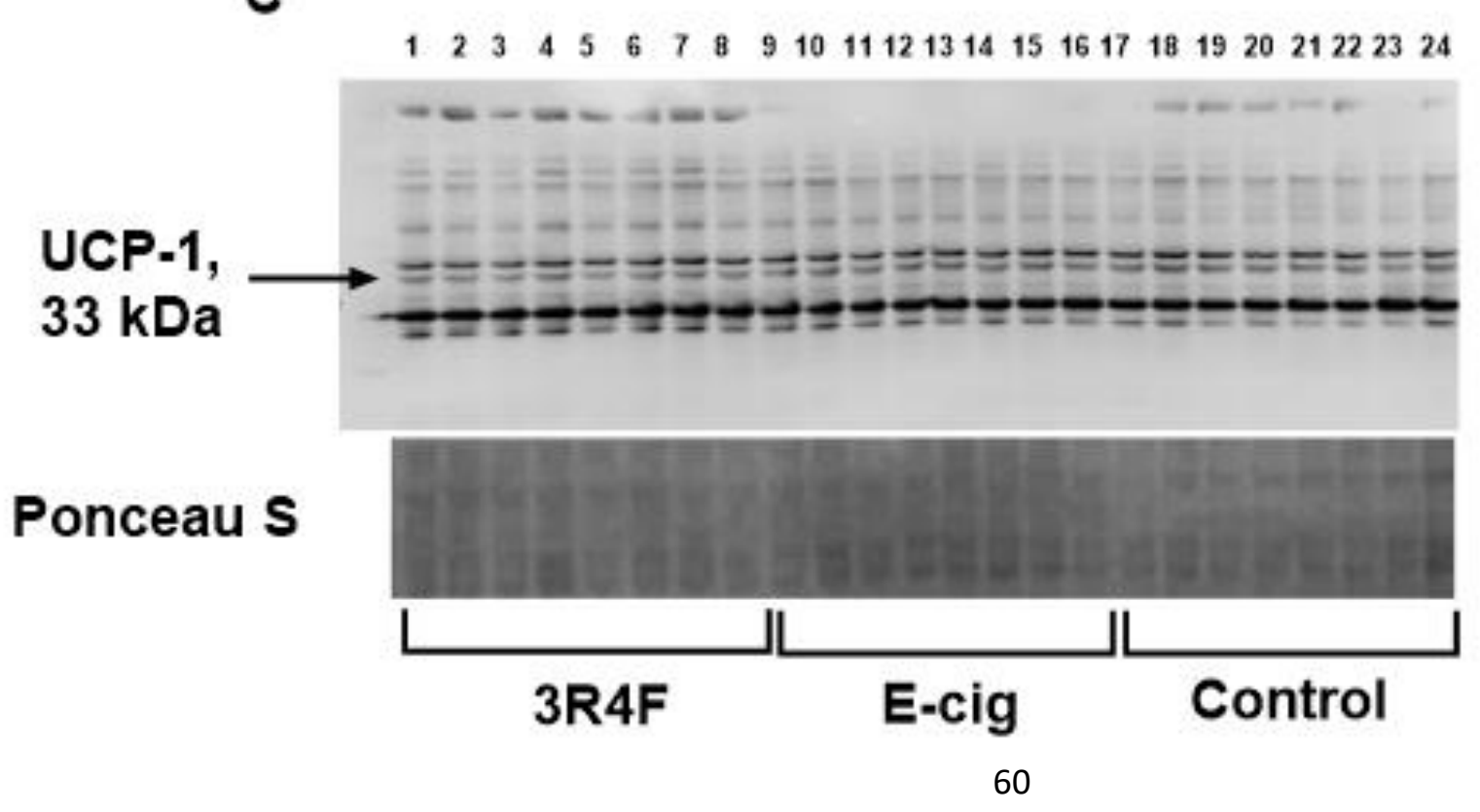

B

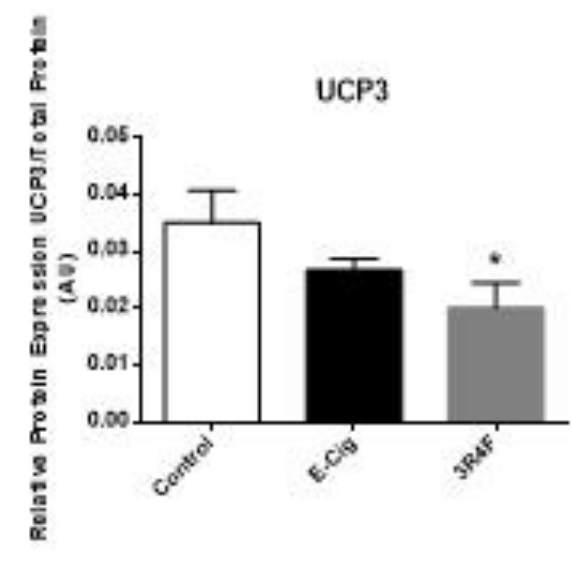

D

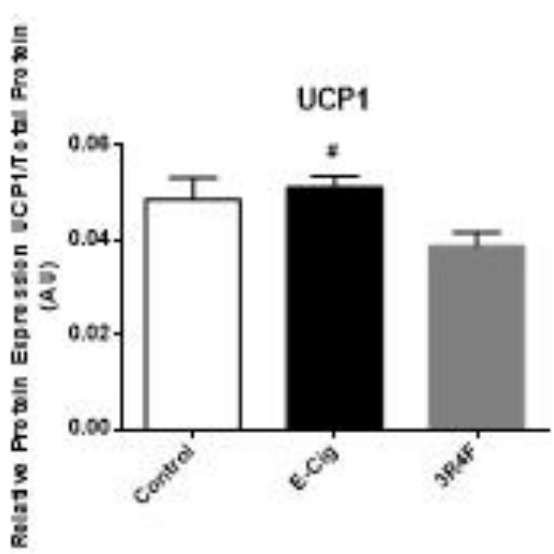


Figure 5. UCP1 and UCP3 protein expression in control, E-cig, and 3R4F mice. (A) Protein isolated from gastrocnemius muscles of control $(n=6)$, E-Cig $(n=6)$, and 3R4F $(n=6)$ mice under basal conditions probed for UCP-3, shown at $34 \mathrm{kDa}$. Ponceau S stained membrane shows equally loaded total protein in each lane. (B) Quantification of UCP-3 normalized to total protein. (C) Protein isolated from BAT of control (n=8), E-cig (n=8), and 3R4F (n=8) mice under basal conditions probed for UCP-1, shown at 33 $\mathrm{kDa}$. Ponceau S stained membrane shows equally loaded total protein in each lane. (D) Quantification of UCP-3 normalized to total protein. Values are expressed as mean \pm SEM. $* \mathrm{p}<0.05$ different from control, \# p<0.05 different from 3R4F. Chronic E-cig exposure had no effect on UCP-1 or UCP3 protein expression compared to control mice. 3R4F exposed mice experienced significant reductions in UCP-3 compared to control mice and UCP-1 compared to E-cig mice. 
A

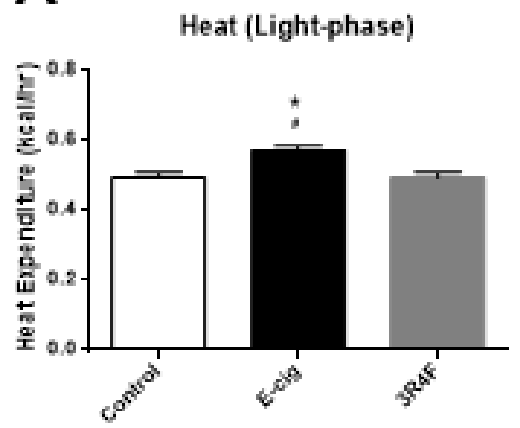

D

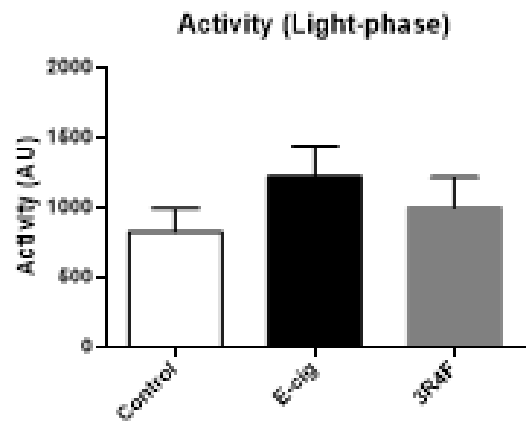

G

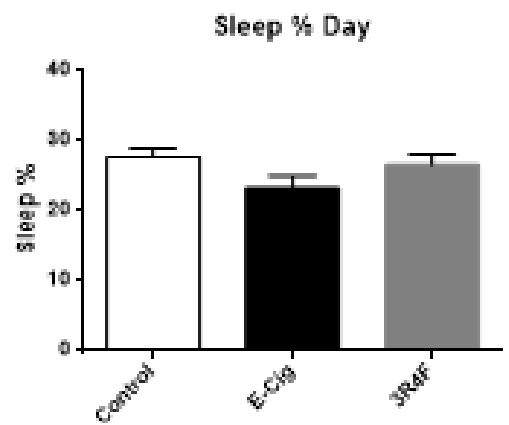

B

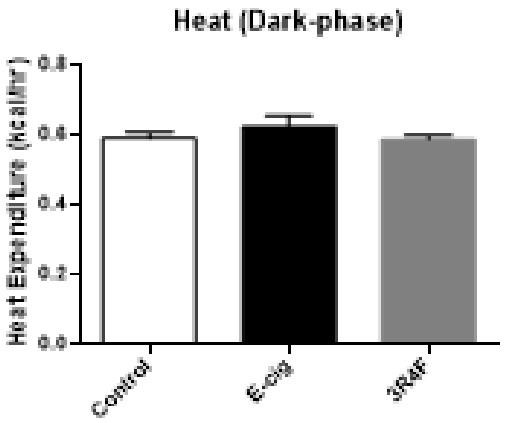

E

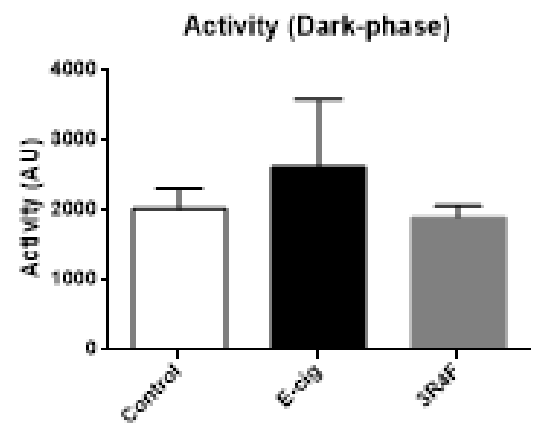

H

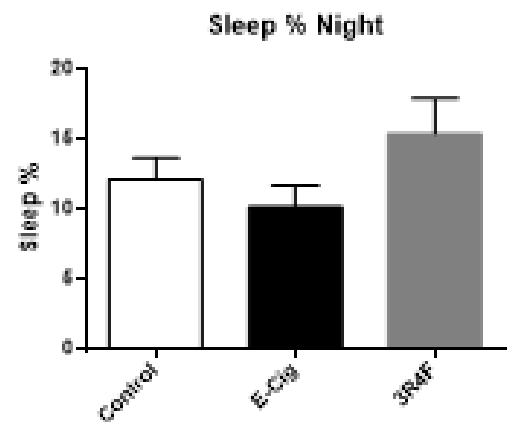

C

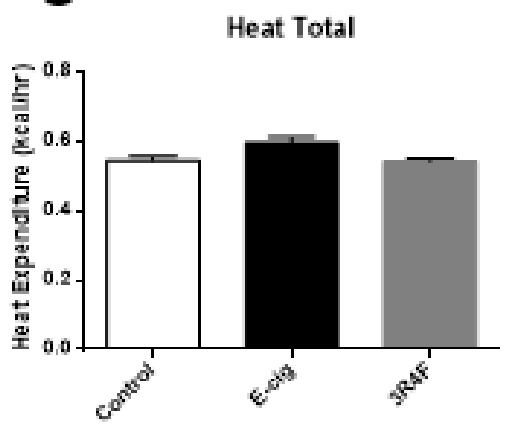

F
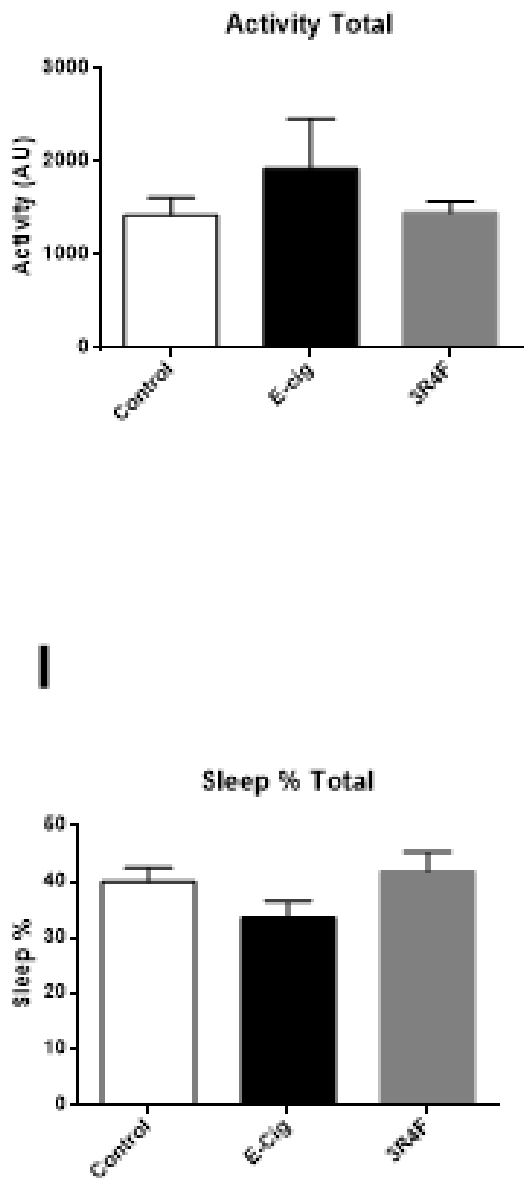

Figure 6 
Figure 6. Heat production, activity, and sleep during both light-phase and dark-phase periods in control, E-cig, and 3R4F mice. Light-phase, dark-phase, and total heat production (A, B, C), activity (D, E, F) and sleep percent $(\mathrm{G}, \mathrm{H}, \mathrm{I})$ were measured in the CLAMS system. Metabolic heat was calculated as: Heat $=(3.815+1.232 * \mathrm{RER}) * \mathrm{VO} 2$. Values are expressed as mean \pm SEM. $* \mathrm{p}<0.05$ different from control, \# $\mathrm{p}<0.05$ different from 3R4F. Chronic E-cig exposure significantly increased light-phase heat production compared to control and 3R4F mice, but not during dark-phase. No significance was found for activity or sleep percent among any group. 
A

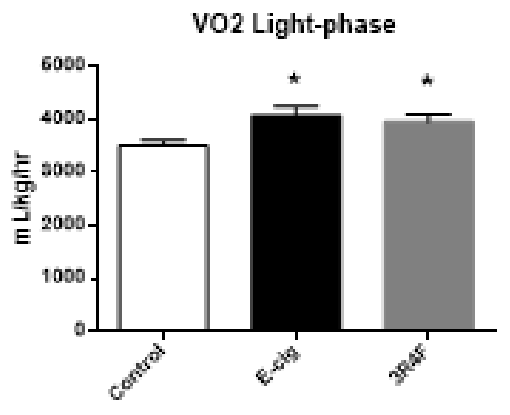

D

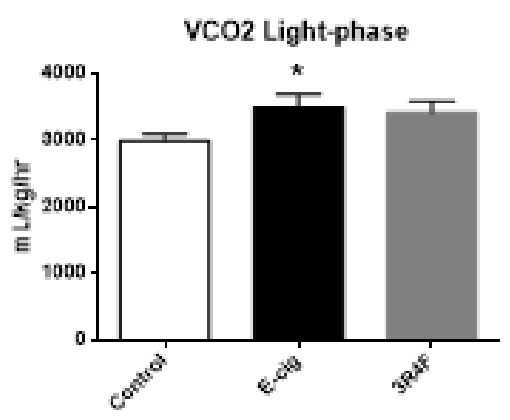

G

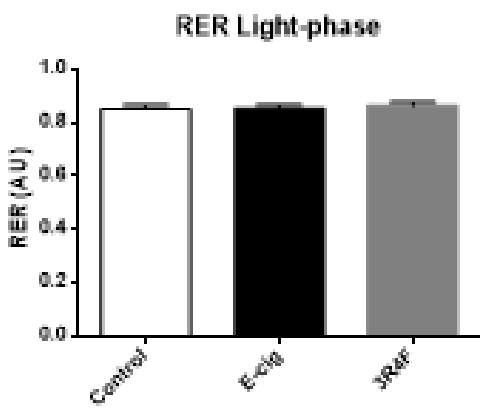

B

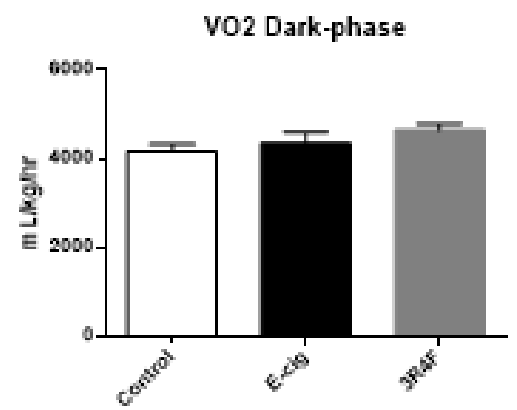

E

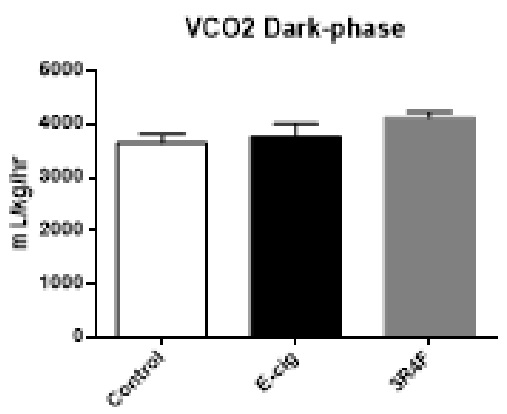

H

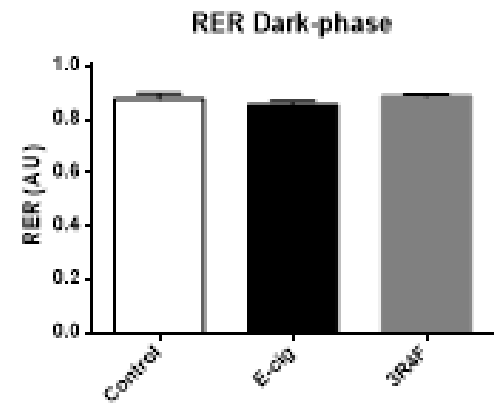

C

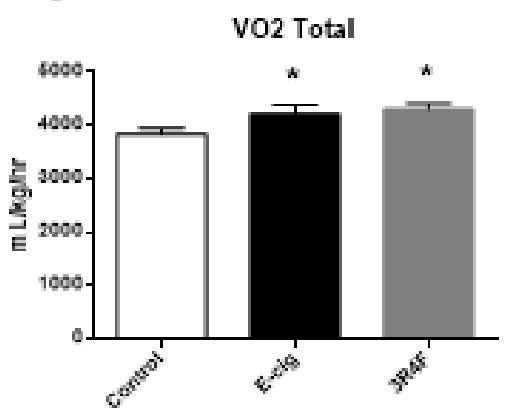

F

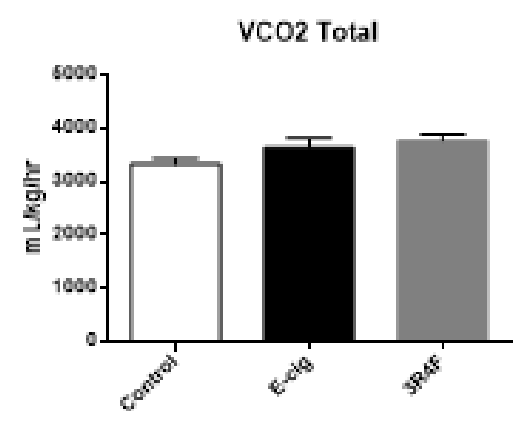

I

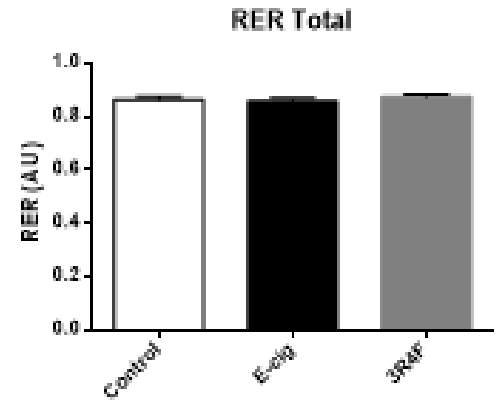

Figure 7 
Figure 7. VO2, VCO2, and RER during both light-phase and dark-phase periods in control, E-cig, and 3R4F mice. Light-phase, dark-phase, and total VO2 (A, B, C), VCO2 (D, E, F) and RER (G, H, I) were measured in the CLAMS system. Values are expressed as mean \pm SEM. $* \mathrm{p}<0.05$ different from control, \# p<0.05 different from 3R4F. Chronic E-cig exposure significantly increased light-phase VO2 and VCO2 production, but not at dark-phase. No significance was found for RER among groups. 


\section{CHAPTER 4: SUMMARY AND DISCUSSION}


The principle finding of this work is that chronic E-cig exposure induces hyperphagia and increases basal metabolic rate, total oxygen consumption, and carbon dioxide production, without changing body mass in a rodent model. Following eight months of vapor exposure, E-cig mice displayed increased body mass, food intake, heat production, and WAT UCP1 expression compared to 3R4F mice, and increased food intake, heat production, $\mathrm{VCO} 2$, and $\mathrm{VO} 2$ compared to control mice. These data suggest that, unlike traditional 3R4F cigarettes, chronic E-cig exposure blunts the anorectic and weight loss effects from smoking and nicotine. Moreover, E-cig vapor increases caloric intake compared to control mice, suggesting an appetite stimulating effect from the flavor, taste, or aroma perception elicited from E-cig vapor.

\subsection{Specific Aim 1: Body mass, body composition, and food intake}

Specific Aim 1 was to determine the effects of long-term E-cig exposure on body mass, feeding behavior, and body composition. It was hypothesized that chronic E-cig vapor would decrease bodyweight, food intake, WAT, BAT, and LBM. To investigate this, we measured body mass $2 \mathrm{x} / \mathrm{wk}, 3-$ day food intake (Fri-Mon) at weeks 3, 7, 19, 23, and 29, WAT, and BAT post euthanasia, and body composition (FFM and Fat Mass) with the EchoMRI Body Composition Analyzer at months 0, 2, 5, and 8. We found that E-cig mice gained weight similarly to control mice, however, gained significantly more weight than 3R4F mice (Chapter 3, Figure 1B). Interestingly, both food intake (Chapter 3, Figure 3A) and heat production (Chapter 3, Figure 6A) were significantly increased in E-cig mice compared to both control and 3R4F mice. FFM, Fat Mass, WAT, and BAT were unchanged compared to control mice (Chapter 3, Table 1), however, E-cig and control mice had significantly elevated mean FFM and fat mass compared to 3R4F mice (Table 1), while month 8 fat mass was similar in all exposure groups and FFM was significantly lower in 3R4F mice compared to E-cig mice (Chapter 3, Figure 1C).

Similar weight gain following eight months of chronic E-cig exposure compared to controls indicate that, unlike traditional cigarette smoke, E-cig vapor does not induce an anorectic state and a 
negative energy balance, but rather, an orexigenic state exhibited by hyperphagia, without inducing obesity. A combination of increased food intake and increased heat production, may provide a mechanism for heat dissipation that would result in an equal energy balance. We propose that this similar weight gain pattern in the face of hyperphagia is due to an increased metabolic rate. These data could also suggest a novel mechanism for increasing food intake and BMR from chronic E-cig use.

Chronic (7-month, 4hr/d, 5d/wk, 30 min breaks) E-cig exposure has been reported to significantly increase body weight compared to control and 3R4F exposed female C57BL/6 mice (Phillips et al. 2015), without affecting food intake. Interestingly, these results were found in the face of similar test atmosphere nicotine content $(34 \mathrm{ug} / \mathrm{L})$ and serum nicotine and cotinine values as $3 \mathrm{R} 4 \mathrm{~F}$ mice. This indicates that content of e-liquid may increase body weight independent of nicotine levels, and through an unrelated food intake mechanism, possibly uncoupling proteins and thermogenesis. However, a similar study (8-month, 3hr/d, 5d/wk, 30 min breaks) exposing female apolipoprotein Edeficient (Apoe -/-) transgenic mice, a model for smoking-related atherosclerosis, exhibited no effect on body weight in the E-cig group, while the 3R4F group lost body weight. Much like the aforementioned study, both 3R4F and E-cig mice had similar serum nicotine and cotinine levels. Urine cotinine values tended to be higher in $3 \mathrm{R} 4 \mathrm{~F}$ mice compared to E-cig mice $(\mathrm{p}=0.070$, Chapter 3 , Table 1$)$ in this study. Control mice serum contained virtually no cotinine levels. The lack of weight loss and suppressed appetite may be driven by a decreased nicotine absorption from E-cigs. E-liquid nicotine content was externally verified (University of Virginia) and contained the listed amount of nicotine (18mg/ml).

Our results agree with Phillips et. al. (2016), Kogel et. al. (2014), and Cannazza et. al. (2015), whom exposed mice to E-cig, 3R4F smoke, or filtered air for 7 months, 8 months, and 7 weeks, respectively, and found significant weight loss in the 3R4F mice and no effect on E-cig mice body mass. However, our findings of hyperphagia are the first to be reported in any rodent or human E-cig study. 
Adding to the controversy between the effect of nicotine on bodyweight, McGrath-Morrow et al. (2015) exposed neonatal C57BL/6 mice to e-liquid with either 1.5\% nicotine and propylene glycol or $0 \%$ nicotine in propylene glycol for 10 days and both groups of mice lost weight (13.3\% and $11.5 \%$, respectively). Nicotine alone did not account for weight loss; however, infants and neonates have a higher capacity to absorb nicotine and E-cig contaminants through the skin due to an increased surface area relative to body weight and an immature epidermal barrier. This could contribute to weight reductions in both nicotine and non-nicotine exposed mice. Counter to this study, it was found that I.P. injections of nicotine $(0.5 \mathrm{mg} / \mathrm{kg} / \mathrm{day})$ and e-liquid $(0.5 \mathrm{mg}$ nicotine $/ \mathrm{kg} /$ day $)$ induce significant weight loss compared to I.P. injections of e-liquid (0\% nicotine) and control male rats (El Golli et al. 2016). Similarly, $0 \%$ e-liquid and control mice ate significantly more kcals than the nicotine-containing e-liquid and nicotine groups. This indicates that nicotine directly inhibited food intake and contributed to weight loss. The use of neonatal mice and male rats may have elicited weight-reducing effects from E-cig usage due to immature epithelial tissue and sexual dimorphism between male and female rodents.

E-cig mice gained significantly more body weight, FMM, and fat mass, while increasing food intake and heat production compared to 3R4F mice. Group food intake during the final month of exposures tended to be higher in E-cig compared to 3R4F mice, but did not reach statistical significance $(\mathrm{p}=0.13$, Figure $3 \mathrm{C})$. Cigarette smoke is known to inhibit appetite, increase energy expenditure, and reduce bodyweight via nicotine's anorectic effects (Zoli and Picciotto 2012). Both E-cig and 3R4F exposure delivered nicotine, however, the artificial sweeteners and added flavors in the cappuccinoflavored e-liquid may have blunted nicotine's anorectic effects. Nicotine is a weak primary reinforcer and acts to enhance responding to reinforcing stimuli. Added flavors in e-liquid could potentially act as reinforcers, which in conjunction with nicotine, may increase a user's drive to smoke E-cigs. Nicotine administration has been shown to increase sucrose seeking behavior as a reward mechanism in male rats (Grimm et al. 2012). Sucrose, like artificial sweeteners and flavoring chemicals, is reinforcing due to its 
tastant (sweetness) properties. However, unlike artificial sweeteners, sucrose is also reinforcing due to its source of calories. Literature surrounding which of these two sucrose-reinforcing properties predominates remains unclear, however, if sweetness reinforcement is enhanced by nicotine, sweet eliquid products may increase high-sugar, sucrose-dense foods. In a study investigating whether nicotine enhances responding to sucrose and if palatable or caloric properties of sucrose drive this process in male rats discovered that nicotine administration significantly enhanced the reinforcement value for sucrose (120\% increase) and saccharin (100\%), however, not for chow food (50\%) (Rupprecht et al. 2016). This discovery demonstrates that smoking and nicotine reinforces the drive for sweet and calorically dense food, instead of a normal diet. The inclusion of added flavors in the E-cig may have increased the reward mechanism for a normal diet more than the $3 \mathrm{R} 4 \mathrm{~F}$ exposed mice, resulting in an increased food intake.

Growth hormone, a peptide hormone that stimulates growth, was significantly increased in 3R4F compared to E-cig and control mice following 7-months of daily exposures (Phillips et al. 2015), yet 3R4F mice exhibited significant weight loss. E-cig mice significantly increased body weight without increasing food intake or growth hormone secretion, indicating a separate mechanism for weight gain, possibly decreased thermogenesis and energy expenditure. Unfortunately, thermogenic markers such as UCP-1 and UCP-3 or heat production in CLAMS was not measured in that study.

\subsection{Specific Aim 2: Appetite Regulation and Energy Metabolism}

Specific Aim 2 was to determine the metabolic and molecular consequences on appetite regulation pathways with long-term E-cig exposure. It was hypothesized that E-cig exposure would decrease serum leptin (in correlation with adipose tissue), GLP-1, and hypothalamic NPY mRNA expression, while increasing hypothalamic POMC mRNA expression, UCP-1 in BAT, and UCP3 in GA muscle. Together, this would result in an anorectic, hypophagic, net negative energy balance physiological response. To investigate this, we attempted to measure serum leptin and GLP-1 
concentrations with a commercially available enzyme-linked immunosorbent assay (ELISA) kit, hypothalamic NPY and POMC mRNA with qPCR, and UCP-1 and UCP-3 by western blot. Among all groups, no differences were observed for serum leptin and GLP-1 protein concentrations, or NPY and POMC mRNA expression. E-cig mice had significantly higher UCP-1 expression than 3R4F mice, and 3R4F mice had significantly reduced UCP-3 compared to control mice.

Hypothalamic NPY and POMC mRNA expression was measured via PCR (Chapter 3, Figure $3 \mathrm{AB})$ to assess neurons within the ARC that are critical for peripheral hormonal sensing to influence appetite regulation. Peripheral signals, such as leptin and ghrelin, act directly on the ARC to influence the release of these two neuropeptides, which ultimately influence appetite (Park and Ahima 2015). Raised levels of ghrelin, suggesting a starvation state and inadequate energy stores, act to stimulate NPY/AgRP expression so as to increase hunger and initiate feeding, while inhibiting POMC/CART expression. Likewise, raised levels of insulin, such as after a meal and indicating a fed state, act to increase expression of POMC/CART to terminate feeding, while decreasing expression of NPY/AgRP. As the current study discovered a hyperphagic response due to E-cig vapor, it would be expected to witness a rise in NPY mRNA, with a concurrent decrease in POMC mRNA. While we did not see any significant differences, nicotine has been shown to excite both hypothalamic NPY and POMC neurons and $\alpha 7 \mathrm{nAChRs}$ on the neurons (Huang et al. 2011), with a greater depolarization and spike frequency response from POMC neurons, eliciting a potential mechanism through which POMC may suppress appetite (Huang et al. 2011). Future studies should evaluate the spike frequencies and depolarization values between NPY and POMC following E-cig exposure. Moreover, other possible neural circuits (reward-based mechanisms) and satiety factors (CCK, PYY, insulin, and gut distention) may also be a factor in E-cig exposure and should be examined in future studies.

Leptin concentrations in serum collected at time of euthanasia were measured (Chapter 3, Figure 3D) via ELISA in attempt to determine differences in circulating levels. Circulating leptin levels are 
directly proportional to fat stores and reflect the status of long-term energy stores within an organism (Park and Ahima 2015). As leptin can be specifically transported through the blood-brain-barrier (BBB) and is likely not synthesized in the brain, intracerebral leptin levels usually reflect serum leptin levels (Zoli and Picciotto 2012). A change in leptin concentration due to E-cig exposure could have several implications. In regards to specific aim 1, changes in serum leptin concentrations may simply reflect changes in white adipose tissue mass. However, regarding specific aim 2, to the best of our knowledge, no one has examined the effect of nicotine and sweet aromatics on satiety hormones. Alterations in leptin concentrations following nicotine or E-cig vapor may be secondary to nutrient intake and fluctuating WAT mass. Proving this notion, it was found that nicotine exposure did not significantly alter leptin mRNA in cultured adipocytes, or leptin release from adipocytes (Reseland et al. 2005). In our mouse model, no differences were observed in circulating serum leptin levels between any of the groups.

To date, only one published study has investigated the effects of E-cig vapor on serum leptin concentrations (Phillips et al. 2015). This is the first study to investigate the effects of E-cig exposure on multiple appetite regulating biomarkers to further elucidate the scientific understanding of appetite and energy balance from E-cig exposure. Serum leptin levels in female 3R4F mice have been reported to be significantly reduced compared to E-cig mice (Phillips et al. 2015), in correlation to reductions in gonadal and retroperitoneal WAT. As most body weight studies are conducted using male animals, this female model must be taken into consideration in light of the limitations. In the current study, gonadal and retroperitoneal WAT masses were not significantly different amongst groups, similarly, leptin levels were unaltered. A lack of change in serum leptin alteration would lead to a null effect on NPY and POMC mRNA expression within the hypothalamus, as leptin binds to LepR to exert its effects directly on these ARC subpopulations. As sweet aromas have been shown to increase feeding patterns and appetite, a decrease in serum leptin would increase NPY and inhibit POMC expression. However, as 
NPY, POMC, leptin, and GLP-1 levels were not altered in this study, other factors (other neural systems) may be at play to influence appetite. To further investigate these findings, shorter-term activation studies may elicit more pronounced effects. Moreover, leptin could be measured intermittently throughout the study or secretion from white adipose tissue.

Serum GLP-1 concentration was also measured to investigate motivation (reward) to eat and the hedonic value (pleasure) of food from chronic E-cig exposure (Chapter 3, Figure 3C). GLP-1, a known potent appetite suppressant, is excreted in response to nutrient intake (Brubaker and Anini 2003) and regulates body weight and food intake (Phillips et al. 2016, Turton et al. 1996). It also acts to decrease mesolimbic dopamine signaling, which controls pleasure-directed food intake (Geloneze, de Lima and Velloso 2017). In a 7-month study, serum GLP-1 tended to be elevated in E-cig mice compared to 3R4F and control mice, but did not reach statistical significance (Phillips et al. 2015). This would have resulted in a decreased hedonic value (pleasure) of food, decreased motivation (reward) to eat, and decreased quantity and frequency of food consumption, yet food consumption was reported to be unaltered and E-cig mice gained significantly more weight. The use of a sweet flavored e-liquid (cappuccino) may have decreased the GLP-1 in this study relative to Phillps et al. (2015) which used tobacco-flavored e-liquid, resulting in a slightly increased hedonic value for chow pellets, an increased motivation to eat, increased meal frequency, and an overall increase in caloric intake.

Heat production via non-shivering thermogenesis is the main function of BAT and norepinephrine is thought to be the main driver in BAT thermogenesis regulation (Cannon and Nedergaard 2004). Nicotine, through central and peripheral binding to nAChRs, triggers the release of both epinephrine and norepinephrine in response to an acute smoke exposure (Sala et al. 2008, Zhao et al. 2007, Westfall and Watts 1964), thereby increasing activity of the sympathetic nervous system. BAT UCP-1, a marker for non-shivering thermogenesis, was markedly reduced in 3R4F mice compared to Ecig mice, but not control mice. As nicotine is a known CNS stimulant and increases thermogenesis in 
BAT, the reduced UCP-1 expression in 3R4F mice may suggest energy expenditure preservation by reducing thermogenesis. The marked elevation in $\mathrm{UCP}-1$ expression in E-cig mice compared to $3 \mathrm{R} 4 \mathrm{~F}$ mice could indicate a relatively elevated energy expenditure, which is evidenced by increased heat production measured in the CLAMS and preservation of body weight. Likewise, muscle UCP-3, important in mitochondrial fatty acid transport and basal metabolic rate, was significantly reduced in 3R4F mice compared to controls, suggesting preservation of energy expenditure and a reduced ability for fatty acid utilization in skeletal muscle. However, both acute (Yoshida et al. 1994) and chronic (Arai et al. 2001, Yoshida et al. 1999) nicotine administration and chronic smoke exposure (Chen et al. 2008) have been reported to increase CNS sympathetic activity, catecholamine release, and BAT UCP-1 expression, which increases thermogenesis.

The lack of increased UCP-1 expression in the 3R4F mice may indicate inadequate smoke exposure, however, the increased UCP-1 expression in E-cig mice compared to 3R4F mice, but similar to controls, could indicate a relatively higher energy expenditure, possibly related to added flavors in conjunction with vaporized nicotine. Light-phase $\mathrm{VO} 2$ was significantly higher in E-cig and 3R4F mice compared to controls (Chapter 3, Figure 7 A\&B) but not during dark-phase, suggesting an increased basal metabolic rate and greater energy expenditure during the period of a rodent's dormant period. Similarly, light-phase VCO2 was significantly higher in E-cig mice (Chapter 3, Figure 7 D\&E), and trended towards significance in 3R4F exposed mice compared to controls. As CO2 is a marker for cellular metabolism, an elevated level suggests an increased metabolism in the E-cig mice compared to 3R4F mice, which was consistent with the UCP-1 data. While activity was not significantly different among groups (Chapter 3, Figure $6 \mathrm{D \& E}$ ), the 3-day measurement window may be too little time to conclude that activity was not an important factor in energy metabolism. Possible increased activity in E-cig mice may also explain the similar body weight to control mice despite an increased caloric intake. 
Adrenergic control of BAT adipocytes is sexually dimorphic in the rat and it has been shown the overfeeding in male rats significantly increases norepinephrine release and $\beta 3$-adrenergic receptor activation in BAT, however, overfeeding in female rats results in significant weight gain and decreased thermogenesis activation (Rodriguez et al. 2001). As E-cig mice consumed significantly more kcals than 3R4F mice and had a significantly higher UCP-1 expression, indicating increased thermogenesis, this is contradictory to the notion that overfeeding decreases thermogenesis activation. Future studies should examine the effects of E-cig vapor exposure on both male and female animals to parse out the sexually dimorphic differences between genders. As this is the first study investigating energy expenditure and uncoupling proteins in an E-cig model, these results may lay the framework for future studies.

\subsection{Future Work, Concerns, and Limitations}

As E-cig use and obesity rates are increasing at an alarming rate, and the physiological effects (i.e. appetite and energy balance) of E-cigs are virtually unknown, it is imperative to expand on the current findings to gain more insight to the understanding of E-cig use on these factors. Cigarette cessation has been attributed to a $14 \%$ rise in US obesity rates (Courtemanche et al. 2016) and alternative nicotine therapies, such as E-cigs, are currently being used to help mitigate these effects. However, with the current study, appetite and obesity rates may increase due to switching to E-cigs. A possible solution may be to increase the nicotine dose in E-cigs to prevent the weight gain effects from smoking cessation. To fully elucidate the effects of e-liquid on body mass and food intake, a study using non-nicotine e-liquid would be able to answer the question if nicotine alone is driving these phenomena.

The melanocortin system, a key player in appetite regulation and food intake, is directly stimulated by nicotine through POMC activation, which ultimately suppresses food intake (Huang et al. 2011, Mineur et al. 2011). Cigarette cessation is immediately followed by weight gain, which is associated with a reduced activity of melanocortin-4 receptors within the hypothalamus, essentially removing the brake from appetite control and resulting in increased food intake. Future studies should 
examine the effects of E-cig vapor on POMC neurons and the melanocortin system, specifically, $\alpha$-MSH protein expression. Moreover, the co-expressed NPY/AgRP and POMC/CART cell populations, as well as reward centers of the brain should be examined to extrapolate any motivational reward of E-cig use. As NPY expression is significantly increased from ingestion of a high-fat chow diet, studying a smoke cessation model and switching to E-cig use would be extremely beneficial to parse out the appetite regulatory mechanisms involved in E-cig use.

Future studies need to include an analysis of leptin receptor expression within the hypothalamus. As leptin is the main anorexigenic peptide influencing appetite, it is imperative to understand possible leptin resistance within the brain. Serum and urine cotinine should also be examined at structured timepoints to determine levels of nicotine absorption, as well as particulate matter, carbon monoxide, and environmental nicotine within the chamber. The inability to determine atmospheric and serum nicotine levels is a major limitation of this study, yet, the smoke exposures were matched for time, so as to provide similar smoke/vapor exposure.

Additionally, future studies using direct smoke/vapor exposure (via direct nose inhalation) will increase the rate of nicotine absorption and mimic a more realistic/translational model. Likewise, measuring food consumption throughout the study, instead of only on weekends (without exposure) should be conducted to get a more accurate measurement of total caloric intake. While this study showed a hyperphagic response in the E-cig group, this may be due to nicotine withdrawal or sweet flavor withdrawal on the weekends. This pilot study employed the use of a group-housed smoking chamber to deliver vapor, cigarette smoke, or filtered air. This excluded routes of administration other than inhalation, such as ingestion and absorption as human smokers experience. E-cig users may have a different phycological stimulus to the mouthfeel, flavor, and aroma perception from directly inhaling the e-liquid, unlike the mice in this study. 
It would be interesting to repeat this present experiment on an OZR rat model, with leptin deficiency, or in a pair-fed control design with control mice consuming identical calories as the E-cig and 3R4F group to determine physiological differences without caloric intake contributing in the equation. An obesogenic model, such as a diet-induced-obesity (DIO) rat or mouse model would be interesting to expose to E-cig exposure, as nicotine has been shown to reverse the effects of DIO (Seoane-Collazo et al. 2014). The added sweeteners in E-cigs may override nicotine's anorectic effects, resulting in the expected DIO from a high-fat diet. Most interesting, providing a high fat diet may provide differing results, as sweet flavors and calorically dense foods increase the desire to consume fat/sweet food, perhaps exposure to E-cig would increase food intake to an even greater extent. As previously stated, numerous homeostatic circuits underlie food intake (Morton et al. 2014) and feeding is regulated by pleasant aromas (hedonic) or reward-based sensations, which override homeostatic controls when consuming energy dense foods, increasing desire to consume palatable foods (Lutter and Nestler 2009). Sight and smell of palatable food increases dopamine release from the ventral tegmental area (VTA), which contributes to the reward value of food (Morin et al. 2017), which when consuming food, this pathway activation results in loss of control over intake of food (Stoeckel et al. 2008). If fed a high-fat, palatable diet instead of standard chow, the E-cig exposure may increase food intake to an even greater degree.

The current study design measured food intake at three distinct timepoints (weeks 3, 7, 19, 23, and 29) over a three-day span (Friday-Monday, during no exposures) in mice individually caged. To accurately calculate total caloric intake, future studies should measure food intake each week throughout the study. Space restrictions and group-housing of mice made it difficult for the current study to measure food intake on a weekly basis. As nicotine withdrawal over the weekends may produce differing food intake, these data may be different throughout the weekly exposures. Moreover, mice were removed from their group-housing during food intake measurements into individually housed cages. The effects 
of social isolation, depression, and anxiety from removal of littermates may have played a role in satiety and total caloric intake. Proving this notion, both E-cig and control mice lost $\approx 2.5 \mathrm{~g}$ of bodyweight during the final week in CLAMS, while 3R4F mice did not significantly alter bodyweight. Finally, as female mice have a more robust protection against weight loss from nicotine administration and smoke exposure, future studies should examine the physiological effects of E-cig vapor in a male mouse/rat model to parse out gender differences.

To date, the FDA has no regulations or restrictions placed on E-cig manufacturers to disclose ingredient lists, product contents, or manufacturing specifications, therefore, the ingredients and nicotine content are virtually unknown. We tested both e-liquids by mass spectrophotometry (University of Virginia) and both samples contained 18.05 and $18.89 \mathrm{mg} / \mathrm{ml}$ nicotine. One study reported more that $75 \%$ of tested e-liquid products contained significantly less nicotine levels ( $6 \%-42 \%$ by concentration) than listed on the label (Lisko et al. 2015). While some studies indicate E-cig refill liquid contain less nicotine content than listed on the bottle (Lisko et al. 2015), the e-liquid in this study contained the listed amount $(18 \mathrm{mg} / \mathrm{ml})$.

Urine cotinine levels were measured for three consecutive hours post exposures at month 5 tended to be higher in $3 \mathrm{R} 4 \mathrm{~F}$ mice compared to E-cig mice $(\mathrm{p}=0.070)$ in our study. In an unpublished intravital study done in our laboratory, C57BL-6 mice were exposed to the same e-liquid used in this study for 5 minutes (30 sec on, 30 seconds off) with a direct first-hand nose exposure. Mice were sacrificed 1.5 hours post exposure, which resulted serum cotinine values exceeding that of our $3 \mathrm{R} 4 \mathrm{~F}$ mice $(9.93 \mathrm{ng} / \mathrm{ml})$. Cotinine has an in-vivo half-life of 16-20 hours (Jarvis et al. 2001), while nicotine has a half-life of 1-2 hours. Clearly, due to the short time interval between exposure and harvest, cotinine values were significantly elevated as the half-life timepoint was not approached. Previous studies indicate possible reasons for lower cotinine levels due to E-cig aerosol being absorbed in the oral mucosa instead of lungs (Farsalinos et al. 2014a). Nicotine administered to oral mucosal should be 
swallowed, which leads to first-pass metabolism to the liver, reducing nicotine's bioavailability. The method of delivery, via liquid droplets of propylene glycol and glycerol, instead of cigarette particulate matter may affect nicotine absorption as well.

\subsection{Translational Significance}

The U.S. Food and Drug Administration (FDA) have approved seven medications to aid in tobacco cessation including: nicotine patches, gum, lozenges, nasal spray, inhaler, and two non-nicotine pills $\left(\right.$ Zyban® and Chantix $\left.{ }^{\circledR}\right)$. With the advent of E-cigs and the massive popularity arising in their use, a better understanding of the mechanisms regulating appetite and energy balance with individuals who use E-cigs will lead to an overall increased public knowledge and awareness as to their effects. With the known anorectic effects of cigarette smoke, followed by smoke cessation weight gain and increased appetite, the consequences of switching to E-cigs may lead to an exacerbated obesity epidemic. This understanding will be important for public health smoke cessation therapeutic programs for individuals currently using E-cigs as an intermediate step to quit smoking. E-cig use following complete cigarette smoke cessation has been seen to significantly increase body weight after 12 and 24 weeks, however, after 12 months of switching to an E-cig, weight gain was reversed and returned to baseline (Russo et al. 2016). A similar 12-month study evaluating the efficacy of E-cig use as a tobacco cessation tool found no difference in body weight, however, only $11 \%$ of smokers were successful at quitting (Caponnetto et al. 2013), which explains the lack of change in body weight. Moreover, sensorimotor components of Ecig use may play a significant role in reinforcement in human subjects rather than an animal model. Perceived hunger ratings were significantly higher after just holding an E-cig compared to using it (Dawkins et al. 2012). These results indicate that sensorimotor aspects of E-cig use, as well as pharmacologic effects, play a significant role in dependence on nicotine and the feeling of smoking. In a study evaluating physiological effects of cigarette cessation and switching to E-cig vapor in 306 human subjects, $14.1 \%$ reported increased appetite, while only $1.0 \%$ of the continued cigarette smokers 
experienced increased appetite. With an alarming increase in the number of E-cig users, if these studies and our results are confirmed, they may provide novel and fundamental findings to aid in the assistance of smoke cessation and obesity prevention programs.

In 2011, almost $70 \%$ of current adult cigarette smokers wanted to quit smoking (USDHHS 2014). Moreover, current smokers were the most willing to try E-cigs (27.2\%) compared to non-smokers $(2.5 \%)$ in a meta-analysis of 67 studies. Most surprising, over half of the study participants $(52.6 \%)$ perceived E-cigs as a healthier alternative to cigarette use, which influenced their willingness to try Ecigs in hope of cessation ( $\mathrm{Xu}$ et al 2016). As smoking cessation increases body mass and using E-cigs increases appetite, smokers may have less motivation to quit smoking in fear of gaining weight. By sharing this knowledge about possible increased food intake due to E-cig use, the public can make informed decisions based on smoking cessation and their overall health.

\subsection{Conclusion}

In conclusion, cigarette smoking causes appetite suppression and weight loss, and while E-cigs are a popular smoking cessation tool, little is known about their metabolic and physiological effects. In contrast to our first hypothesis (specific aim 1), E-cig vapor significantly increased caloric intake and did not alter body mass, fat mass, or lean mass. Also in contrast with our second hypothesis (specific aim 2), compared to controls, E-cig vapor does not significantly alter NPY or POMC mRNA, serum leptin and GLP-1 concentrations, or BAT UCP-1 and GA UCP-3 concentrations. However, we demonstrate a significant increase in heat production ( $\mathrm{kcal} / \mathrm{hr}), \mathrm{VCO} 2$, and $\mathrm{VO} 2$, and cannot exclude the possibility that increased caloric consumption offsets the increased basal metabolism to result in a similar net weight gain, despite hyperphagia. Weight gain does not necessarily manifest due to increased food consumption, but rather, complex and varied shifts in biochemical processes in energy metabolic pathways that govern energy balance. We demonstrate here that chronic E-cig vapor induces hyperphagia and increases basal metabolism without affecting body mass. Future studies should be 
conducted to verify and expand on these results as millions of Americans are currently using E-cig as a smoking cessation device. 


\section{REFERENCES}

1. AHA. 2014. Non-Nutritive Sweeteners (Artificial Sweeteners). Dallas, TX: American Heart Association.

2. ALA. 2017. E-cigarettes and Lung Health. In Smoking Facts.

3. Albanes, D., D. Y. Jones, M. S. Micozzi \& M. E. Mattson (1987) Associations between smoking and body-weight in the united-states population - analysis of NHANES-ii. American Journal of Public Health, 77, 439-444.

4. Alhadeff, A. L., L. E. Rupprecht \& M. R. Hayes (2012) GLP-1 Neurons in the Nucleus of the Solitary Tract Project Directly to the Ventral Tegmental Area and Nucleus Accumbens to Control for Food Intake. Endocrinology, 153, 647-658.

5. $\quad$ Allen, J. G., S. S. Flanigan, M. LeBlanc, J. Vallarino, P. MacNaughton, J. H. Stewart \& D. C. Christiani (2016) Flavoring Chemicals in E-Cigarettes: Diacetyl, 2,3-Pentanedione, and Acetoin in a Sample of 51 Products, Including Fruit-, Candy-, and Cocktail-Flavored E-Cigarettes. Environmental Health Perspectives, 124, 733-739.

6. An, Z. B., H. Wang, P. Song, M. Zhang, X. M. Geng \& M. H. Zou (2007) Nicotine-induced activation of AMP-activated protein kinase inhibits fatty acid synthase in 3T3L1 Adipocytes - A role for oxidant stress. Journal of Biological Chemistry, 282, 26793-26801.

7. Ansari, S., K. Baumer, S. Boue, S. Dijon, R. Dulize, K. Ekroos, A. Elamin, C. Foong, E. Guedj, J. Hoeng, N. V. Ivanov, S. Krishnan, P. Leroy, F. Martin, C. Merg, M. J. Peck, M. C. Peitsch, B. Phillips, W. K. Schlage, T. Schneider, M. Talikka, B. Titz, P. Vanscheeuwijck, E. Veljkovic, T. Vihervaara, G. Vuillaume \& C. Q. Woon (2016) Comprehensive systems biology analysis of a 7month cigarette smoke inhalation study in C57BL/6 mice. Scientific data, 3, 150077-150077.

8. Arai, K., K. Kim, K. Kaneko, M. Iketani, A. Otagiri, N. Yamauchi \& T. Shibasaki (2001) Nicotine infusion alters leptin and uncoupling protein $1 \mathrm{mRNA}$ expression in adipose tissues of rats. American Journal of Physiology-Endocrinology and Metabolism, 280, E867-E876.

9. Arqueros, L., D. Naquira \& E. Zunino (1978) Nicotine-induced release of catecholamines from rat hippocampus and striatum. Biochemical Pharmacology, 27, 2667-2674.

10. Arrazola, R., T. Singh, C. Corey, C. Husten, L. Neff, B. Apelberg, R. Bunnell, C. Choiniere, B. King, S. Cox, T. McAfee \& R. Caraballo. 2015. Tobacco Use Among Middle and High School Students - United States, 2011-2014. In Morbidity and Mortality Weekly Report, 381-385. Atlanta, GA: Center for Disease Control and Prevention.

11. Audrain-McGovern, J. \& N. L. Benowitz (2011) Cigarette Smoking, Nicotine, and Body Weight. Clinical Pharmacology \& Therapeutics, 90, 164-168.

12. Azzu, V. \& M. D. Brand (2010) The on-off switches of the mitochondrial uncoupling proteins. Trends in Biochemical Sciences, 35, 298-307.

13. Blouet, C. \& G. J. Schwartz (2010) Hypothalamic nutrient sensing in the control of energy homeostasis. Behavioural Brain Research, 209, 1-12. 
14. Brees, D. J., M. R. Elwell, F. D. Tingley, S. B. Sands, A. B. Jakowski, A. C. Shen, J. H. Cai \& M. B. Finkelstein (2008) Pharmacological Effects of Nicotine on Norepinephrine Metabolism in Rat Brown Adipose Tissue: Relevance to Nicotinic Therapies for Smoking Cessation. Toxicologic Pathology, 36, 568-575.

15. Breslow, M. J., K. Min-Lee, D. R. Brown, V. P. Chacko, D. Palmer \& D. E. Berkowitz (1999) Effect of leptin deficiency on metabolic rate in ob/ob mice. American Journal of PhysiologyEndocrinology and Metabolism, 276, E443-E449.

16. Brubaker, P. L. \& Y. Anini (2003) Direct and indirect mechanisms regulating secretion of glucagon-like peptide-1 and glucagon-like peptide-2. Canadian Journal of Physiology and Pharmacology, 81, 1005-1012.

17. Cannon, B. \& J. Nedergaard (2004) Brown adipose tissue: Function and physiological significance. Physiological Reviews, 84, 277-359.

18. Caponnetto, P., D. Campagna, F. Cibella, J. B. Morjaria, M. Caruso, C. Russo \& R. Polosa (2013) EffiCiency and Safety of an eLectronic cigAreTte (ECLAT) as Tobacco Cigarettes Substitute: A Prospective 12-Month Randomized Control Design Study. Plos One, 8.

19. CDC. 2016. Adult Obesity Facts. Atlanta, GA: Centers for Disease Control and Prevention.

20. Chajekshaul, T., G. Scherer, V. Barash, E. Shiloni, Y. Caine, O. Stein \& Y. Stein (1994) Metabolic effects of nicotine on human adipose-tissue in organ-culture. Clinical Investigator, 72, 94-99.

21. Champigny, O. \& D. Ricquier (1990) Effects of fasting and refeeding on the level of uncoupling protein messenger-rna in rat brown adipose-tissue - evidence for diet-induced and cold-induced responses. Journal of Nutrition, 120, 1730-1736.

22. Chen, H., M. J. Hansen, J. E. Jones, R. Vlahos, G. P. Anderson \& M. J. Morris (2008) Long-term cigarette smoke exposure increases uncoupling protein expression but reduces energy intake. Brain Research, 1228, 81-88.

23. Chen, H., M. J. Hansen, J. E. Jones, R. Vlahos, S. Bozinovski, G. P. Anderson \& M. J. Morris (2007) Regulation of hypothalamic NPY by diet and smoking. Peptides, 28, 384-389.

24. Chen, H., R. Vlahos, S. Bozinovski, J. Jones, G. P. Anderson \& M. J. Morris (2005) Effect of short-term cigarette smoke exposure on body weight, appetite and brain neuropeptide $\mathrm{Y}$ in mice. Neuropsychopharmacology, 30, 713-719.

25. Chiolero, A., D. Faeh, F. Paccaud \& J. Cornuz (2008) Consequences of smoking for body weight, body fat distribution, and insulin resistance. American Journal of Clinical Nutrition, 87, 801-809.

26. Cioffi, F., R. Senese, P. de Lange, F. Goglia, A. Lanni \& A. Lombardi (2009) Uncoupling proteins: A complex journey to function discovery. Biofactors, 35, 417-428.

27. Clinic, C. 2013. Nonnutritive Sweeteners. Cleveland Clinic. 
28. Courtemanche, C., R. Tchernis \& B. Ukert. 2016. The Effect of Smoking on Obesity: Evidence from a Randomized Trial. National Bureau of Economic Research.

29. Cravo, A. S., J. Bush, G. Sharma, R. Savioz, C. Martin, S. Craige \& T. Walele (2016) A randomised, parallel group study to evaluate the safety profile of an electronic vapour product over 12 weeks. Regulatory Toxicology and Pharmacology, 81, S1-S14.

30. Dawkins, L., J. Turner, S. Hasna \& K. Soar (2012) The electronic-cigarette: Effects on desire to smoke, withdrawal symptoms and cognition. Addictive Behaviors, 37, 970-973.

31. de Araujo, I. E., A. J. Oliveira-Maia, T. D. Sotnikova, R. R. Gainetdinov, M. G. Caron, M. A. L. Nicolelis \& S. A. Simon (2008) Food reward in the absence of taste receptor signaling. Neuron, 57, 930-941.

32. Dhurandhar, N. V., L. D. Whigham, D. H. Abbott, N. J. Schultz-Darken, B. A. Israel, S. M. Bradley, J. W. Kemnitz, D. B. Allison \& R. L. Atkinson (2002) Human adenovirus Ad-36 promotes weight gain in male rhesus and marmoset monkeys. Journal of Nutrition, 132, 31553160.

33. Egecioglu, E., J. A. Engel \& E. Jerlhag (2013) The Glucagon-Like Peptide 1 Analogue Exendin4 Attenuates the Nicotine-Induced Locomotor Stimulation, Accumbal Dopamine Release, Conditioned Place Preference as well as the Expression of Locomotor Sensitization in Mice. Plos One, 8.

34. El Golli, N., H. Dkhili, Y. Dallagi, D. Rahali, M. Lasram, I. Bini-Dhouib, M. Lebret, J.-P. Rosa, S. El Fazaa \& M. Allal-El Asmi (2016) Comparison between electronic cigarette refill liquid and nicotine on metabolic parameters in rats. Life Sciences, 146, 131-138.

35. Erickson, J. C., K. E. Clegg \& R. D. Palmiter (1996) Sensitivity to leptin and susceptibility to seizures of mice lacking neuropeptide Y. Nature, 381, 415-418.

36. Farsalinos, K. E., K. A. Kistler, G. Gillman \& V. Voudris (2015) Evaluation of Electronic Cigarette Liquids and Aerosol for the Presence of Selected Inhalation Toxins. Nicotine \& Tobacco Research, 17, 168-174.

37. Farsalinos, K. E., A. Spyrou, K. Tsimopoulou, C. Stefopoulos, G. Romagna \& V. Voudris (2014a) Nicotine absorption from electronic cigarette use: comparison between first and newgeneration devices. Scientific Reports, 4.

38. Farsalinos, K. E., D. Tsiapras, S. Kyrzopoulos, M. Savvopoulou \& V. Voudris (2014b) Acute effects of using an electronic nicotine-delivery device (electronic cigarette) on myocardial function: comparison with the effects of regular cigarettes. Bmc Cardiovascular Disorders, 14.

39. Fedoroff, I., J. Polivy \& C. P. Herman (2003) The specificity of restrained versus unrestrained eaters' responses to food cues: general desire to eat, or craving for the cued food? Appetite, 41, 7 13.

40. Feijo, F. D., C. R. Ballard, K. C. Foletto, B. A. M. Batista, A. M. Neves, M. F. M. Ribeiro \& M. C. Bertoluci (2013) Saccharin and aspartame, compared with sucrose, induce greater weight gain in adult Wistar rats, at similar total caloric intake levels. Appetite, 60, 203-207. 
41. Foletto, K. C., B. A. M. Batista, A. M. Neves, F. D. Feijo, C. R. Ballard, M. F. M. Ribeiro \& M. C. Bertoluci (2016) Sweet taste of saccharin induces weight gain without increasing caloric intake, not related to insulin-resistance in Wistar rats. Appetite, 96, 604-610.

42. Fornari, A., P. Pedrazzi, G. Lippi, M. R. Picciotto, M. Zoli \& I. Zini (2007) Nicotine withdrawal increases body weight, neuropeptide $\mathrm{Y}$ and Agouti-related protein expression in the hypothalamus and decreases uncoupling protein-3 expression in the brown adipose tissue in high-fat fed mice. Neuroscience Letters, 411, 72-76.

43. Frank, G. K. W., T. A. Oberndorfer, A. N. Simmons, M. P. Paulus, J. L. Fudge, T. T. Yang \& W. H. Kaye (2008) Sucrose activates human taste pathways differently from artificial sweetener. Neuroimage, 39, 1559-1569.

44. Frankish, H. M., S. Dryden, Q. Wang, C. Bing, I. A. Macfarlane \& G. Williams (1995) Nicotine administration reduces neuropeptide-y and neuropeptide-y messenger-rna concentrations in the rat hypothalamus - npy may mediate nicotines effects on energy-balance. Brain Research, 694, 139-146.

45. Galgani, J. E., S. R. Smith \& E. Ravussin (2011) Assessment of EchoMRI-AH versus dualenergy X-ray absorptiometry to measure human body composition. International Journal of Obesity, 35, 1241-1246.

46. Geloneze, B., J. C. de Lima \& L. A. Velloso (2017) Glucagon-Like Peptide-1 Receptor Agonists (GLP-1RAs) in the Brain-Adipocyte Axis. Drugs, 77, 493-503.

47. Golli, N. E., A. Jrad-Lamine, H. Neffati, H. Dkhili, D. Rahali, Y. Dallagi, M. V. El May \& S. El Fazaa (2016) Impact of e-cigarette refill liquid exposure on rat kidney. Regulatory Toxicology and Pharmacology, 77, 109-116.

48. Grimm, J. W., C. Ratliff, K. North, J. Barnes \& S. Collins (2012) Nicotine increases sucrose selfadministration and seeking in rats. Addiction Biology, 17, 623-633.

49. Hayes, M. R., L. Bradley \& H. J. Grill (2009) Endogenous Hindbrain Glucagon-Like Peptide-1 Receptor Activation Contributes to the Control of Food Intake by Mediating Gastric Satiation Signaling. Endocrinology, 150, 2654-2659.

50. Hodge, A. M., R. A. Westerman, M. P. deCourten, G. R. Collier, P. Z. Zimmet \& K. Alberti (1997) Is leptin sensitivity the link between smoking cessation and weight gain? International Journal of Obesity, 21, 50-53.

51. Hofstetter, A., Y. Schutz, E. Jequier \& J. Wahren (1986) Increased 24-hour energy-expenditure in cigarette smokers. New England Journal of Medicine, 314, 79-82.

52. Huang, H., Y. Xu \& A. N. van den Pol (2011) Nicotine excites hypothalamic arcuate anorexigenic proopiomelanocortin neurons and orexigenic neuropeptide $\mathrm{Y}$ neurons: similarities and differences. Journal of Neurophysiology, 106, 1191-1202.

53. Hur, Y.-N., G.-H. Hong, S.-H. Choi, K.-H. Shin \& B.-G. Chun (2010) High Fat Diet Altered the Mechanism of Energy Homeostasis Induced by Nicotine and Withdrawal in C57BL/6 Mice. Molecules and Cells, 30, 219-226. 
54. Hwang, J. H., M. Lyes, K. Sladewski, S. Enany, E. McEachern, D. P. Mathew, S. Das, A. Moshensky, S. Bapat, D. T. Pride, W. M. Ongkeko \& L. E. C. Alexander (2016) Electronic cigarette inhalation alters innate immunity and airway cytokines while increasing the virulence of colonizing bacteria. Journal of Molecular Medicine-Jmm, 94, 667-679.

55. Ilebekk, A., N. E. Miller \& O. D. Mjos (1975) Effects of nicotine and inhalation of cigarettesmoke on total-body oxygen-consumption in dogs. Scandinavian Journal of Clinical \& Laboratory Investigation, 35, 67-72.

56. Jamal, A., I. Agaku, E. O'Connor, B. King, J. Kenemer \& L. Neff. 2014. Current Cigarette Smoking Among Adults — United States, 2005-2013. In Morbidity and Mortality Weekly Report. Centers for Disease Control and Prevention.

57. Jamal, A., B. King, L. Neff, J. Whitmill, S. Babb \& C. Graffunder. 2016. Current Cigarette Smoking Among Adults-United States, 2005-2015. In Morbidity and Mortality Weekly Report. Centers for Disease Control and Prevention.

58. Jang, M. H., M. C. Shin, K. H. Kim, S. Y. Cho, G. H. Bahn, E. H. Kim \& C. J. Kim (2003) Nicotine administration decreases neuropeptide $Y$ expression and increases leptin receptor expression in the hypothalamus of food-deprived rats. Brain Research, 964, 311-315.

59. Jarvis, M. J., R. Boreham, P. Primatesta, C. Feyerabend \& A. Bryant (2001) Nicotine yield from machine-smoked cigarettes and nicotine intakes in smokers: Evidence from a representative population survey. Jnci-Journal of the National Cancer Institute, 93, 134-138.

60. Jensen, R. P., W. T. Luo, J. F. Pankow, R. M. Strongin \& D. H. Peyton (2015) Hidden Formaldehyde in E-Cigarette Aerosols. New England Journal of Medicine, 372, 392-394.

61. Jo, Y. H., D. A. Talmage \& L. W. Role (2002) Nicotinic receptor-mediated effects on appetite and food intake. Journal of Neurobiology, 53, 618-632.

62. Klesges, R. C., A. W. Meyers, L. M. Klesges \& M. E. Lavasque (1989) Smoking, body-weight, and their effects on smoking-behavior - a comprehensive review of the literature. Psychological Bulletin, 106, 204-230.

63. Kogel, U., W. K. Schlage, F. Martin, Y. Xiang, S. Ansari, P. Leroy, P. Vanscheeuwijck, S. Gebel, A. Buettner, C. Wyss, M. Esposito, J. Hoeng \& M. C. Peitsch (2014) A 28-day rat inhalation study with an integrated molecular toxicology endpoint demonstrates reduced exposure effects for a prototypic modified risk tobacco product compared with conventional cigarettes. Food and Chemical Toxicology, 68, 204-217.

64. Lam, C. \& A. West (2015) Are electronic nicotine delivery systems an effective smoking cessation tool? Canadian journal of respiratory therapy : CJRT = Revue canadienne de la therapie respiratoire : $R C T R, 51,93-8$.

65. Landau, S. M. 2015. System and Method for Altering the Perceived Flavor of a Liquid or Vapor Passing into the Mouth. Google Patents.

66. Li, M. D. \& J. K. Kane (2003) Effect of nicotine on the expression of leptin and forebrain leptin receptors in the rat. Brain Research, 991, 222-231. 
67. Li, M. D., J. K. Kane, S. L. Parker, K. McAllen, S. G. Matta \& B. M. Sharp (2000) Nicotine administration enhances NPY expression in the rat hypothalamus. Brain Research, 867, 157-164.

68. Lisko, J. G., H. Tran, S. B. Stanfill, B. C. Blount \& C. H. Watson (2015) Chemical Composition and Evaluation of Nicotine, Tobacco Alkaloids, pH, and Selected Flavors in E-Cigarette Cartridges and Refill Solutions. Nicotine \& Tobacco Research, 17, 1270-1278.

69. Liu, R. H., M. Mizuta \& S. Matsukura (2004) The expression and functional role of nicotinic acetylcholine receptors in rat adipocytes. Journal of Pharmacology and Experimental Therapeutics, 310, 52-58.

70. Lo Sasso, G., B. Titz, C. Nury, S. Boue, B. Phillips, V. Belcastro, T. Schneider, S. Dijon, K. Baumer, D. Peric, R. Dulize, A. Elamin, E. Guedj, A. Buettner, P. Leroy, S. Kleinhans, G. Vuillaume, E. Veljkovic, N. V. Ivanov, F. Martin, P. Vanscheeuwijck, M. C. Peitsch \& J. Hoeng (2016) Effects of cigarette smoke, cessation and switching to a candidate modified risk tobacco product on the liver in Apoe(-/-) mice - a systems toxicology analysis. Inhalation Toxicology, 28, 226-240.

71. Lupien, J. R. \& G. A. Bray (1988) Nicotine increases thermogenesis in brown adipose-tissue in rats. Pharmacology Biochemistry and Behavior, 29, 33-37.

72. Lutter, M. \& E. J. Nestler (2009) Homeostatic and Hedonic Signals Interact in the Regulation of Food Intake. Journal of Nutrition, 139, 629-632.

73. Mangubat, M., K. Lutfy, M. L. Lee, L. Pulido, D. Stout, R. Davis, C. S. Shin, M. Shahbazian, S. Seasholtz, A. Sinha-Hikim, I. Sinha-Hikim, L. E. O'Dell, A. Lyzlov, Y. J. Liu \& T. C. Friedman (2012) Effect of nicotine on body composition in mice. Journal of Endocrinology, 212, 317-326.

74. Martinez de Morentin, P. B., A. J. Whittle, J. Ferno, R. Nogueiras, C. Dieguez, A. Vidal-Puig \& M. Lopez (2012) Nicotine Induces Negative Energy Balance Through Hypothalamic AMPActivated Protein Kinase. Diabetes, 61, 807-817.

75. Marvyn, P., R. Bradley, E. Mardian, K. Marks \& R. Duncan. 2015. Data on oxygen consumption rate, respiratory exchange ratio, and movement in C57BL/6J female mice on the third day of consuming a high-fat diet. 472-475. Data Brief.

76. McCarthy, T., C. Bruen, F. O'Halloran, H. Schellekens, K. Kilcawley, J. F. Cryan \& L. Giblin (2017) Aroma compound diacetyl suppresses glucagon-like peptide-1 production and secretion in STC-1 cells. Food Chemistry, 228, 35-42.

77. McFadden, K. L., M.-A. Cornier \& J. R. Tregellas (2014) The role of alpha-7 nicotinic receptors in food intake behaviors. Frontiers in Psychology, 5.

78. McGrath-Morrow, S. A., M. Hayashi, A. Aherrera, A. Lopez, A. Malinina, J. M. Collaco, E. Neptune, J. D. Klein, J. P. Winickoff, P. Breysse, P. Lazarus \& G. Chen (2015) The Effects of Electronic Cigarette Emissions on Systemic Cotinine Levels, Weight and Postnatal Lung Growth in Neonatal Mice. Plos One, 10. 
79. McMahon, L. R. \& P. J. Wellman (1998) PVN infusion of GLP-1-(7-36) amide suppresses feeding but does not induce aversion or alter locomotion in rats. American Journal of Physiology-Regulatory Integrative and Comparative Physiology, 274, R23-R29.

80. Meguid, M. M., S. O. Fetissov, M. Varma, T. Sato, L. H. Zhang, A. Laviano \& F. Rossi-Fanelli (2000) Hypothalamic dopamine and serotonin in the regulation of food intake. Nutrition, 16, 843-857.

81. Miao, S., E. S. Beach, T. J. Sommer, J. B. Zimmerman \& S. E. Jordt (2016) High-Intensity Sweeteners in Alternative Tobacco Products. Nicotine \& Tobacco Research, 18, 2169-2173.

82. Mineur, Y. S., A. Abizaid, Y. Rao, R. Salas, R. J. DiLeone, D. Guendisch, S. Diano, M. De Biasi, T. L. Horvath, X.-B. Gao \& M. R. Picciotto (2011) Nicotine Decreases Food Intake Through Activation of POMC Neurons. Science, 332, 1330-1332.

83. Mitchell, P. (1961) Coupling of phosphorylation to electron and hydrogen transfer by a chemiosmotic type of mechanism. Nature, 191, 144-\&.

84. Morin, J. P., L. F. Rodriguez-Duran, K. Guzman-Ramos, C. Perez-Cruz, G. Ferreira, S. DiazCintra \& G. Pacheco-Lopez (2017) Palatable Hyper-Caloric Foods Impact on Neuronal Plasticity. Frontiers in Behavioral Neuroscience, 11.

85. Morton, G. J., T. H. Meek \& M. W. Schwartz (2014) Neurobiology of food intake in health and disease. Nature Reviews Neuroscience, 15, 367-378.

86. Moskowitz, H. R., R. A. Kluter, J. Westerling \& H. L. Jacobs (1974) Sugar sweetness and pleasantness - evidence for different psychological laws. Science, 184, 583-585.

87. Mozaffarian, D., T. Hao, E. B. Rimm, W. C. Willett \& F. B. Hu (2011) Changes in Diet and Lifestyle and Long-Term Weight Gain in Women and Men. New England Journal of Medicine, 364, 2392-2404.

88. Nederkoorn, C., F. T. Y. Smulders \& A. Jansen (2000) Cephalic phase responses, craving and food intake in normal subjects. Appetite, 35, 45-55.

89. Nicholls, D. G. \& E. Rial (1984) BROWN FAT MITOCHONDRIA. Trends in Biochemical Sciences, 9, 489-491.

90. Norgren, R., A. Hajnal \& S. S. Mungarndee (2006) Gustatory reward and the nucleus accumbens. Physiology \& Behavior, 89, 531-535.

91. Park, H. K. \& R. S. Ahima (2015) Physiology of leptin: energy homeostasis, neuroendocrine function and metabolism. Metabolism-Clinical and Experimental, 64, 24-34.

92. Pelleymounter, M. A. (1997) Leptin and the physiology of obesity. Current Pharmaceutical Design, 3, 85-97.

93. Pelleymounter, M. A., M. J. Cullen, M. B. Baker, R. Hecht, D. Winters, T. Boone \& F. Collins (1995) Effects of the obese gene-product on body-weight regulation in ob/ob mice. Science, 269, $540-543$. 
94. Phillips, B., E. Veljkovic, S. Boue, W. K. Schlage, G. Vuillaume, F. Martin, B. Titz, P. Leroy, A. Buettner, A. Elamin, A. Oviedo, M. Cabanski, H. De Leon, E. Guedj, T. Schneider, M. Talikka, N. V. Ivanov, P. Vanscheeuwijck, M. C. Peitsch \& J. Hoeng (2016) An 8-Month Systems Toxicology Inhalation/Cessation Study in Apoe(-/-) Mice to Investigate Cardiovascular and Respiratory Exposure Effects of a Candidate Modified Risk Tobacco Product, THS 2.2, Compared With Conventional Cigarettes (vol 149, pg 411, 2016). Toxicological Sciences, 151, 462-464.

95. Phillips, B., E. Veljkovic, M. J. Peck, A. Buettner, A. Elamin, E. Guedj, G. Vuillaume, N. V. Ivanov, F. Martin, S. Boue, W. K. Schlage, T. Schneider, B. Titz, M. Talikka, P. Vanscheeuwijck, J. Hoeng \& M. C. Peitsch (2015) A 7-month cigarette smoke inhalation study in C57BL/6 mice demonstrates reduced lung inflammation and emphysema following smoking cessation or aerosol exposure from a prototypic modified risk tobacco product. Food and Chemical Toxicology, 80, 328-345.

96. Ponzoni, L., M. Moretti, M. Sala, F. Fasoli, V. Mucchietto, V. Lucini, G. Cannazza, G. Gallesi, C. N. Castellana, F. Clementi, M. Zoli, C. Gotti \& D. Braida (2015) Different physiological and behavioural effects of e-cigarette vapour and cigarette smoke in mice. European Neuropsychopharmacology, 25, 1775-1786.

97. Potter, B. K., L. L. Pederson, S. S. H. Chan, J. A. L. Aubut \& J. J. Koval (2004) Does a relationship exist between body weight, concerns about weight, and smoking among adolescents? An integration of the literature with an emphasis on gender. Nicotine \& Tobacco Research, 6, 397-425.

98. Ramaekers, M. G., S. Boesveldt, C. M. M. Lakemond, M. van Boekel \& P. A. Luning (2014) Odors: appetizing or satiating? Development of appetite during odor exposure over time. International Journal of Obesity, 38, 650-656.

99. Rasmussen, D. D. (1998) Effects of chronic nicotine treatment and withdrawal on hypothalamic proopiomelanocortin gene expression and neuroendocrine regulation.

Psychoneuroendocrinology, 23, 245-259.

100. Reseland, J. E., H. H. Mundal, K. Hollung, F. Haugen, N. Zahid, S. A. Anderssen \& C. A. Drevon (2005) Cigarette smoking may reduce plasma leptin concentration via catecholamines. Prostaglandins Leukotrienes and Essential Fatty Acids, 73, 43-49.

101. Ricquier, D. \& F. Bouillaud (2000) The uncoupling protein homologues: UCP1, UCP2, UCP3, StUCP and AtUCP. Biochemical Journal, 345, 161-179.

102. Rodriguez, E., M. Monjo, S. Rodriguez-Cuenca, E. Pujol, B. Amengual, P. Roca \& A. Palou (2001) Sexual dimorphism in the adrenergic control of rat brown adipose tissue response to overfeeding. Pflugers Archiv-European Journal of Physiology, 442, 396-403.

103. Rupprecht, L. E., T. T. Smith, R. L. Schassburger, E. C. Donny \& A. F. Sved (2016) Effects of Nicotine on Rewards Varying in Palatability and Caloric Value: Implications for E-cigarette Flavoring. Tobacco Regulatory Science, 2, 343-351. 
104. Russo, C., F. Cibella, P. Caponnetto, D. Campagna, M. Maglia, E. Frazzetto, E. Mondati, M. Caruso \& R. Polosa (2016) Evaluation of Post Cessation Weight Gain in a 1-Year Randomized Smoking Cessation Trial of Electronic Cigarettes. Scientific Reports, 6.

105. Sala, F., A. Nistri \& M. Criado (2008) Nicotinic acetylcholine receptors of adrenal chromaffin cells. Acta Physiologica, 192, 203-212.

106. Sanigorski, A., R. Fahey, D. Cameron-Smith \& G. R. Collier (2002) Nicotine treatment decreases food intake and body weight viaa leptin-independent pathway in Psammomys obesus. Diabetes Obesity \& Metabolism, 4, 346-350.

107. Sargent, P. B. (1993) The diversity of neuronal nicotinic acetylcholine-receptors. Annual Review of Neuroscience, 16, 403-443.

108. Schoenborn, C. \& R. Gindi (2015) Electronic Cigarette Use Among Adults: United States, 2014. NCHS Data Brief, no 217.

109. Seoane-Collazo, P., P. B. M. de Morentin, J. Ferno, C. Dieguez, R. Nogueiras \& M. Lopez (2014) Nicotine Improves Obesity and Hepatic Steatosis and ER Stress in Diet-Induced Obese Male Rats. Endocrinology, 155, 1679-1689.

110. Stoeckel, L. E., R. E. Weller, E. W. Cook, D. B. Twieg, R. C. Knowlton \& J. E. Cox (2008) Widespread reward-system activation in obese women in response to pictures of high-calorie foods. Neuroimage, 41, 636-647.

111. Suminski, R. R., L. T. Wier, W. Poston, B. Arenare, A. Randles \& A. S. Jackson (2009) The Effect of Habitual Smoking on Measured and Predicted VO(2)max. Journal of Physical Activity \& Health, 6, 667-673.

112. Sussan, T. E., S. Gajghate, R. K. Thimmulappa, J. F. Ma, J. H. Kim, K. Sudini, N. Consolini, S. A. Cormier, S. Lomnicki, F. Hasan, A. Pekosz \& S. Biswal (2015) Exposure to Electronic Cigarettes Impairs Pulmonary Anti-Bacterial and Anti-Viral Defenses in a Mouse Model. Plos One, 10.

113. Swithers, S. E. \& T. L. Davidson (2008) A role for sweet taste: Calorie predictive relations in energy regulation by rats. Behavioral Neuroscience, 122, 161-173.

114. Sztalryd, C., J. Hamilton, B. A. Horwitz, P. Johnson \& F. B. Kraemer (1996) Alterations of lipolysis and lipoprotein lipase in chronically nicotine-treated rats. American Journal of Physiology-Endocrinology and Metabolism, 270, E215-E223.

115. Tierney, P. A., C. D. Karpinski, J. E. Brown, W. T. Luo \& J. F. Pankow (2016) Flavour chemicals in electronic cigarette fluids. Tobacco Control, 25, E10-E15.

116. Tomoda, K., K. Kubo, Y. Nishii, Y. Yamamoto, M. Yoshikawa \& H. Kimura (2012) Changes of ghrelin and leptin levels in plasma by cigarette smoke in rats. Journal of Toxicological Sciences, 37, 131-138. 
117. Turnbaugh, P. J., F. Baeckhed, L. Fulton \& J. I. Gordon (2008) Diet-induced obesity is linked to marked but reversible alterations in the mouse distal gut microbiome. Cell Host \& Microbe, 3, 213-223.

118. Turton, M. D., D. Oshea, I. Gunn, S. A. Beak, C. M. B. Edwards, K. Meeran, S. J. Choi, G. M. Taylor, M. M. Heath, P. D. Lambert, J. P. H. Wilding, D. M. Smith, M. A. Ghatei, J. Herbert \& S. R. Bloom (1996) A role for glucagon-like peptide-1 in the central regulation of feeding. Nature, 379, 69-72.

119. Tweed, J. O., S. H. Hsia, K. Lutfy \& T. C. Friedman (2012) The endocrine effects of nicotine and cigarette smoke. Trends in Endocrinology and Metabolism, 23, 334-342.

120. USDHHS. 2014. The Health Consequences of Smoking: 50 Years of Progress. A Report of the Surgeon General. Atlanta, GA: Centers for Disease Control and Prevention, National Center for Chronic Disease Prevention and Health Promotion, Office on Smoking and Health.

121. ---. 2016. E-Cigarette Use Among Youth and Young Adults. A Report of the Surgeon General. Atlanta, GA: Centers for Disease Control and Prevention, National Center for Chronic Disease Prevention and Health Promotion, Office on Smoking and Health.

122. Wang, Q. P., Y. Q. Lin, L. Zhang, Y. A. Wilson, L. J. Oyston, J. Cotterell, Y. Qi, T. M. Khuong, N. Bakhshi, Y. Planchenault, D. T. Browman, M. T. Lau, T. A. Cole, A. C. N. Wong, S. J. Simpson, A. R. Cole, J. M. Penninger, H. Herzog \& G. G. Neely (2016) Sucralose Promotes Food Intake through NPY and a Neuronal Fasting Response. Cell Metabolism, 24, 75-90.

123. Westfall, T. C. \& D. T. Watts (1964) Catecholamine excretion in smokers + nonsmokers. Journal of Applied Physiology, 19, 40-\&.

124. WHO. 2011. WHO Report on the Global Tobacco Epidemic, 2011. Italy.

125. Williams, J. R. 2016. Alkaloid Composition for E-Cigarette. Google Patents.

126. Xu, X., E. E. Bishop, S. M. Kennedy, S. A. Simpson \& T. F. Pechacek (2015) Annual Healthcare Spending Attributable to Cigarette Smoking An Update. American Journal of Preventive Medicine, 48, 326-333.

127. Xu, Y., Y. F. Guo, K. Q. Liu, Z. Liu \& X. B. Wang (2016) E-Cigarette Awareness, Use, and Harm Perception among Adults: A Meta-Analysis of Observational Studies. Plos One, 11.

128. Yeomans, M. R. (2006) Olfactory influences on appetite and satiety in humans. Physiology \& Behavior, 87, 800-804.

129. Yoshida, T., N. Sakane, T. Umekawa, A. Kogure, M. Kondo, K. Kumamoto, T. Kawada, I. Nagase \& M. Saito (1999) Nicotine induces uncoupling protein 1 in white adipose tissue of obese mice. International Journal of Obesity, 23, 570-575.

130. Yoshida, T., N. Sakane, T. Umekawa \& M. Kondo (1994) Effect of nicotine on sympathetic nervous-system activity of mice subjected to immobilization stress. Physiology \& Behavior, 55, 53-57. 
131. Zhao, R. J., H. Chen \& B. M. Sharp (2007) Nicotine-induced norepinephrine release in hypothalamic paraventricular nucleus and amygdala is mediated by N-methyl-D-aspartate receptors and nitric oxide in the nucleus tractus solitarius. Journal of Pharmacology and Experimental Therapeutics, 320, 837-844.

132. Zoli, M. \& M. R. Picciotto (2012) Nicotinic Regulation of Energy Homeostasis. Nicotine \& Tobacco Research, 14, 1270-1290. 